Universidade de São Paulo Faculdade de Medicina de Ribeirão Preto - SP

Programa de Pós-Graduação em Gestão das Organizações de Saúde

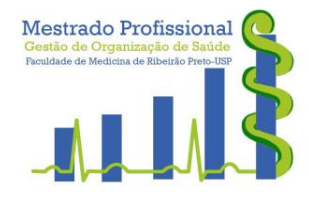

Diego Marques Moroço

Impacto da Informatização do Processo de Alta Hospitalar em um Hospital Público Terciário

Ribeirão Preto

2020 


\section{Diego Marques Moroço}

\section{Impacto da Informatização do Processo de Alta Hospitalar em um Hospital Público Terciário}

Dissertação apresentada ao Programa de Pós Graduação em Mestrado Profissionalizante em Gestão de Organizações de Saúde, da Faculdade de Medicina de Ribeirão Preto da Universidade de São Paulo, como um requisito para obtenção do título de Mestre em Gestão das Organizações de Saúde.

Orientador: Prof. Dr. Antônio Pazin Filho

\section{Ribeirão Preto}


Autorizo a reprodução e divulgação total ou parcial deste trabalho, por qualquer meio convencional ou eletrônico, para fins de estudo e pesquisa, desde que citada a fonte.

\section{FICHA CATALOGRÁFICA}

Moroço, Diego Marques

Impacto da Informatização do Processo de Alta Hospitalar em um Hospital Público Terciário

$$
\text { Ribeirão Preto - SP, } 2020 .
$$

74 p. : il. ; $30 \mathrm{~cm}$

Dissertação de Mestrado, apresentada à Faculdade de Medicina de Ribeirão Preto/USP. Área de concentração: Gestão.

Orientador: Antônio Pazin Filho.

1.Alta hospitalar; 2. Tempo de Permanência; 3. Seis Sigma e Lean; 4.Qualidade Hospitalar 
Nome: MOROÇO, Diego Marques

Título: Impacto da Informatização do Processo de Alta Hospitalar em um Hospital Público Terciário.

Dissertação apresentada ao Programa de Pós Graduação em Mestrado Profissionalizante em Gestão de Organizações de Saúde, da Faculdade de Medicina de Ribeirão Preto da Universidade de São Paulo, como um requisito para obtenção do título de Mestre em Gestão das Organizações de Saúde.

Aprovado em:

\author{
Banca Examinadora
}

Prof. Dr.:

Institutição:

Julgamento:

Prof. Dr.:

Institutição:

Julgamento:

Prof. Dr.:

Institutição:

Julgamento: 


\section{DEDICATÓRIA}

Ao meu avô Oswaldo Moroço (in memorian) e a minha avó Inês que sempre foram pessos maravilhosas. Sinto muito sua falta meu querido avô.

Aos meus pais, Denise Oswaldo Moroço e Maria de Fátima Ruy Moroço que sempre lutaram bravamente pela minha educação.

Ao meu tio Marcos, grande professor e educador. Posso dizer que minha inspiração para os estudos veio através do seu exemplo.

A minha tia Tarcísia, uma grande pessoa que sempre me apoiou em todos os momentos. 


\section{AGRADECIMENTOS}

Primeiramente agradeço a Deus a oportunidade da vida por me permitir estar aqui escrevendo esta tese. Agradeço aos meus pais que nunca pouparam esforços durante toda a minha vida para que eu pudesse sempre estudar. Agradeço ao meu orientador, o Professor Pazin pela oportunidade, pela orientação e acima de tudo pela paciência.

E por último, não menos menos importante, a minha querida esposa Valquíria e aos meus filhos Vitor e Lucas pela compreensão nas horas passadas em frente ao computador. A eles todo o meu carinho e todo o meu amor. 


\section{ABREVIATURAS E SÍMBOLOS}

ANS: Agência Nacional de Saúde

CDS: Clinical Decision Suport

CFM: Conselho Federal de Medicina

CROSS: Central de Regulação de Ofertas de Serviços de Saúde

CSV: Comma Separated Values

DAS: Departamento de Assistência à Saúde

DMAIC: Define, Measure, Analyse, Improve, Control

DRS: Diretoria Regional de Saúde

EUA: Estados Unidos da América

EHR: Eletronic Health Records

FAEPA: Fundação de Apoio, Pesquisa e Assistência

HAS: Hospital Auxiliar de Suzano

HCFMRP-USP: Hospital das Clínicas da Faculdade de Medicina de Ribeirão Preto da Universidade de São Paulo.

HCFM-USP: Hospital das Clínicas da Faculdade de Medicina da Universidade de São Paulo

HIE: Sistemas de Troca de Informações Hospitalares

NIR: Núcleo Interno de Regulação

PDCA: Plan, Do, Check, Act

PTS: Projeto Terapêutico Singular

SAMU: Serviço de Atendimento Móvel de Urgência

SES: Secretaria do Estado de Saúde

PEP: Prontuário Eletrônico do Paciente

RES: Registro Eletrônico em Saúde

SQL: Structured Query Language 
SRUE: Sistema de Regulação de Urgência e Emergência

SBIS: Sociedade Brasileira de Informática em Saúde (SBIS)

SCCM: Society of Critical Care Medicine

SUS: Sistema Único de Saúde

TISS: Troca de Informação em Saúde Suplementar

TUSS: Terminologia Unificada de Saúde Suplementar

UE: Unidade de Emergência 


\section{RESUMO}

Moroço, D. M. (2020). Impacto da Informatização do Processo de Alta Hospitalar em um Hospital Público Terciário. Faculdade de Medicina de Ribeirão Preto, Universidade de São Paulo, São Paulo.

Introdução: $O$ incremento da demanda sobre qualidade e segurança dos pacientes e as restrições econômicas atuais têm impulsionado as instituições hospitalares a reverem seus diversos processos. Um destes processos é a alta hospitalar, que dentre seus vários aspectos a serem considerados, existe a necessidade de agilizar o tempo entre a alta e a saída do hospital. As novas técnicas incorporadas nas instituições hospitalares, como a assinatura digital oferecem oportunidades de melhoria deste processo. O Hospital das Clínicas da Faculdade de Medicina de Ribeirão Preto da Universidade de São Paulo (HCFMRP-USP) implantou um novo passo no processo de alta com base na assinatura digital que pode trazer implicações significativas e deve ser caracterizada.

Objetivos: Avaliar se houve redução do tempo de saída do paciente da instituição após a alta médica (fechamento de alta) antes e após a incorporação de uma nova intervenção no processo, baseada em ferramentas de informática.

Métodos: Foi realizado estudo quasi-experimental, tipo antes e depois de intervenção para agilizar a liberação do paciente da instituição após a alta médica. A análise foi realizada com base em dados administrativos (número de altas, rotatividade do leito, tempo entre a alta médica e o fechamento do atendimento) do HCFMRP-USP, unidade Campus nos anos de 2011 a 2019. Utilizou-se análise de séries temporais interrompidas.

Resultados: A análise de série temporal interrompida demonstrou um comportamento de mudança de nível imediato (Coeficiente $\beta 2$-3,6 horas- Intervalo de Confiança 95\% -3,9; -3,4 - Lag1), mas não uma modificação da inclinação do comportamento da curva pós-intervenção (Coeficiente $\beta 3$ 0,0005 - Intervalo de Confiança 95\% -0,0040; 0,0050 - Lag1).

Conclusão: A intervenção implicou em redução do tempo de liberação após a alta hospitalar.

Palavras-chave: Alta hospitalar, Tempo de Permanência, Seis Sigma e Lean, Qualidade Hospitalar 


\begin{abstract}
Moroço, D. M. (2020). Automation Impact of Discharging Process in a Tertiary Public Hospital. Faculdade de Medicina de Ribeirão Preto, Universidade de São Paulo, São Paulo.

Introduction: With the growing demand on quality and patient security and economic constraints, several hospital institutions had pushed to review their processes. One of these processes is the hospital discharge, which among its various aspects to be considered, there is the need to reduce hospital discharge time. New techniques implemented on hospital institutions such as digital signature offers oportunities of improvement on these processes. The HCFMRP-USP implemented a new digital signature based routine on hospital discharge that can bring significative implications and should be known.
\end{abstract}

Goals: Evaluate impact on hospital discharge process of HCFMRP-USP. Characterising this impact on indicators related to hospital discharge and supply chain.

Methods: Exploratory analysis will be carried out on indicators related to admission process (number of discharge, hospital-bed turnover, elapsed time between medical discharge and attendance closing) on HCFMRP-USP facility.

Methods: We conducted a quasi-experimental study, before and after an intervention, to expedite the patient's release from the institution after medical discharge. We performed the analysis based on administrative data (number of hospital discharge, bed turnover, time between medical discharge and the closing of the appointment) from HCFMRP-USP, Campus unit in the years 2011 to 2019. We used Interrupted Time Series Analysis.

Results: The interrupted time series analysis showed an immediate change in level (Coefficient $\beta 2$-3.6 hours - 95\% confidence interval -3.9; -3.4 - Lag1), but not a change in the slope of the behavior of the post-intervention curve ( $\beta 30.0005$ coefficient - $95 \%$ confidence interval -0.0040; 0.0050 - Lag1).

Conclusion: The intervention implied a reduction in the release time after hospital discharge.

Keywords: Hospital discharge, length of stay, Six sigma and lean, hospital quality. 


\section{Índice de Tabelas}

Tabela 1 - HCFMRP-USP - Estatísticas de produção anual. ..................................................29

Tabela 2 - HCFMRP-USP - Estatísticas de produção anual (continuação) .............................29

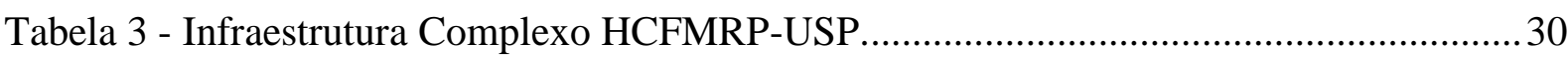

Tabela 4 - Tempo mediano entre a alta médica e o fechamento do atendimento de acordo com o ano e mês

Tabela 5 - Tempo mediano de saída do paciente da instituição após a alta médica segundo Enfermaria de Alta e Ano

Tabela 6 - Comparação entre os valores medianos de tempo para saída após alta hospitalar de acordo com o grupo (< ou > de 7 dias) e o período de intervenção ........................................ 49

Tabela 7 - Análise de Série Temporal Interrompida com Lag 1 ............................................51

Tabela 8 - Análise de Série Temporal Interrompida Geral com Lag 8 .................................51

Tabela 9 - Série Temporal Interrompida estratificada para 2 grupos (internação até 7 dias e

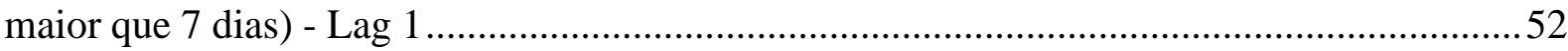

Tabela 10 - Série Temporal Interrompida estratificada para 2 grupos (internação até 7 dias e maior que 7 dias) - Lag 8 


\section{Índice de Figuras}

Figura 1 - Complexo HCFMRP-USP

Figura 2 - Diagrama do Processo de Saída do Paciente da Instituição após a Alta do HCFMRP-USP antes e após revisão do processo. 33

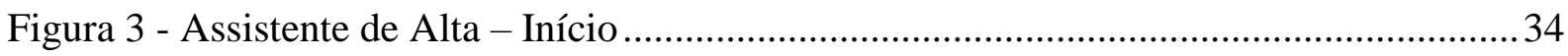

Figura 4 - Assistente de Alta - Especificação de Diagnósticos .............................................. 35

Figura 5 - Assistente de Alta - Especificação de Receitas ........................................................ 35

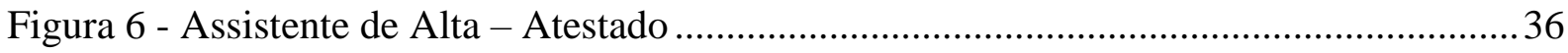

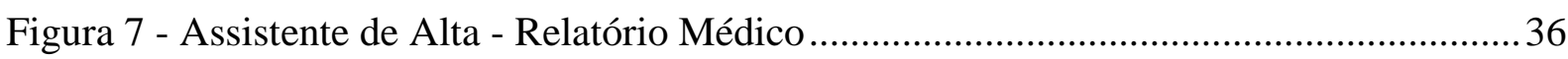

Figura 8 - Assistente de Alta - Declaração ........................................................................... 37

Figura 9 - Assistente de Alta - Agendamento de Retornos Ambulatoriais ..............................37

Figura 10 - Assistente de Alta - Sumário de Alta (Epicrise) ................................................... 38

Figura 11 - Assistente de Alta - Referência/Contra-referência .............................................. 38

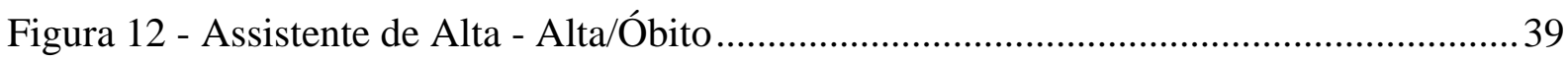

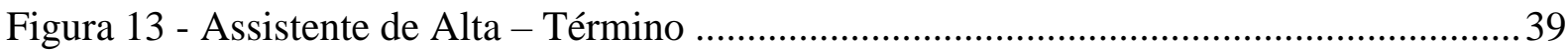

Figura 14 - Pacientes internados por Unidade. Destaque em verde para o paciente que recebeu alta pela Equipe Médica

Figura 15 - Volume de Saídas de Pacientes segundo Hora do Fechamento do Atendimento -

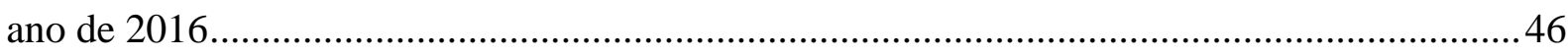

Figura 16 - Volume de Saída de Pacientes segundo Hora do Fechamento do Atendimento ano de 2017 .46

Figura 17 - Histograma de distribuição do número de pacientes dispensados de acordo com o horário dia.

Figura 18 - Análise de auto-correlação do tempo de alta médica ao fechamento do

Atendimento

Figura 19 - Análise de auto-correlação parcial do tempo de alta médica ao fechamento do

Atendimento

Figura 20 - Análise de Série Temporal Interrompida Geral para o tempo mediano de Alta

Médica ao Fechamento do Atendimento 50

Figura 21 - Análise de Série Temporal Interrompida Estratificada comparando-se o impacto da intervenção de acordo com a duração da internação hospitalar. 


\section{Índice de Equações}

Equação 1 - Série de Tempo Interrompida para um grupo........................................... 41

Equação 2 - Série de Tempo Interrompida - Comparação entre grupos ......................... 41 


\section{SUMÁRIO}

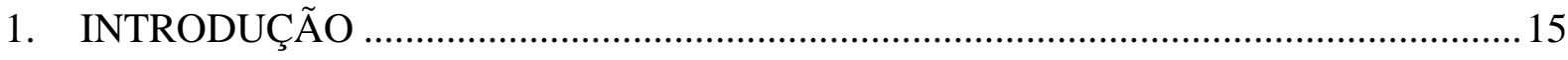

1.1 - A INTERNAÇÃO HOSPITALAR COMO FATOR DE RISCO PARA MORBI-

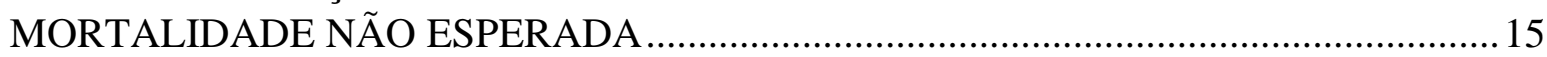

1.2 - CARACTERIZAÇÃO DA DURAÇÃO DA PERMANÊNCIA HOSPITALAR ....... 16

1.3 - GESTÃO DE FLUXO E GERÊNCIA DA CLÍNICA ….......................................... 17

1.4 - INICIATIVAS DE GESTÃO DA CLÍNICA ESTABELECIDAS NO HCFMRP-USP

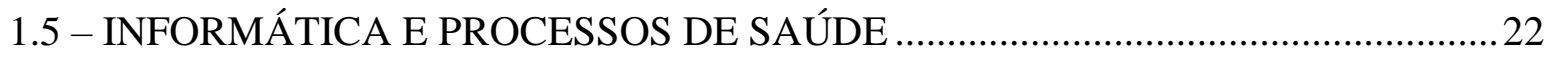

1.6- AS CARACTERÍSTICAS DO HCFMRP-USP ....................................................... 27

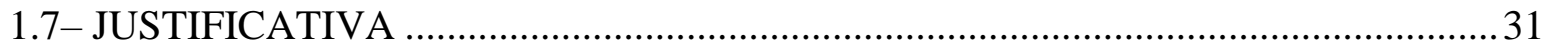

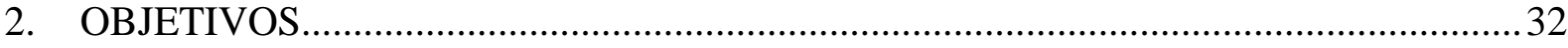

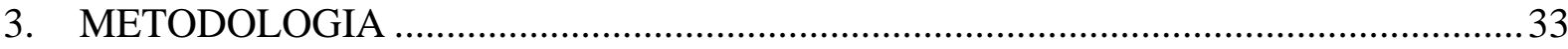

3.1 DESCRIÇÃO DO PROCESSO DE LIBERAÇÃO DO PACIENTE APÓS A ALTA

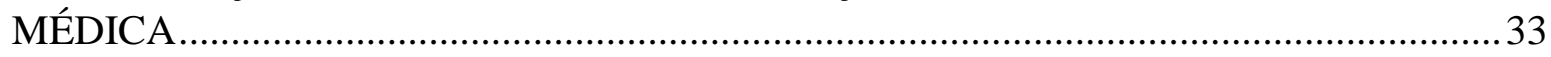

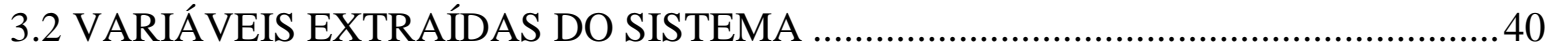

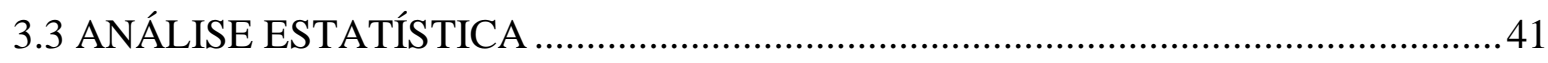

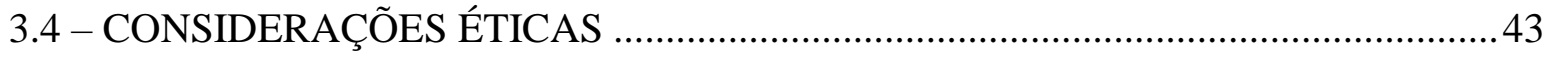

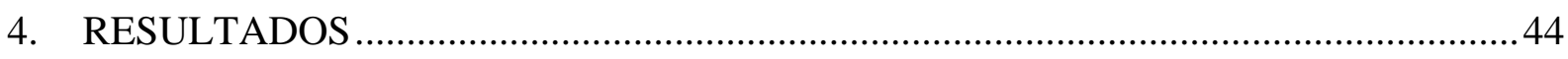

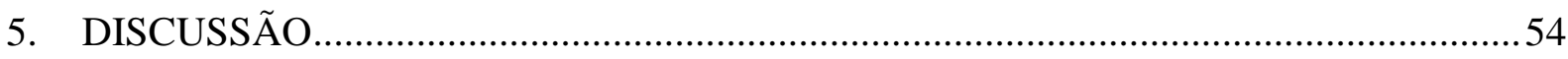

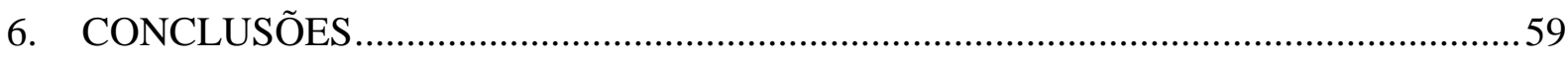

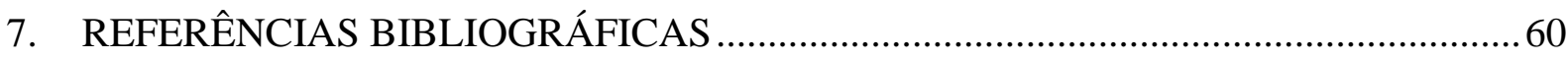

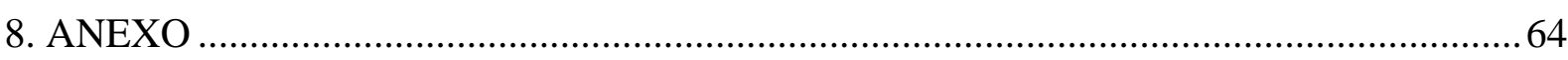

ANEXO 1 - PUBLICAÇÃO NA REVISTA QUALIDADE HC ......................................6

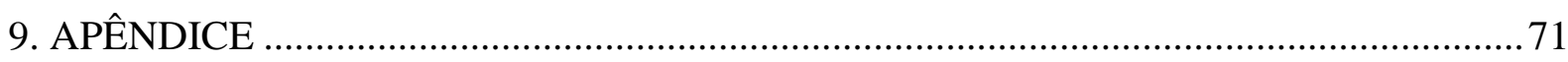

APÊNDICE 1 - APROVAÇÃO NO COMITÊ DE ÉTICA MÉDICA - HCFMRP-USP ... 71 APÊNDICE 2 - DECLARAÇÃO DA SUPERINTENDÊNCIA DO HCFMRP-USP ............................74 


\section{INTRODUÇÃO}

A qualidade na Assistência ao paciente caracteriza-se como um tema de extrema relevância sendo de interesse mútuo entre paciente, instituições de saúde, órgãos de regulação e a sociedade como um todo. Trata-se de um processo que se iniciou há duas décadas com a publicação "To Err is Human"(1) do Institute of Medicine e que foi recentemente revisada ${ }^{(2)}$. Estes artigos iniciaram uma revolução no sistema Flexnireniano estabelecido em 1910 nos Estados Unidos e que se constitue ainda a base da estrutura dos Serviços de Saúde no Brasil, embora muitas modificações já tenham ocorrido.

Tal relevância impulsiona a demanda sobre a qualidade e a segurança dos pacientes, levando as instituições de saúde a revisarem seus processos para garantir a qualidade no atendimento, bem como a criar estratégias para contenção de custos. Sua gestão constitui-se como tema mais complexo do que aqueles observados em outros tipos de instituição, por envolver especialidades e procedimentos de grande diversidade. Em última análise, a "voz" do paciente tem sido ouvida e busca-se a todo momento resgatar a humanização do atendimento com iniciativas como o atendimento interdisciplinar, multidisciplinar e transdisciplinar.

\section{1 - A INTERNAÇÃO HOSPITALAR COMO FATOR DE RISCO PARA MORBI-MORTALIDADE NÃO ESPERADA}

Um dos pilares deste movimento pela qualidade no atendimento ao paciente é a percepção dos riscos que uma internação hospitalar implica além dos associados à entidade nosológica que a motivou. Dentre as múltiplas causas, três principais situações guardam maior relação com este risco: erros de prescrição médica, tromboembolismo venoso desencadeado pela imobilização ao leito e a ocorrência de infecções hospitalares. Enquanto os erros de prescrição sejam os mais relacionados à internação tanto precoce como tardia, o tromboembolismo e a infecção hospitalar são grandes causas de complicações mais tardias ${ }^{(3-5)}$.

A classificação simplificada exposta acima exemplifica a relação direta que existe entre o aumento do risco de complicações e a permanência hospitalar. Embora soluções como protocolos preventivos para tromboembolismo venoso e medidas para prevenção e contenção da infecção hospitalar estejam disponíveis, os melhores resultados de redução destas complicações também guardam associação direta com a redução do tempo de permanência hospitalar.

Diversos esforços têm sido empreendidos para redução do tempo de permanência de pacientes nas instituições hospitalares. Para a correta compreensão destes esforços e seu impacto, é 
preciso primeiro se caracterizar a epidemiologia da Permanência Hospitalar (Duração da Internação) e os fatores que a influenciam.

\section{2 - CARACTERIZAÇÃO DA DURAÇÃO DA PERMANÊNCIA HOSPITALAR}

A duração da permanência hospitalar é influenciada por diversas dimensões, sendo que cada uma delas é influenciada por sua vez por fatores que devem ser compreendidos para melhor atuar num processo sistêmico e multifacetado ${ }^{(6)}$.

Uma primeira dimensão é caracterizada pela natureza da internação, sendo ela eletiva ou de urgência. As internações de urgência tendem a ser de menor duração e ter menor variabilidade quanto ao tempo para resolução dos problemas.

Diversas interpretações para estes achados são elencadas na literatura, como por exemplo, as internações eletivas estarem mais sujeitas à periodicidade semanal, na qual se observa aumento do número de casos durante o início da semana e redução aos finais de semana. Além disto, muitas vezes a condução clínica das internações eletivas é de responsabilidade de profissionais em treinamento, que dependem de supervisão escalada diariamente para resolução dos casos. Isto faz com que a solicitação de exames, sua interpretação e o desencadeamento de procedimentos sejam fragmentados em dias, quando poderiam ser manejados em horas. Já nas situações de emergência, a disponibilidade de supervisão contínua permite maior agilidade neste $\operatorname{processo}^{(7)}$.

A variabilidade da duração da permanência hospitalar também é influenciada por uma segunda dimensão, determinada pela natureza da programação para a admissão hospitalar ou, em outras palavras, pelo Projeto Terapêutico Singular (PTS). O PTS é o conjunto de objetivos ou ações que se pretende alcançar durante uma internação. Pacientes que são admitidos com objetivos claros e previamente planejados tendem a permanecer menos no hospital, enquanto o oposto ocorre com falta de clareza, planejamento ou por planejamentos muito ambiciosos ${ }^{(8)}$.

Dados clássicos de literatura, que são repetidamente repetidos em diversos estudos, demonstram que ao se realizar a distribuição num Diagrama de Pareto, cerca de 75 a $80 \%$ das internações duram menos do que 7 dias, embora respondam por apenas cerca de $30 \%$ da capacidade de leitos disponíveis ${ }^{(9)}$. Estes dados ilustram que a simples observação da duração da internação não é um indicador confiável para um processo complexo. Assim, continuando o exemplo, a maior parte da capacidade de internação é ocupada por pacientes que permanecem 
por mais de uma semana no hospital e que apresentam enorme variabilidade quanto ao momento da alta hospitalar.

Neste ponto, fica clara uma terceira dimensão, representada pela variabilidade das características individuais de cada paciente. Hospitais especializados, como centros oftalmológicos ou clínicas de cirurgia plástica estética, apresentam menor variabilidade de permanência hospitalar por se tratarem de casos de maior previsibilidade. Ao contrário, quanto maior a variabilidade da demanda dos pacientes, representada pela maior variabilidade das condições clínicas de cada especialidade ou pelo número de especialidades num hospital, aumenta a diversidade (“Case Mix”) e maior será a variabilidade do tempo de permanência.

Novamente, a utilização apenas do indicador de duração da permanência hospitalar ou da relação capacidade (número de leitos) x demanda (número de pacientes a serem internados) não permite que a variabilidade expressa pelas características dos pacientes seja capturada ou explicada de modo apropriado e já foram responsáveis por soluções inadequadas de gestão da capacidade em diversas instituições ${ }^{(10)}$.

Finalmente, uma quarta dimensão pode ser representada pela documentação e registro das ações que o paciente recebe na instituição. Há processos para a alta, a evolução, a realização de procedimentos e para a alta hospitalar que necessitam documentação em prontuário clínico para possibilitar o resgate para fins jurídicos e de pagamento. Embora aparentemente não pareçam exercer variabilidade na Permanência Hospitalar, há evidências na literatura em contrário ${ }^{(11)}$.

Estas quatro dimensões são as mais representativas, embora outras possam ser elencadas ou outras classificações utilizadas. $\mathrm{O}$ esboço apresentado tem a função de demonstrar a moderna compreensão da necessidade de novas estratégias num caráter mais integrativo, sem, no entanto, desmerecer em excesso o indicador de duração da permanência hospitalar. É um indicador de fácil obtenção, de enorme consistência e reprodutibilidade e que guarda relação com algumas condições que podem ser acompanhadas pelo seu desempenho. No entanto, como ele não consegue explicar todas as situações encontradas, faz-se necessário a construção de novos paradigmas, como a abordagem por gestão de fluxo.

\section{3 - GESTÃO DE FLUXO E GERÊNCIA DA CLÍNICA}

Fluxo é definido como acrescentar valor aos processos e serviços, aumentando os benefícios, diminuindo gastos ou pela combinação dessas duas estratégias, no atendimento de pacientes ao longo dos serviços e filas de espera que compreendem o moderno sistema de saúde ${ }^{(12)}$. 
Esta compreensão de que o sistema de saúde é uma enorme possibilidade de caminhos que o paciente deve percorrer ao longo do seu tratamento, traz associada a identificação de gargalos, em que podem ocorrer represamento e formação de filas. A gestão destas filas deu origem ao moderno conceito de Gestão da Clínica, compreendida como o "Conjunto de tecnologias de microgestão destinadas a prover uma atenção à saúde de qualidade, centrada nas pessoas, efetiva, segura, eficiente, oportuna, equitativa e humanizada". As ferramentas de gestão da clínica são operacionalizadas adotando como principais tecnologias da microgestão: diretrizes clínicas; gestão do caso; gestão das condições de saúde, protocolos clínicos, linhas de cuidado, auditoria clínica e gestão das listas de espera ${ }^{(13)}$.

As diretrizes clínicas são recomendações preparadas, de forma sistemática, com o propósito de influenciar decisões dos profissionais de saúde e das pessoas usuárias a respeito da atenção apropriada, em circunstâncias clínicas específicas. Devem combinar: medicina baseada em evidências, avaliação tecnológica em saúde e avaliação econômica dos serviços de saúde.

A gestão do caso é processo cooperativo que se desenvolve entre um profissional gestor do caso, a pessoa portadora de uma condição de saúde muito complexa e sua rede de suporte, para planejar, monitorar e avaliar opções de cuidados e de coordenação da atenção à saúde, de acordo com as necessidades da pessoa. Tem por objetivo propiciar uma atenção de qualidade, humanizada e capaz de aumentar a capacidade funcional e de preservar autonomia individual e familiar. A estratégia de gestão de casos também pode ser aplicada para situações específicas que envolvam a mobilização de múltiplas instâncias da instituição.

A Gestão das Condições de Saúde busca mudar o foco da atenção em saúde do indivíduo para uma população adscrita, usando processos de gerenciamento de uma determinada condição de saúde, já estabelecida, por meio de um conjunto de intervenções gerenciais, educacionais e no cuidado, com o objetivo de alcançar bons resultados clínicos, de reduzir os riscos para os profissionais e para as pessoas usuárias, contribuindo para a melhoria da eficiência e a da qualidade da atenção à saúde.

Os protocolos clínicos são recomendações sistematicamente desenvolvidas com o objetivo de prestar a atenção à saúde apropriada em relação a partes do processo de uma condição de saúde e em um ponto de atenção à saúde determinado.

As linhas de cuidado representam o itinerário terapêutico do paciente na rede, fornecendo uma referência para prever um conjunto mínimo de atividades e procedimentos necessários a estimar seus custos. Estas linhas expressam os fluxos assistenciais que devem ser garantidos ao usuário, 
no sentido de atender às suas necessidades de saúde, definindo as ações e serviços que devem ser desenvolvidos nos diferentes pontos da rede de atenção à saúde, assim como, nos sistemas de apoio.

A Auditoria Clínica consiste na análise crítica e sistemática da qualidade da atenção à saúde, incluindo os procedimentos usados no diagnóstico e tratamento, o uso dos recursos e os resultados para os pacientes em todos os pontos de atenção, observada a utilização dos protocolos clínicos estabelecidos.

A Gestão da Lista de Espera é uma tecnologia que busca estabelecer critérios de ordenamento pautados nos riscos e necessidades, promovendo a transparência e a busca da racionalização dos recursos em saúde, intervindo, assim, tanto na oferta, incrementando a produtividade do serviço, quanto na demanda, com a instituição de políticas de redução das necessidades por melhorias em outros pontos da rede de atenção à saúde.

\section{4 - INICIATIVAS DE GESTÃO DA CLÍNICA ESTABELECIDAS NO HCFMRP-USP}

\section{Sistema de Regulação de Urgência e Emergência (SRUE)}

A Diretoria Regional de Saúde (DRS) XIII foi pioneira na Instalação de um Sistema de Regulação Médica para organizar o fluxo dos pacientes, no entanto, a comunicação inicial era realizada por telefone e após 10 anos de sua implantação, inadequações ainda geravam sobrecarga no atendimento em instituições e prejuízo para os usuários, o que motivou a implantação do SRUE para comunicação imediata entre as unidades participantes do processo de regulação médica ${ }^{(14)}$.

O fluxo se inicia quando o médico solicitante preenche um formulário de solicitação de vaga, os dados são enviados ao médico regulador por via eletrônica, que avalia as informações, categoriza como baixa, moderada ou alta prioridade, ou como "vaga zero", e encaminha a solicitação ao hospital mais adequado que aceita, recusa ou solicita mais informações, gerando um processo de negociação sigiloso e documentado.

Este processo foi a base da Central de Regulação de Ofertas de Serviços de Saúde (CROSS) da Secretaria do Estado de Saúde (SES) de São Paulo.

\section{Leitos de Longa Permanência}

A permanência prolongada de pacientes crônicos com alta dependência também é um dos problemas que impactam na aglomeração de serviços. Para resolver esse problema que afeta a 
Unidade de Emergência (U.E.) do HCFMRP-USP, buscou-se a instalação de leitos de longa permanência, que são leitos alocados em hospitais de pequeno porte, que enfrentam dificuldades econômicas para subsistência e têm baixa taxa de ocupação(15).

A Coordenação da U.E.- HCFMRP-USP, o DRS XIII, a Prefeitura de Ribeirão Preto e o Serviço de Atendimento Móvel de Urgência (SAMU) Regional identificaram três hospitais para estabelecer parcerias, foram realizadas visitas técnicas in loco e estabelecidos protocolos de encaminhamento de pacientes de longa permanência. Os critérios para encaminhamento foram baseados nas condições de atendimento e as responsabilidades de cada instituição, baseando-se no benefício para ambas as partes, a liberação de mais leitos no Departamento de Emergência para pacientes de alta complexidade e ganho financeiro para os hospitais-parceiros. Além disso, esses hospitais receberam capacitação de seus funcionários, ficando acordado que caso houvesse necessidade de retorno do paciente ao hospital terciário, isso seria feito independentemente da Regulação Médica. A partir de abril de 2014, o projeto foi sancionado e apoiado financeiramente pela Secretaria da Saúde do Estado de São Paulo e acontece até os dias atuais.

Este processo teve impacto considerável no aumento de vagas oferecidas pelo Departamento de Emergência para áreas de estrangulamento do sistema, como a Neurologia e Terapia Intensiva, notando-se a tendência de aumento de vagas gerais de atendimento, totalizando 9,3\%, além de abrir possibilidade de discussão para de que cada município possa ser responsável em fornecer esse apoio para pacientes de longa permanência, transferindo-os para instâncias primárias do SUS localizadas nos municípios de residência do paciente.

\section{Sistematização da Solicitação de leitos em terapia intensiva}

Outra estratégia adotada na U.E-HCFMRP/USP para auxiliar nos fluxos internos e melhorar sua capacidade operacional foi organizar a priorização de pacientes para Unidade de Terapia Intensiva, com a criação de um sistema de informação para a organização da fila de espera por leitos, e o objetivo inicial foi avaliar sua utilização sob a perspectiva da mortalidade e permanência hospitalar ${ }^{(5)}$.

O sistema funciona por meio de sistema informatizado. A requisição contém informações diagnósticas do paciente, motivo da solicitação e marcadores de gravidade, como necessidade de suporte ventilatório, presença de choque circulatório e rebaixamento do nível de consciência. Após os pacientes são avaliados por médicos intensivistas, à beira do leito, e classificados quanto à prioridade conforme as diretrizes da Society of Critical Care Medicine (SCCM), de 
acordo com a gravidade e benefício da utilização do leito da terapia intensiva e em caso de pacientes com mesmo grau de prioridade clínica, são priorizados aqueles provenientes de locais estratégicos para facilitar o fluxo dessas unidades. E ainda permanecendo a semelhança o desempate é realizado pelo tempo da requisição de vaga na terapia intensiva, priorizando-se os mais antigos ${ }^{(16)}$.

Este novo sistema de informação foi eficaz na medida em que envolveu o compartilhamento de responsabilidades entre médicos e gestores e facilitou o suporte técnico durante a tomada de decisões, reduziu o atrito entre os intensivistas e os outros médicos do hospital, além de prover transparência na gestão da fila e como resultado pode promover a redução da mortalidade hospitalar e ter impacto na permanência hospitalar.

\section{Núcleo Interno de Regulação}

O Núcleo Interno de Regulação (NIR) é estabelecido foi uma das estratégias de gestão criadas pela Política Nacional de Atenção Hospitalar do Ministério da Saúde (PNHOSP) em 2013, sendo regulamentado por Manual específico publicado pelo Ministério da Saúde ${ }^{(17)}$. Trata-se de uma unidade administrativa para gestão de micro e macro-regulação do fluxo de pacientes, composto por uma equipe de profissionais que envolve médicos, enfermeiros e outros profissionais de saúde. Sua implantação no HCFMRP USP foi iniciada em 2016 na Unidade de Emergência e na Unidade Campus, em 2017 ${ }^{(18)}$.

Na U.E-HCFMRP/USP a equipe de trabalho do NIR foi composta por 2 enfermeiros, 01 médico e 01 assistente social, com horário de funcionamento em horário comercial, de segunda à sextafeira, das 07 às 19h. As principais funções atribuídas foram: intercomunicação entre os diversos setores clínicos e enfermarias e Controle de Leitos, setor de Farmácia e Nutrição, com objetivo de redução do tempo de permanência do paciente na instituição e administração dos leitos.

O NIR está em processo contínuo de estruturação, buscando os três pilares propostos pelo Ministério da Saúde em Manual específico em que o autor atuou como membro do corpo editorial (VIII - B - 21): (i) Práticas de Regulação; (ii) Articulação com a RAS e (iii) Monitoramento.

Dentro das Práticas de Regulação, as condições disponíveis para atendimento são constantemente atualizadas, garantindo-se que a epidemiologia seja equiparada à capacidade instalada. Isto exige constante comunicação entre o NIR e as unidades assistenciais. O NIR está localizado fisicamente nas dependências do Departamento de Assistência à Saúde (DAS), possibilitando a rapidez de decisões administrativas necessárias. A implantação do projeto de 
médicos hospitalistas foi iniciada no HC Criança. Durante os últimos dois anos, estendeu-se o projeto para o prédio central do HC Campus e para a Unidade de Emergência.

\section{Hospitalista}

A Medicina Hospitalar é uma especialidade recente no Brasil e no mundo ${ }^{(19)}$. Nos Estados Unidos da América (EUA), iniciou sua atuação na década de 90 nos EUA e já existem iniciativas no Brasil, principalmente na Medicina Complementar, embora ainda não seja reconhecida como especialidade médica. Define-se a Medicina Hospitalar como uma área de atuação médica voltada para o cuidado dos pacientes internados, envolvendo uma gama de atribuições, que adquire maior ou menor importância de acordo com o grau de desenvolvimento das organizações ${ }^{(20)}$. Pode ser agrupada em duas vertentes, uma voltada para a atividade médica propriamente dita e outra, voltada para um componente de gestão. As atividades médicas compreendem intervenções diagnósticas ou terapêuticas pontuais, de modo a garantir a segurança e o cuidado de pacientes sob o cuidado das diversas equipes, embora em algumas instituições sejam observados que estes profissionais assumem o cuidado integral dos pacientes, principalmente, em áreas cirúrgicas. Já as atividades de gestão estão voltadas para monitorar processos de trabalho institucionais.

A diversidade das instituições hospitalares implica que as atividades destes profissionais sejam adaptadas para cada realidade. No contexto do HCFMRP USP, a natureza distinta do HC Criança e da Unidade de Emergência implicaram adaptações, mesmo com princípios gerais determinados pela Administração Central. Foi estabelecido um Regimento dedicado, com objetivo de organizar, normatizar e disciplinar as atividades dos Médicos Hospitalistas do HCFMRP USP, incluindo a sua atuação no HC Criança, na Unidade de Emergência, na Clínica FAEPA e em outras unidades que, porventura, vierem a ser criadas. Compreende-se como Médico Hospitalista, o profissional médico dedicado ao acompanhamento do fluxo do atendimento prestado aos pacientes, ao longo de sua internação, em consonância com as demais Equipes Clínicas.

\section{5 - INFORMÁTICA E PROCESSOS DE SAÚDE}

A permanência hospitalar acima do tempo necessário caracteriza-se como uma preocupação de longa data, contribuindo para redução da qualidade da assistência e aumento dos custos. Além do mais, mantém o usuário do sistema de saúde longe do convívio de sesus familiares e da comunidade, além de aumentar a chance de exposição à riscos evitáveis, como infecções hospitalares, depressão, perda de condicionamento físico, quedas e outros ${ }^{(21)}$. 
Neste contexto, a Tecnologia da Informação desempenha papel estratégico como ferramenta de apoio à mudança. Estudos mostram que a tecnologia da informação pode contribuir em aspectos relacionados à segurança do paciente, bem como servir de suporte para otimização de atividades $^{(22)}$. Ferramentas de Registros Eletrônicos de Saúde (EHR) e Sistemas de Troca de Informações Hospitalares (HIE), se bem implementados, podem contribuir na redução do número de admissões desnecessárias, reduzindo custos relacionados à Internação ${ }^{(23)}$.

A adoção das EHR em conjunto com a integração de dados genômicos, bem como outros dados tem permitido o surgimento de oportunidades de implementações de pesquisas que levam a medicina personalizada nos EUA e em outros lugares. A disponibilidade de um grande conjunto de dados oriundos destes sistemas está abrindo novos campos de pesquisa, bem como oportunidades de melhoria no gerenciamento da saúde. EHRs também podem possuir habilidades de oferecer Suporte a Decisão Clínica - Clinical Decision Suport (CDS), o que por sua vez, pode ser considerada uma funcionalidade chave para oferecer um melhor cuidado ao paciente e melhores condições de segurança. Podemos citar como exemplos de intervenções do CDS alertas computadorizados a em funções de características do paciente informados, como alergias ou a suspeita de doenças respiratórias transmissíveis ou eventos específicos que podem ocorrer durante seu tratamento que possua relevância em termos de segurança como a ocorrência de quedas, úlcera de lesão por pressão e outros. Tais ferramentas possuem finalidades a melhorar a decisão clínica feita por médicos e não substituí-los ${ }^{(24)}$.

Outro ponto importante a salientar são as contribuições que a Tecnologia da Informação oferece em termos de segurança ao oferecer normas e especificações que contribuam na melhoria do registro das informações relativas ao paciente, bem como a progressiva transformação dos registros em papel para registros eletrônicos. Nessa vertente é muito importante destacar o trabalho conjunto desenvolvido entre a Sociedade Brasileira de Informática em Saúde (SBIS) e o Conselho Federal de Medicina (CFM), ocorrido através de um convênio de cooperação técnica-científica que está em vigência desde o ano de 2002. Neste trabalho conjunto foram estabelecidas definições do que é um Sistema de Prontuário Eletrônico do Paciente ou Registro Eletrônico em Saúde (PEP/RES) no território brasileiro, bem como requisitos indispensáveis para esta categoria de sistemas. Como frutos desta parceria podemos destacar a elaboração da resolução $n^{\circ}$ 1639/2002, que dispunha sobre normas referentes ao uso de sistemas informatizados, bem como a guarda e manuseio de prontuários médicos. Posteriormente essa resolução veio a ser substitúida pela resolução $n^{\circ} 1821 / 2007$. Nesta resolução foi autorizado a 
Eliminação do Papel e troca de Informação Identificada em Saúde, como podemos observar em seus $\operatorname{artigos} 1^{\circ}$ a $4^{\circ}$, a seguir ${ }^{(25}$ p. 1):

Art. $1^{\circ}$ Aprovar o Manual de Certificação para Sistemas de Registro Eletrônico em Saúde, versão 3.0 e/ou outra versão aprovada pelo Conselho Federal de Medicina, anexo e também disponível nos sites do Conselho Federal de Medicina e Sociedade Brasileira de Informática em Saúde (SBIS), respectivamente, www.portalmedico.org.br e www.sbis.org.br.

Art. $2^{\circ}$ Autorizar a digitalização dos prontuários dos pacientes, desde que o modo de armazenamento dos documentos digitalizados obedeça a norma específica de digitalização contida nos parágrafos abaixo e, após análise obrigatória da Comissão de Revisão de Prontuários, as normas da Comissão Permanente de Avaliação de Documentos da unidade médico - hospitalar geradora do arquivo.

$\S 1^{\circ}$ Os métodos de digitalização devem reproduzir todas

as informações dos documentos originais.

$\S 2^{\circ}$ Os arquivos digitais oriundos da digitalização dos documentos do prontuário dos pacientes deverão ser controlados por sistema especializado (Gerenciamento eletrônico de documentos - GED), que possua, minimamente, as seguintes características:

a) Capacidade de utilizar base de dados adequada para o armazenamento dos arquivos digitalizados;

b) Método de indexação que permita criar um arquivamento organizado, possibilitando a pesquisa de maneira simples e eficiente;

c) Obediência aos requisitos do "Nível de garantia de segurança 2 (NGS2)", estabelecidos no Manual de Certificação para Sistemas de Registro Eletrônico e em Saúde.

Art. $3^{\circ}$ Autorizar o uso de sistemas informatizados para a guarda e manuseio de prontuários de pacientes e para a troca de informação identificada em saúde, eliminando a obrigatoriedade do registro em papel, desde que esses sistemas atendam integralmente aos requisitos do "Nível de garantia de segurança 2 (NGS2)", estabelecidos no Manual de Certificação para Sistemas de Registro Eletrônico em Saúde;

Art. $4^{\circ}$ Não autorizar a eliminação do papel quando da utilização somente do "Nível de garantia de segurança 1 (NGS1)", por falta de amparo legal.

Importante também destaque na Resolução CFM n ${ }^{\circ}$ 1821/2007, no seu Artigo $1^{\circ}$ sobre a aprovação de Manual de Certificação para Sistemas de Registro Eletrônico em Saúde, atualmente em sua vesão 4.3, o qual norteia estabelecimentos de saúde e desenvolvedores de 
sistemas enumerando definições, cadastros, padrões de troca de informações (notoriamente os padrões de Troca de Informação em Saúde Suplementar (TISS) e a Terminologia Unificada de Saúde Suplementar (TUSS), que constitui em uma padronização de terminologias estabelecidas pela Agência Nacional de Saúde (ANS), que é de uso obrigatório em transações realizadas dentro do padrão TISS). O manual estabelece que para eliminação total do papel, é necessário que um sistema esteja em conformidade com o nível de Garantia 2 (NGS2). Para se alcançar tal nível se faz necessário o uso de certificados digitais, o qual caracteriza-se como um documento que identifica um cidadão e possibilita que o mesmo possa efetuar a assinatura em meio eletrônico.

Dentro desta vertente de digitalização proposto é muito importante destacar o estabelecimento da Medida Provisória (MP) no 2.200-2, de 24 de agosto de 2001. Esta MP institui a InfraEstrutura de Chaves Públicas Brasileira, estabelecendo diretrizes de organização e suas competências em seus Artigos $1^{\circ}$ a $4^{\circ}$ a saber ${ }^{(26 \text { p. 1): }}$

Art. 1o Fica instituída a Infra-Estrutura de Chaves Públicas Brasileira - ICP-Brasil, para garantir a autenticidade, a integridade e a validade jurídica de documentos em forma eletrônica, das aplicações de suporte e das aplicações habilitadas que utilizem certificados digitais, bem como a realização de transações eletrônicas seguras.

Art. 2o A ICP-Brasil, cuja organização será definida em regulamento, será composta por uma autoridade gestora de políticas e pela cadeia de autoridades certificadoras composta pela Autoridade Certificadora Raiz - AC Raiz, pelas Autoridades Certificadoras - AC e pelas Autoridades de Registro - AR.

Art. 3o A função de autoridade gestora de políticas será exercida pelo Comitê Gestor da ICP-Brasil, vinculado à Casa Civil da Presidência da República e composto por cinco representantes da sociedade civil, integrantes de setores interessados, designados pelo Presidente da República, e um representante de cada um dos seguintes órgãos, indicados por seus titulares:

I - Ministério da Justiça;

II - Ministério da Fazenda;

III - Ministério do Desenvolvimento, Indústria e Comércio Exterior;

IV - Ministério do Planejamento, Orçamento e Gestão;

V - Ministério da Ciência e Tecnologia;

VI - Casa Civil da Presidência da República; e

VII - Gabinete de Segurança Institucional da Presidência da República. 
§ 1o A coordenação do Comitê Gestor da ICP-Brasil será exercida pelo representante da Casa Civil da Presidência da República.

$\S 20$ Os representantes da sociedade civil serão designados para períodos de dois anos, permitida a recondução.

§ 3o A participação no Comitê Gestor da ICP-Brasil é de relevante interesse público e não será remunerada.

§ 4o O Comitê Gestor da ICP-Brasil terá uma Secretaria-Executiva, na forma do regulamento.

Art. 4o Compete ao Comitê Gestor da ICP-Brasil:

I - adotar as medidas necessárias e coordenar a implantação e o funcionamento da ICP-Brasil;

II - estabelecer a política, os critérios e as normas técnicas para o credenciamento das AC, das AR e dos demais prestadores de serviço de suporte à ICP-Brasil, em todos os níveis da cadeia de certificação;

III - estabelecer a política de certificação e as regras operacionais da AC Raiz;

IV - homologar, auditar e fiscalizar a AC Raiz e os seus prestadores de serviço;

$\mathrm{V}$ - estabelecer diretrizes e normas técnicas para a formulação de políticas de certificados e regras operacionais das AC e das AR e definir níveis da cadeia de certificação;

VI - aprovar políticas de certificados, práticas de certificação e regras operacionais, credenciar e autorizar o funcionamento das $\mathrm{AC}$ e das AR, bem como autorizar a AC Raiz a emitir o correspondente certificado;

VII - identificar e avaliar as políticas de ICP externas, negociar e aprovar acordos de certificação bilateral, de certificação cruzada, regras de interoperabilidade e outras formas de cooperação internacional, certificar, quando for o caso, sua compatibilidade com a ICP-Brasil, observado o disposto em tratados, acordos ou atos internacionais; $\mathrm{e}$

VIII - atualizar, ajustar e revisar os procedimentos e as práticas estabelecidas para a ICP-Brasil, garantir sua compatibilidade e promover a atualização tecnológica do sistema e a sua conformidade com as políticas de segurança.

Parágrafo único. O Comitê Gestor poderá delegar atribuições à AC Raiz.

Conceitualmente, o ICP-Brasil constitui-se em uma cadeia de confiança que torna viável a emissão de certificados digitais para a identificação de pessoas, sendo, no Brasil adotado o modelo de certificação de raiz única, onde o Instituto Nacional de Tecnologia da Informação desempenha papel de Autoridade Certificadora Raiz (AC-Raiz). Ela tem, dentre outras funções, 
realizar o credenciamento ou descredenciamento de participantes dessa cadeia, que, por sua vez, atuam como emissores de certificados digitais, atividades de supervisão e auditoria.

Conforme mencionado anteriormente, o certificado digital possui função de identificar digitalmente uma pessoa (seja física ou jurídica), podendo ser emitido e armazenado em computador, dispositivo móvel ou em mídias externas (Cartão, Tokens ou mesmo na Nuvem), tendo validade, normalmente de 1 a 5 anos. Com ela, é assumido que toda assinatura digital possua autenticidade, integridade, confiabilidade, bem como o aspecto do não repúdio, onde o seu autor não poderá negar a responsabilidade pelo seu conteúdo. Importante salientar que a assinatura permite atestar a imutabilidade do conteúdo, pois caso o conteúdo de um documento assinado digitalmente seja alterado, a assinatura digital efetuada será invalidada.

\section{6- AS CARACTERÍSTICAS DO HCFMRP-USP}

O HCFMRP-USP é uma autarquia pública estadual, vinculada em termos administrativos à Secretaria de Estado da Saúde de São Paulo, estando regulamentada pelo Decreto no 13.297 de 05 de março de 1979 e integrada ao SUS desde 1988. Foi fundada no ano de 1956. Sua principal atividade é oferecer Assistência Médico-Hospitalar, servindo de campo de Ensino e Pesquisa na área da Saúde. Está caracterizada como um Hospital de Alta Complexidade e se constitui como referência terciária para a região nordeste do Estado de São Paulo, tendo como área de atuação as regiões de Ribeirão Preto, Franca, Araraquara e Barretos, além de receber pacientes de outras regiões do país ${ }^{(27)}$.

Para o exercício de suas atividades, o HCFMRP-USP conta para o atendimento de Urgência/Emergência oriundas da Regulação Municipal e Regional de média e alta complexidade, o HCFMRP-USP conta com a Unidade de Emergência (U.E.). Suas outras duas unidades estão localizadas no Campus Universitário, a saber: HC Campus e o Centro Regional de Hemoterapia. Em conjunto com a Fundação de Apoio, Pesquisa e Assistência (FAEPA), o HCFMRP-USP estabeleceu convênios com a Secretaria de Estado da Saúde de São Paulo (SES) com finalidade de estruturação de uma rede de serviços de média e baixa complexidade na região. Nesse contexto o Centro Estadual de Referência a Saúde da Mulher (MATER) com inauguração em 2009 e em 2010, o Hospital de Américo Brasiliense é integrado ao Complexo de Saúde HCRP/FMRP/FAEPA/USP. Além dos locais citados anteriormente, o complexo conta com outros pontos de atendimento de baixa complexidade (vide Figura 1) ${ }^{(27)}$. 


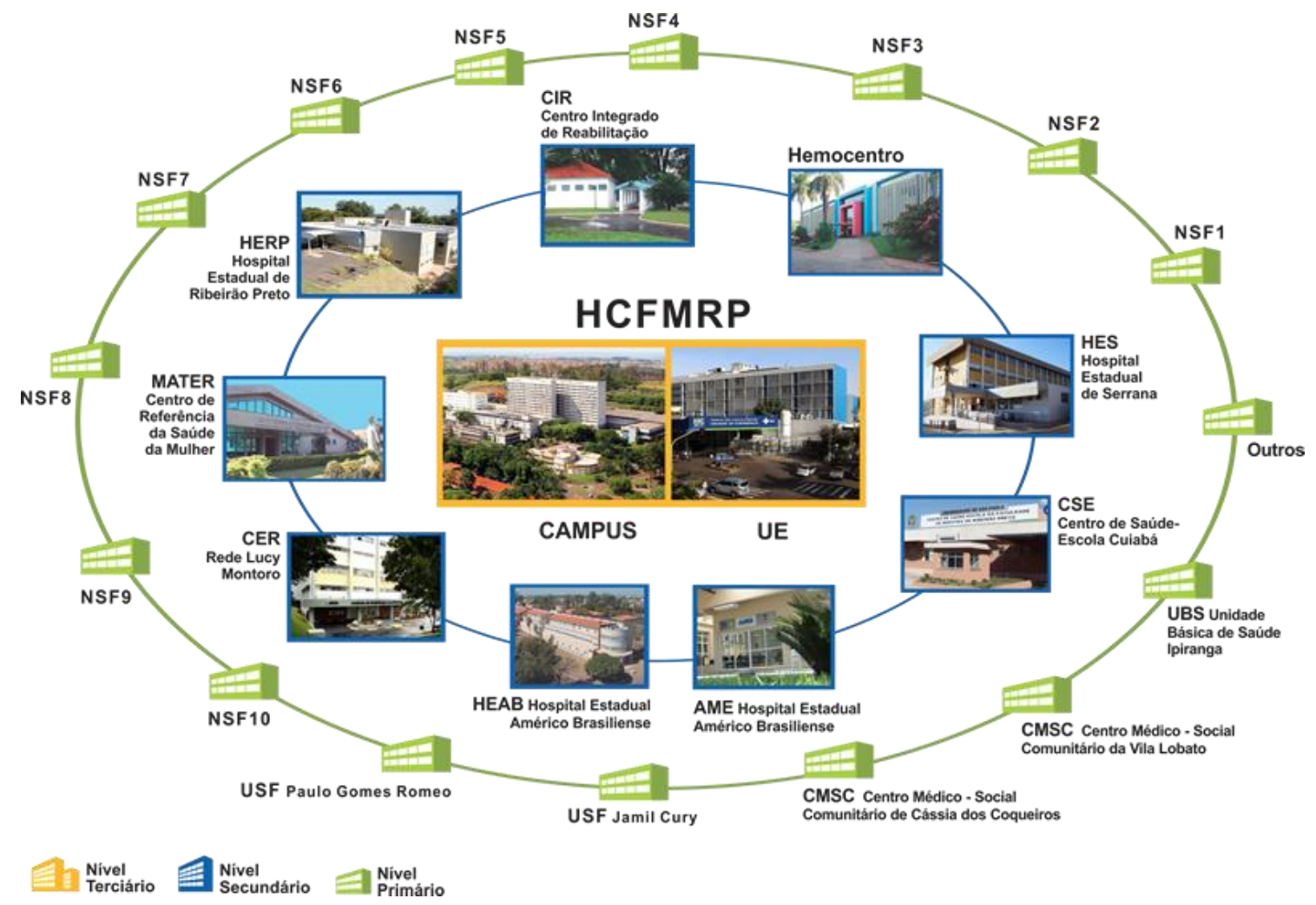

Fonte: Site www.hcrp.usp.br. Acesso em 17/06/2020

No eixo da Assistência, o Hospital proporciona atendimento de alta complexidade em nível ambulatorial e hospitalar. Estes atendimentos, por sua vez, compreendem cuidados de prevenção, tratamento e reabilitação de natureza clínica e/ou cirúrgica em diversas especialidades médicas, bem como atendimentos complementares de diagnóstico e tratamento. Todos esses atendimentos são exercidos através de equipes multidisciplinares compostas por médicos, enfermeiros, fisioterapeutas, psicólogos, terapeutas ocupacionais, nutricionistas, assistentes sociais e outros. Segundo as Tabelas 1 e 2, com informações obtidas no site da instituição, o HCFMRP-USP realizou, entre 2015 e 2019 aproximadamente: 710.000 consultas e procedimentos/ano, 35.000 internações/ano, 30.000 cirurgias/ano, 1700 partos/ano, 270 transplantes/ano, 3.150.000 exames laboratoriais/ano e 500.000 exames especializados/ano ${ }^{(28)}$. 
Tabela 1 - HCFMRP-USP - Estatísticas de produção anual.

\begin{tabular}{crrrr}
\hline Ano & $\begin{array}{c}\text { Coo de } \\
\text { Consultas / } \\
\text { Procedimentos }\end{array}$ & $\begin{array}{c}\text { № de } \\
\text { Internações }\end{array}$ & № de Cirurgias & № de Partos \\
\hline 2.015 & 679.631 & 34.924 & 32.820 & 1.744 \\
\hline 2.016 & 712.006 & 35.182 & 30.971 & 1.793 \\
\hline 2.017 & 717.235 & 35.299 & 31.254 & 1.693 \\
\hline 2.018 & 720.664 & 35.418 & 28.425 & 1.594 \\
\hline 2.019 & 732.121 & 33.932 & 26.313 & 1.645 \\
\hline $\begin{array}{c}\text { Média } \\
2015 \text { - } 2019\end{array}$ & 712.331 & 34.951 & 29.957 & 1.694 \\
\hline
\end{tabular}

Fonte: Site http://www.hcrp.usp.br Acesso em 17/06/2020.

Tabela 2 - HCFMRP-USP - Estatísticas de produção anual (conclusão)

\begin{tabular}{c|r|r|r}
\hline Ano & № de Transplantes & $\begin{array}{l}\text { № de Exames } \\
\text { Laboratoriais }\end{array}$ & $\begin{array}{c}\text { № de Exames } \\
\text { Especializados / } \\
\text { Procedimentos }\end{array}$ \\
\hline 2.015 & 325 & 3.043 .593 & 534.154 \\
\hline 2.016 & 270 & 3.095 .340 & 468.981 \\
\hline 2.017 & 248 & 3.067 .326 & 480.400 \\
\hline 2.018 & 283 & 3.211 .385 & 497.244 \\
\hline 2.019 & 214 & 3.340 .050 & 508.267 \\
\hline $\begin{array}{c}\text { Média } \\
2015-2019\end{array}$ & 268 & 3.151 .539 & 497.809 \\
\hline
\end{tabular}

Fonte: Site http://www.hcrp.usp.br Acesso em 17/06/2020.

No campo do ensino, o HCFMRP-USP possibilita atuação prática para alunos nas áreas de Medicina, Enfermagem, Nutrição, Terapia Ocupacional, Fisioterapia e outras áreas relacionadas à saúde Hospitalar através da oferta de diversos programas de Residência Médica, Multiprofissional, bem como programas de Complementação Especializada.

No campo de pesquisa possui uma Unidade de Pesquisa Clínica, que oferece suporte a pesquisa em seres humanos, realizadas dentro do HCFMRP-USP, apoiando a elaboração de orçamento e apoio logístico na execução de projetos. A Tabela 3 a seguir demonstra a infraestrutura onde estas atividades são desenvolvidas. 
Tabela 3 - Infraestrutura Complexo HCFMRP-USP.

\begin{tabular}{|c|c|c|}
\hline Instalações HCFMRP-USP & U.E. & Total \\
\hline Área Construída & $16.254,67 \mathrm{~m}^{2}$ & $179.027,94 \mathrm{~m}^{2}$ \\
\hline \multicolumn{3}{|l|}{ Unidades do Complexo de Saúde HCRP-USP/FMRP/FAEPA/USP } \\
\hline \multicolumn{3}{|l|}{ Número de Leitos } \\
\hline \multicolumn{3}{|l|}{ HCFMRP-USP - Unidade Campus } \\
\hline Leitos Gerais & & 599 \\
\hline Leitos Particulares & & 38 \\
\hline Leitos de Hospital - Dia & & 40 \\
\hline Leitos de UTI & & 67 \\
\hline \multicolumn{3}{|l|}{ HCFMRP-USP - Unidade de emergência } \\
\hline Leitos Gerais & & 138 \\
\hline Leitos de UTI & & 38 \\
\hline Total de Leitos HCFMRP-USP & & 920 \\
\hline Hospital Estadual de Ribeirão Preto - HER & & 46 \\
\hline Hospital Estadual de Américo Brasiliense - HEAB & & 107 \\
\hline - Leitos de UTI & & 10 \\
\hline Centro de Referência à Saúde da Mulher - MATER & & 40 \\
\hline - Leitos de UCI & & 5 \\
\hline Total de Leitos do Complexo HCFMRP-USP & & 1128 \\
\hline \multicolumn{3}{|l|}{ Número de Consultórios } \\
\hline HCFMRP-USP - Unidade Campus & & 279 \\
\hline HCFMRP-USP - Unidade de Emergência & & 15 \\
\hline Hospital Estadual de Ribeirão Preto - HER & & 10 \\
\hline Centro de Referência à Saúde da Mulher - MATER & & 9 \\
\hline \multicolumn{3}{|l|}{ Número de Salas Cirúrgicas } \\
\hline HCFMRP-USP - Unidade Campus & & 30 \\
\hline HCFMRP-USP - Unidade de Emergência & & 6 \\
\hline Hospital Estadual de Ribeirão Preto - HER & & 4 \\
\hline Hospital Estadual de Américo Brasiliense - HEAB & & 4 \\
\hline Centro de Referência à Saúde da Mulher - MATER & & 5 \\
\hline
\end{tabular}

Fonte: HCFMRP-USP - Relatório de Atividades 2018 


\section{7- JUSTIFICATIVA}

Com o estabelecimento do NIR e da Gestão da Clínica no HCFMPR-USP a partir de 2015 em maior intensidade, várias práticas e processos hospitalares foram revistos, buscando-se medidas que pudessem otimizar o fluxo dos pacientes.

Um dos problemas que mais prementes era a dificuldade de rotatividade de leitos para absorver internações não-programadas que ocorriam nos períodos vespertinos oriundas dos ambulatórios do HCFMRP-USP Campus. Na revisão do processo, observou-se que uma das variáveis que implicavam em maior retardo era a demora para a documentação e registro do processo de alta hospitalar. Foi feita a hipótese de que a utilização de ferramentas de informática, principalmente com a inclusão de assinatura digital, poderia simplificar este processo e ampliar a rotatividade de leitos, diminuindo o retardo vespertino de internações não programadas. 


\section{OBJETIVOS}

Avaliar se houve redução do tempo de saída do paciente da instituição após a alta médica (fechamento de alta) antes e após a incorporação de uma nova intervenção no processo, baseada em ferramentas de informática.

Avaliar se a introdução desta intervenção implicou na redução de gargalos para a oferta de leitos para internações não-programadas dos ambulatórios do HCFMRP-USP. 


\section{METODOLOGIA}

Trata-se de um estudo quasi-experimental, tipo antes e depois de uma intervenção, baseado em dados administrativos do tempo para a saída do paciente do hospital após a alta médica.

Denominou-se intervenção no presente estudo a reestruturação do processo de saída do paciente da instituição após a alta médica, na qual se realizou a descrição do processo que estava em voga na instituição antes da intervenção. Em um segundo momento, definiu-se qual seria a intervenção a ser executada e mapeou-se o processo que seria modificado. Finalmente, observou-se o impacto através da mensuração dos tempos previamente definidos.

\subsection{DESCRIÇÃO DO PROCESSO DE LIBERAÇÃO DO PACIENTE APÓS A ALTA MÉDICA}

A Figura 2 detalha o fluxo do processo de Alta Hospitalar do Hospital das Clínicas de Ribeirão Preto antes e após a sua revisão.

Figura 2 - Diagrama do Processo de Saída do Paciente da Instituição após a Alta do HCFMRP-USP antes e após revisão do processo.

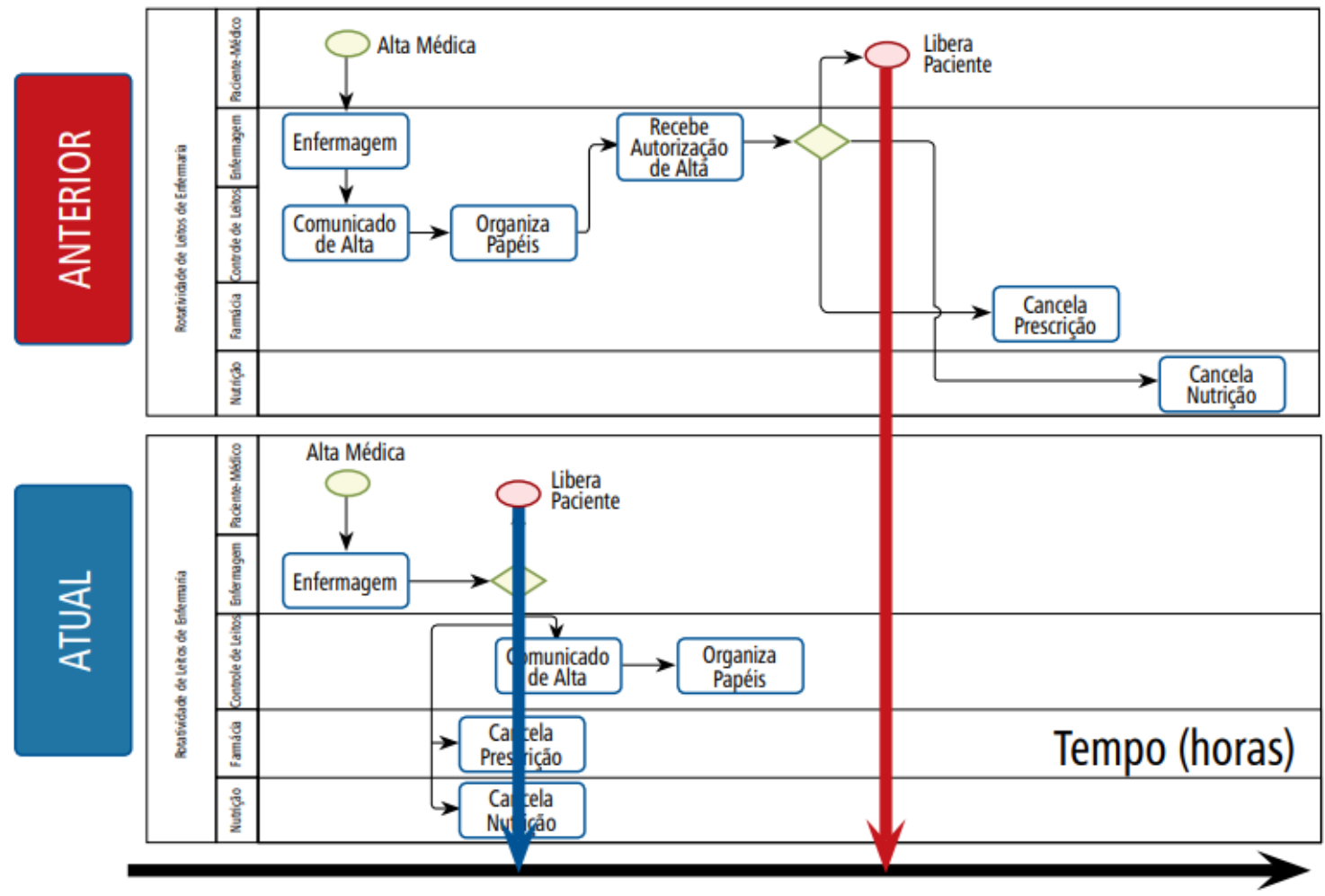

Define-se a relação matricial entre os diversos processos paralelos que ocorrem nos serviços de Enfermagem, Nutrição e Dietética, Farmácia e Controle de Leitos da Instituição. Fonte: Relatório de Gestão HCFMRP-USP $2015-2018$ 
Conforme observa-se na parte superior da Figura 2 (ANTERIOR), o médico registrava a alta médica em sistema informatizado e o registro de atendimento ao paciente permanecia em aberto até toda a documentação pertinente ao paciente fosse entregue ao setor de Controle de Leitos, o qual efetivava o fechamento do atendimento, e assim o leito era então disponibilizado para nova admissão. Da Figura 3 até a Figura 13 temos as etapas do assistente de alta dos Sistemas HCFMRP-USP, sistema mantido por equipe própria de desenvolvimento do Hospital até a época de confecção deste documento. Nele, o médico inicia a ação de alta do paciente, sendo percorridas diversas etapas para o registro de informações pertinentes a alta, como diagnósticos, emissão de atestados, agendamento de retornos ambulatoriais de seguimento, dentre outros. Por razões de privacidade do paciente algumas partes das figuras foram ocultas.

Figura 3 - Assistente de Alta - Início

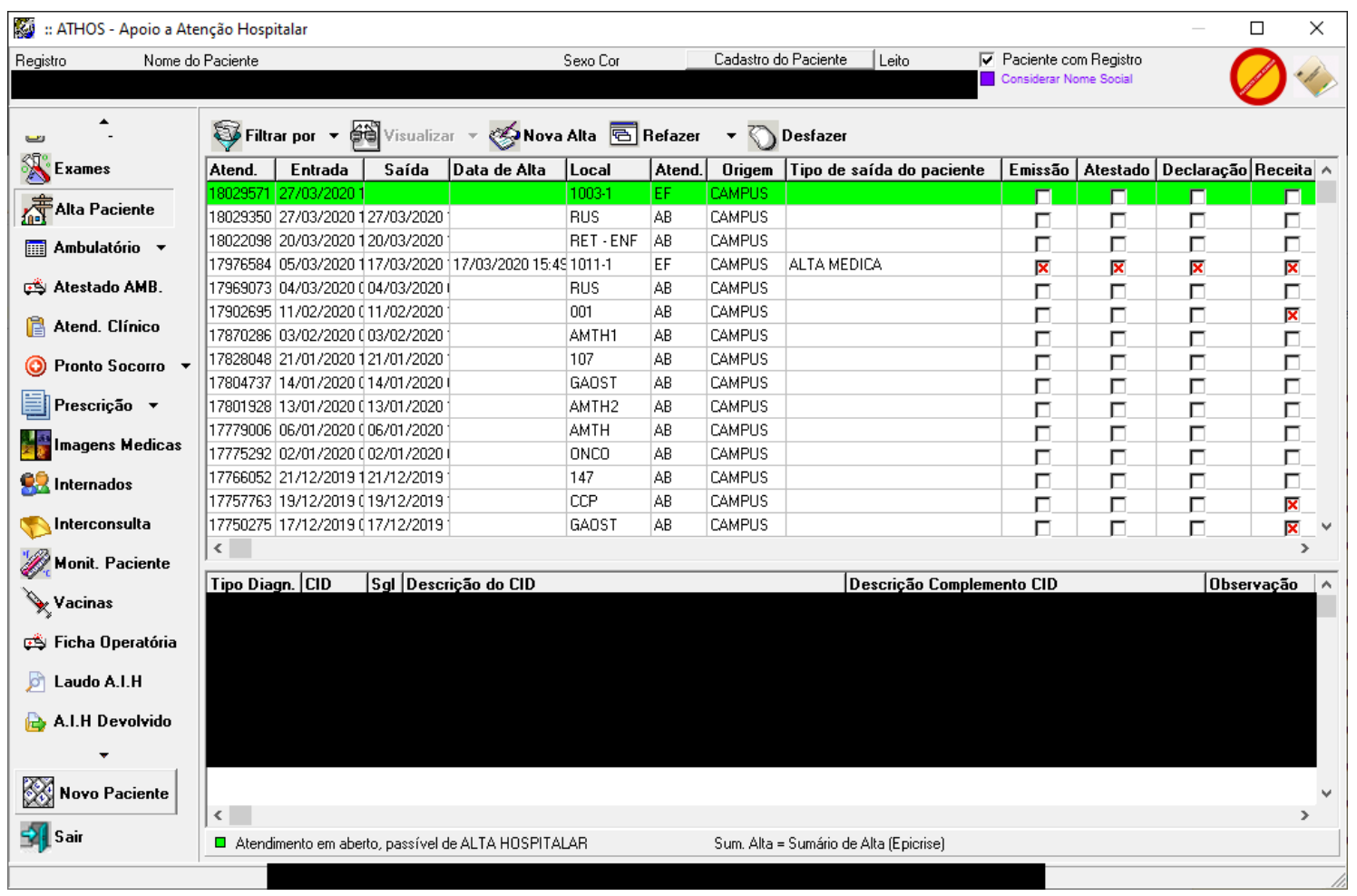

Fonte: Sistemas HCFMRP-USP. 
Figura 4 - Assistente de Alta - Especificação de Diagnósticos

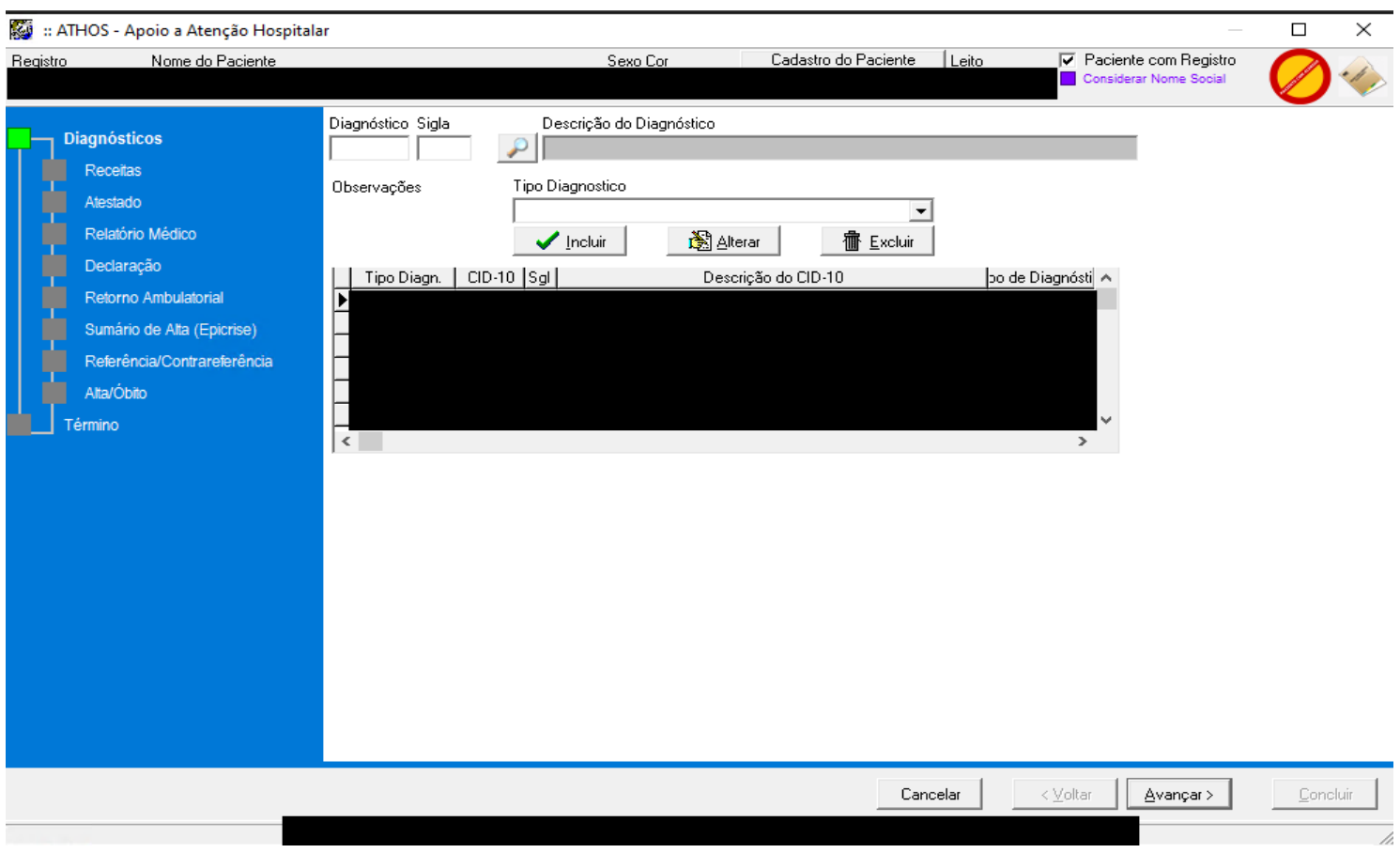

Fonte: Sistemas HCFMRP-USP.

Figura 5 - Assistente de Alta - Especificação de Receitas

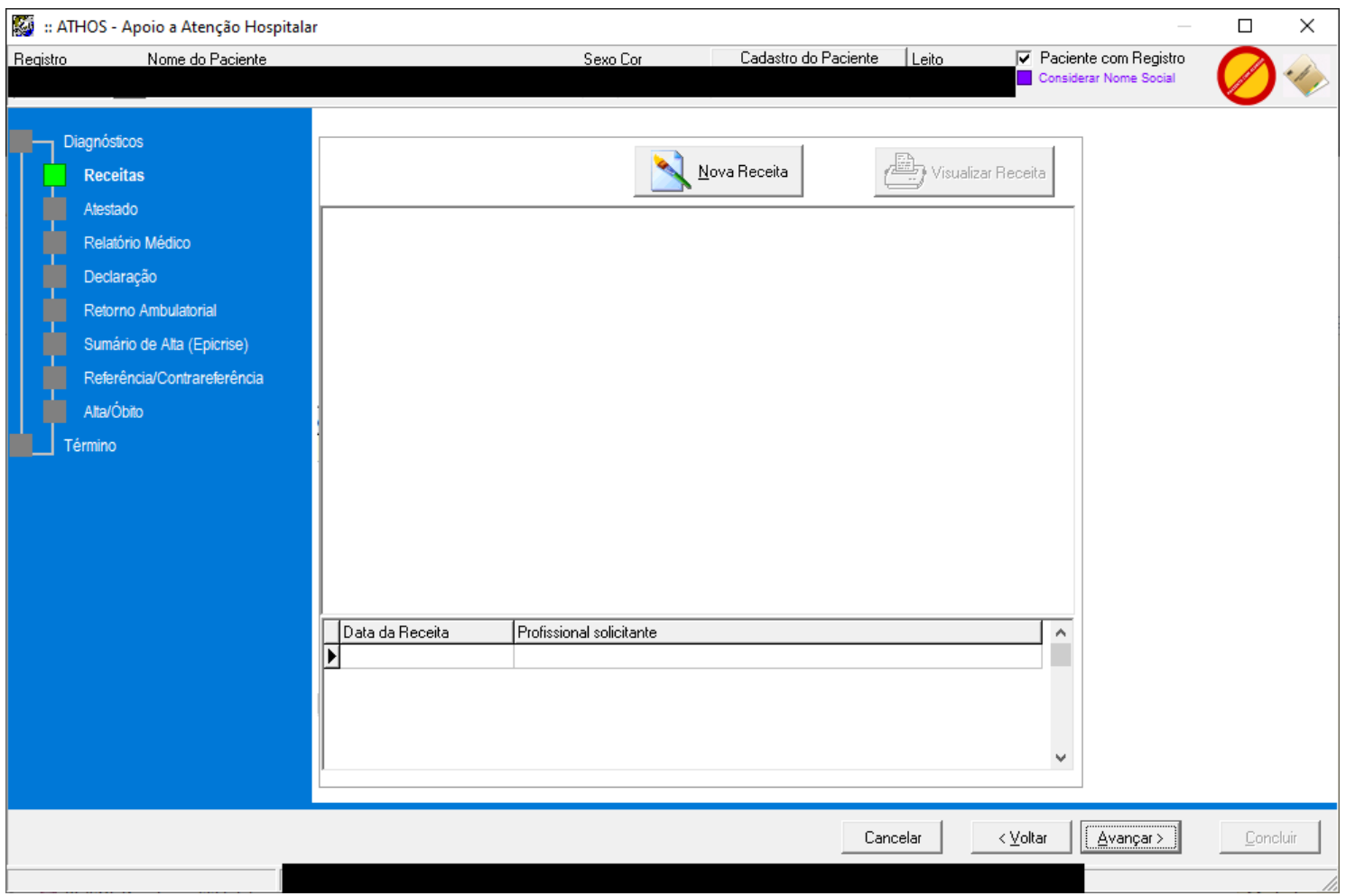

Fonte: Sistemas HCFMRP-USP. 
Figura 6 - Assistente de Alta - Atestado

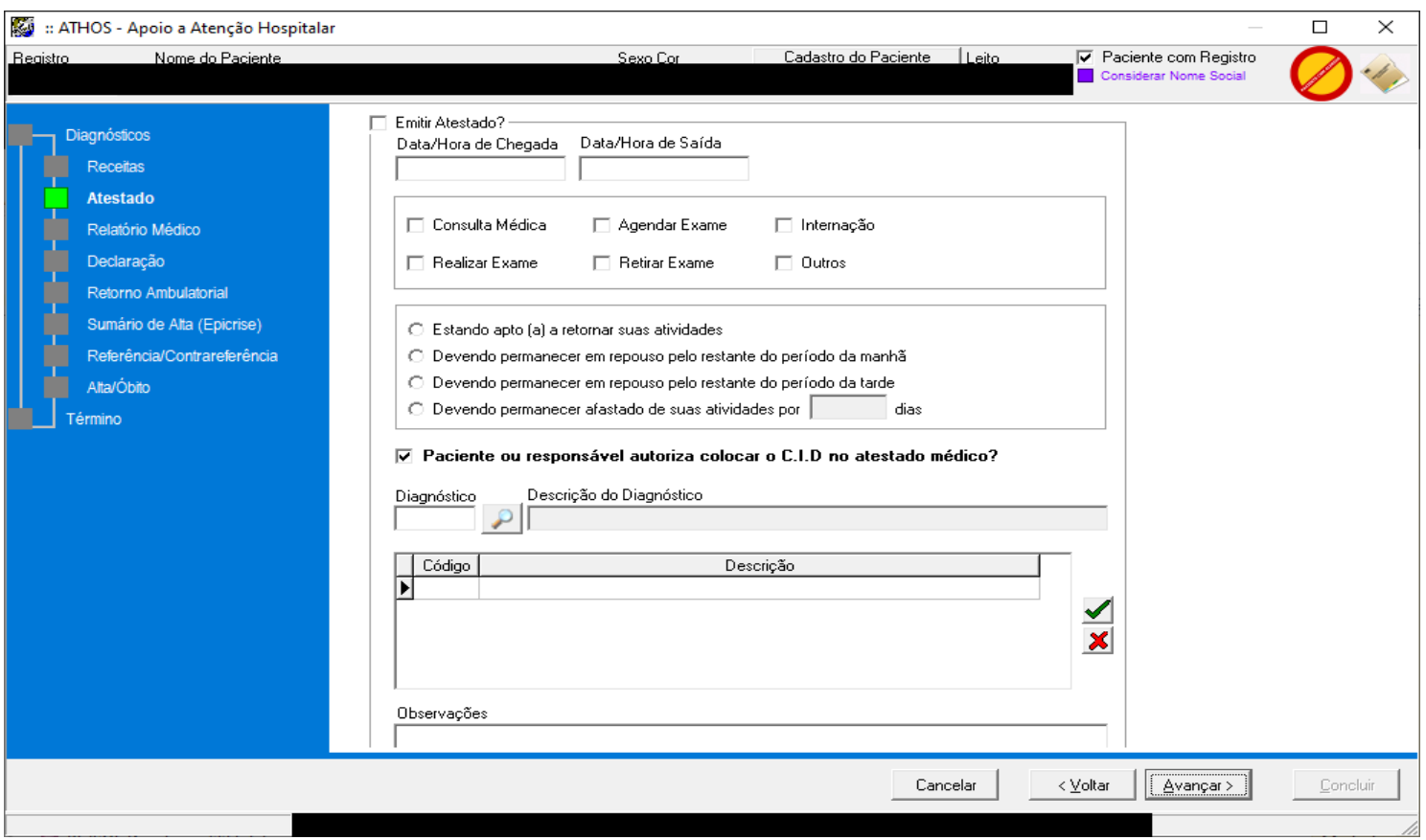

Fonte: Sistemas HCFMRP-USP.

Figura 7 - Assistente de Alta - Relatório Médico

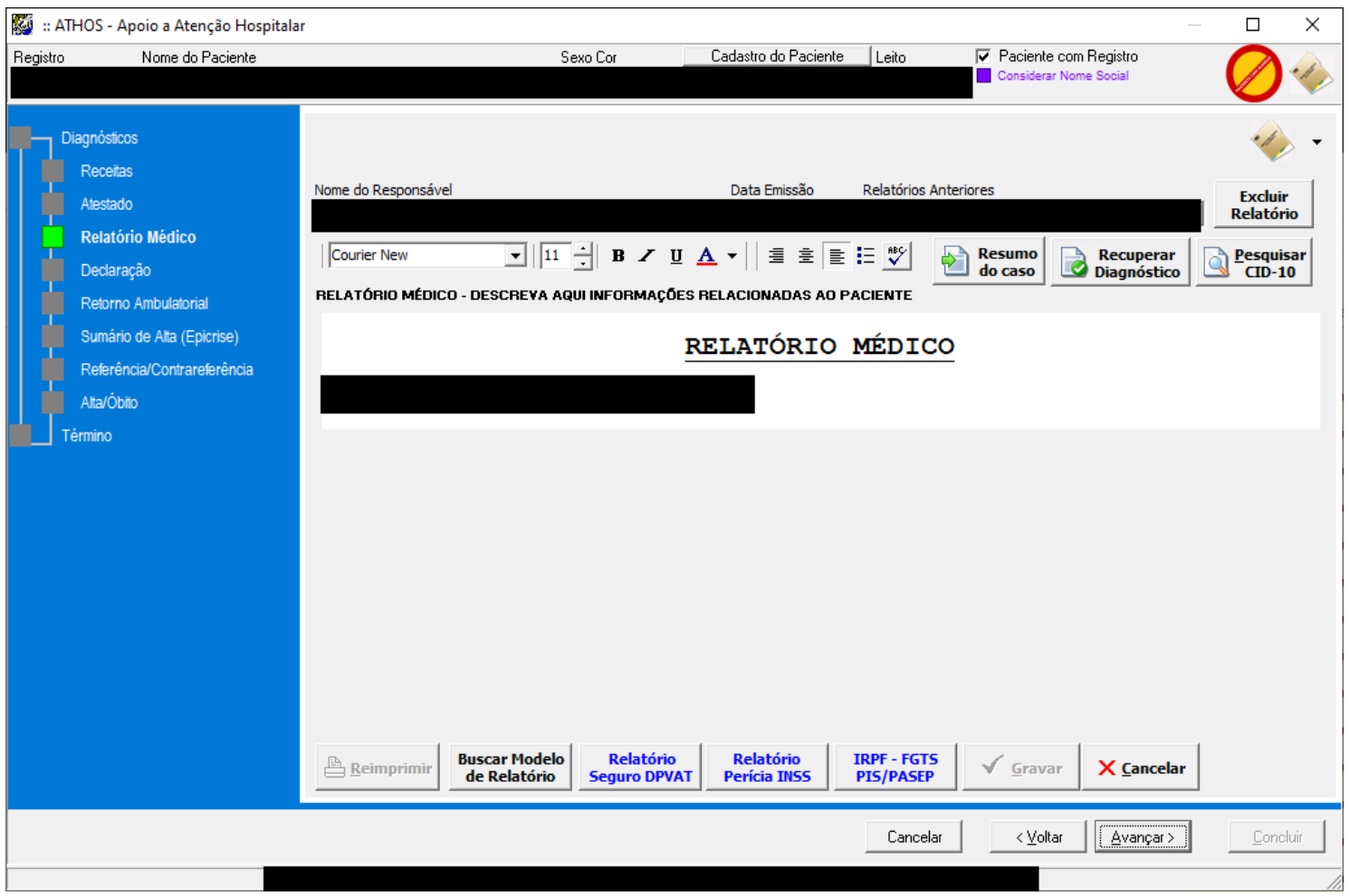

Fonte: Sistemas HCFMRP-USP. 
Figura 8 - Assistente de Alta - Declaração

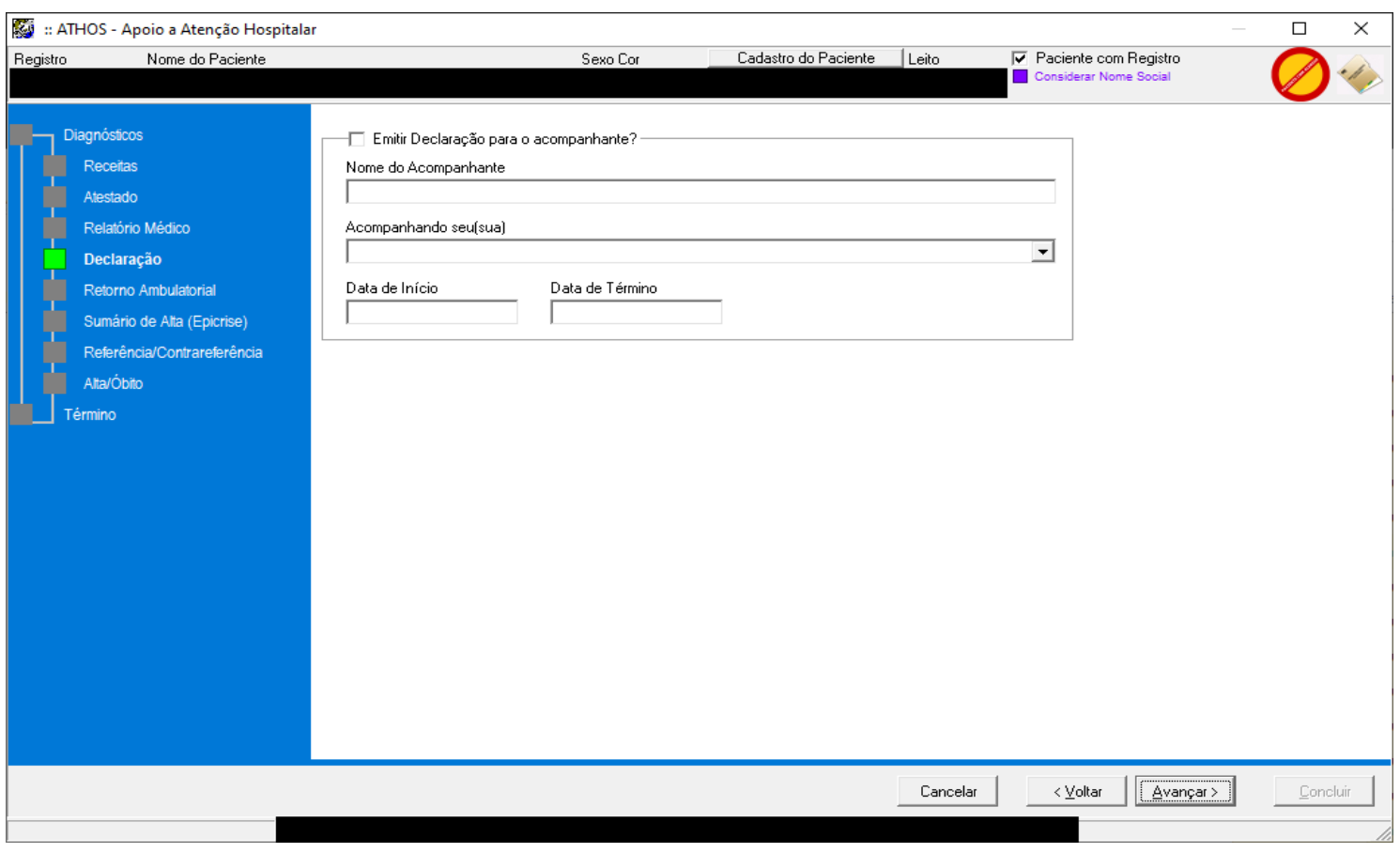

Fonte: Sistemas HCFMRP-USP.

Figura 9 - Assistente de Alta - Agendamento de Retornos Ambulatoriais

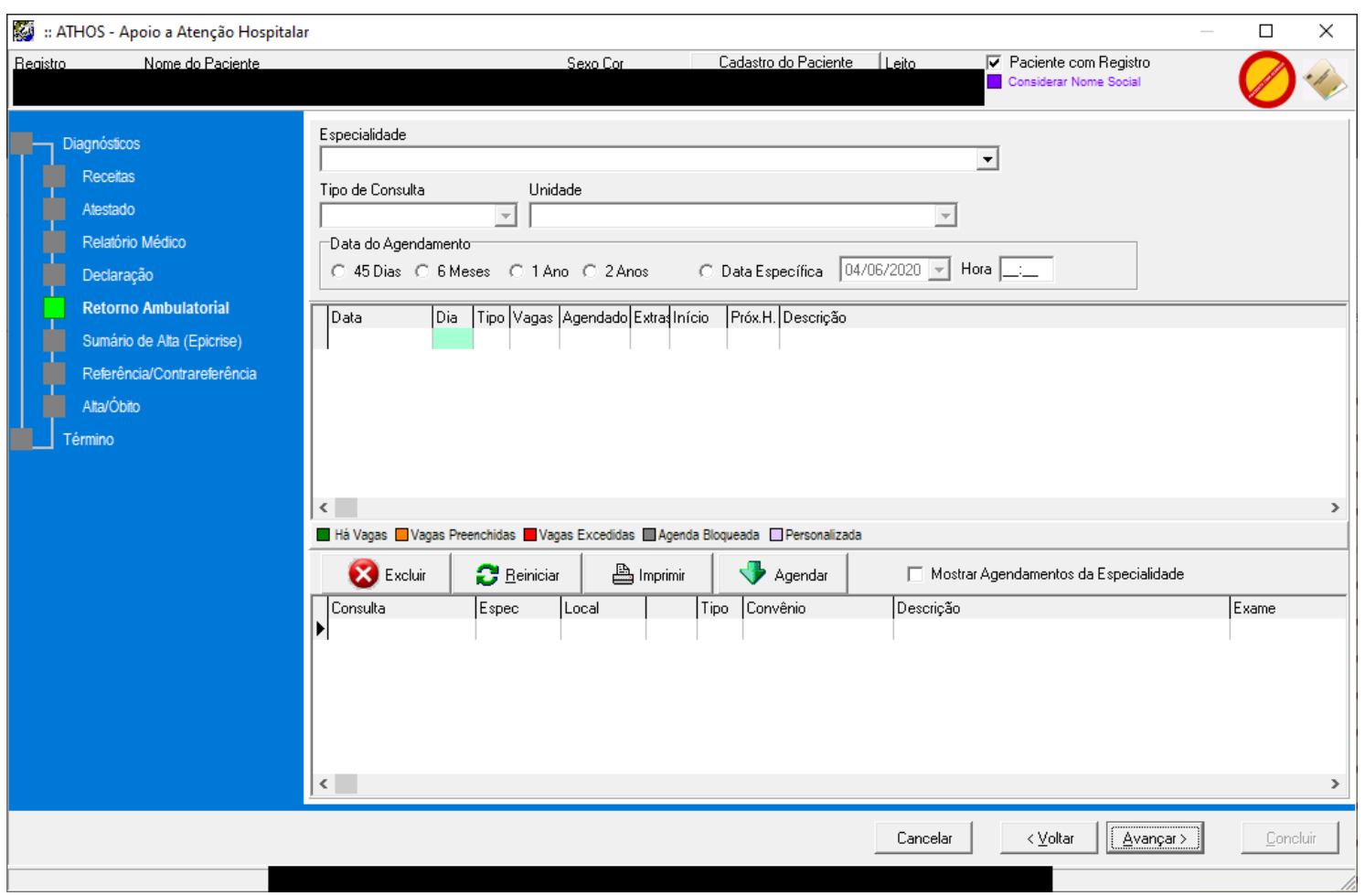

Fonte: Sistemas HCFMRP-USP. 
Figura 10 - Assistente de Alta - Sumário de Alta (Epicrise)

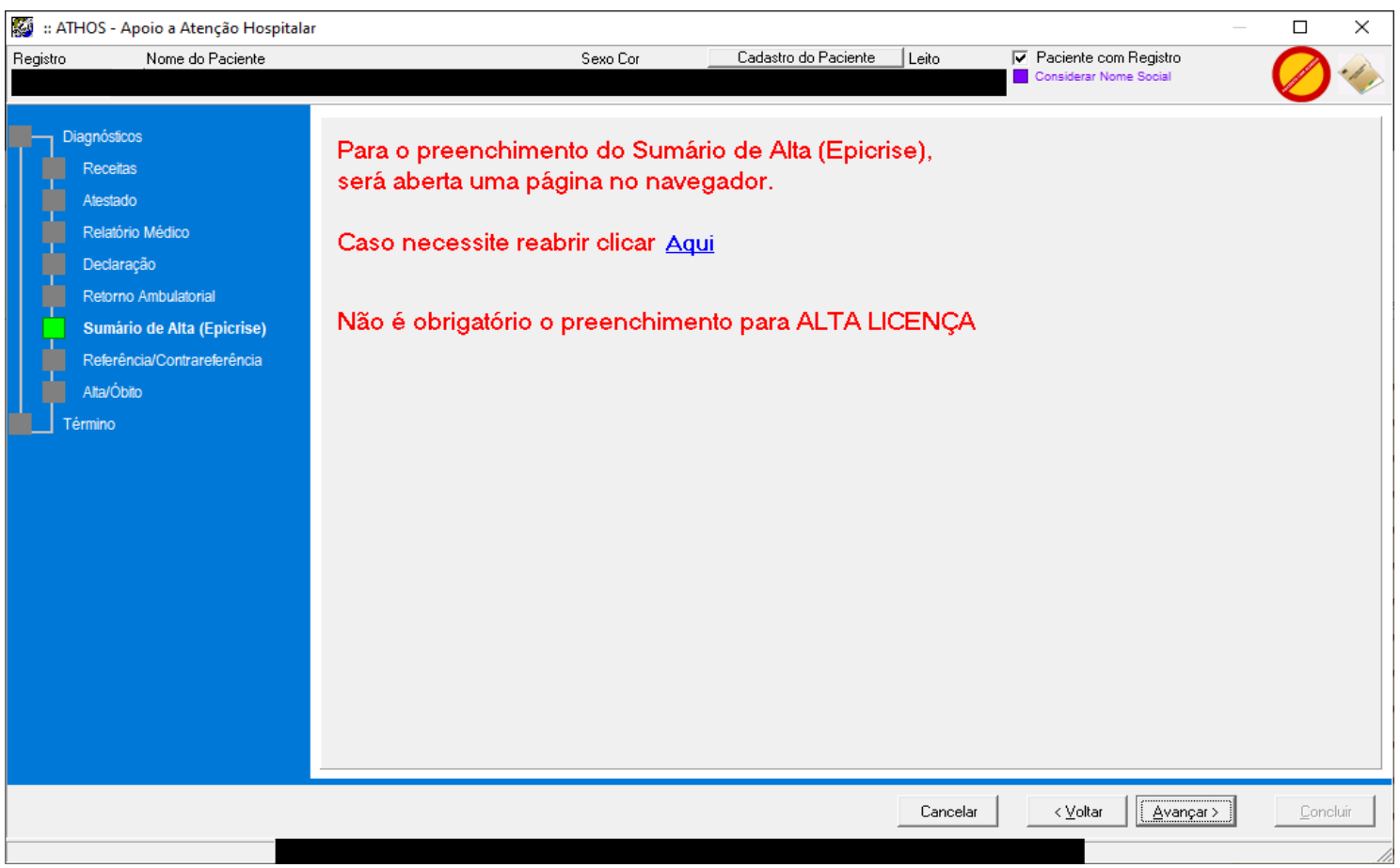

Fonte: Sistemas HCFMRP-USP.

Figura 11 - Assistente de Alta - Referência/Contra-referência

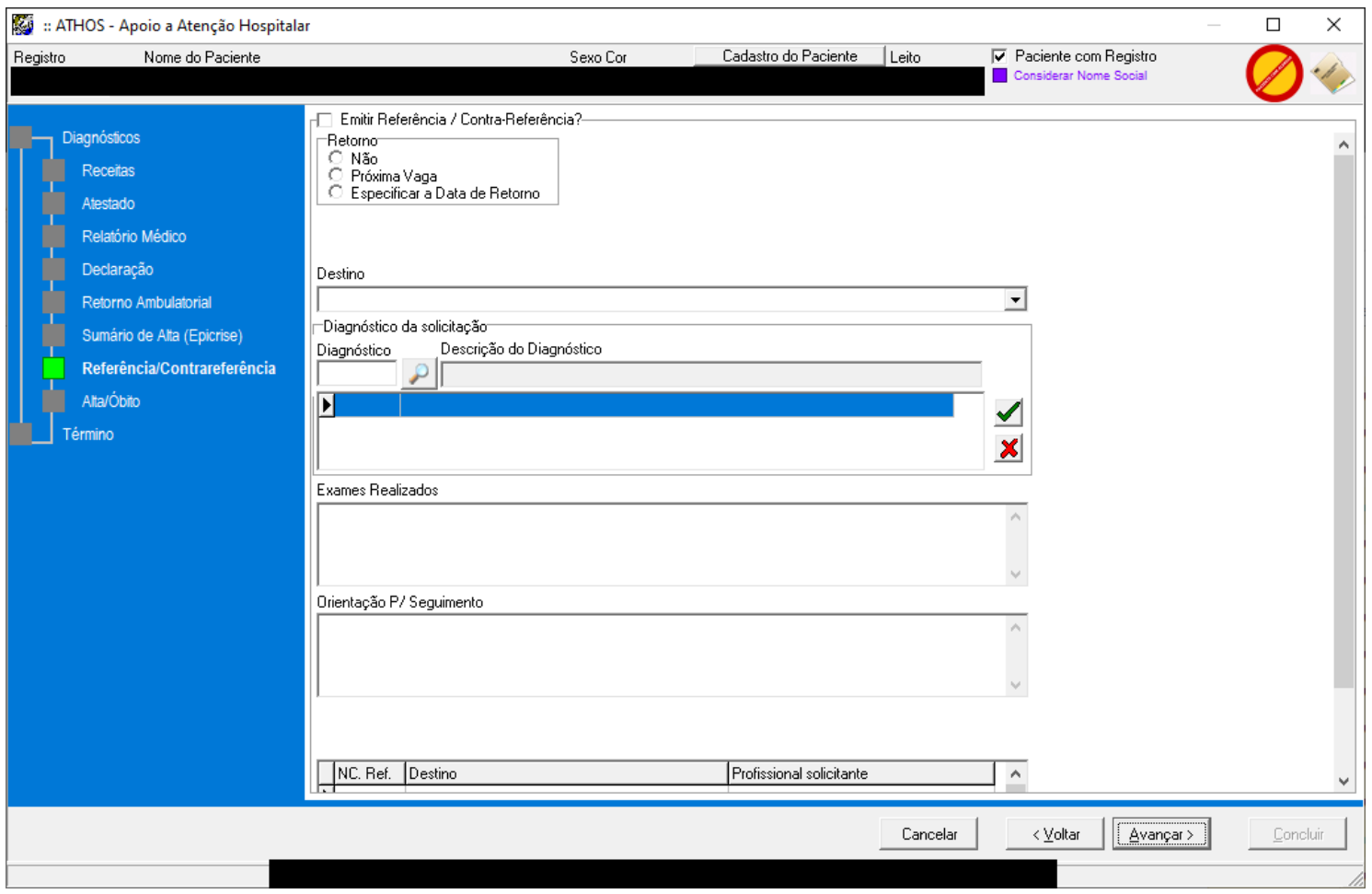

Fonte: Sistemas HCFMRP-USP. 
Figura 12 - Assistente de Alta - Alta/Óbito

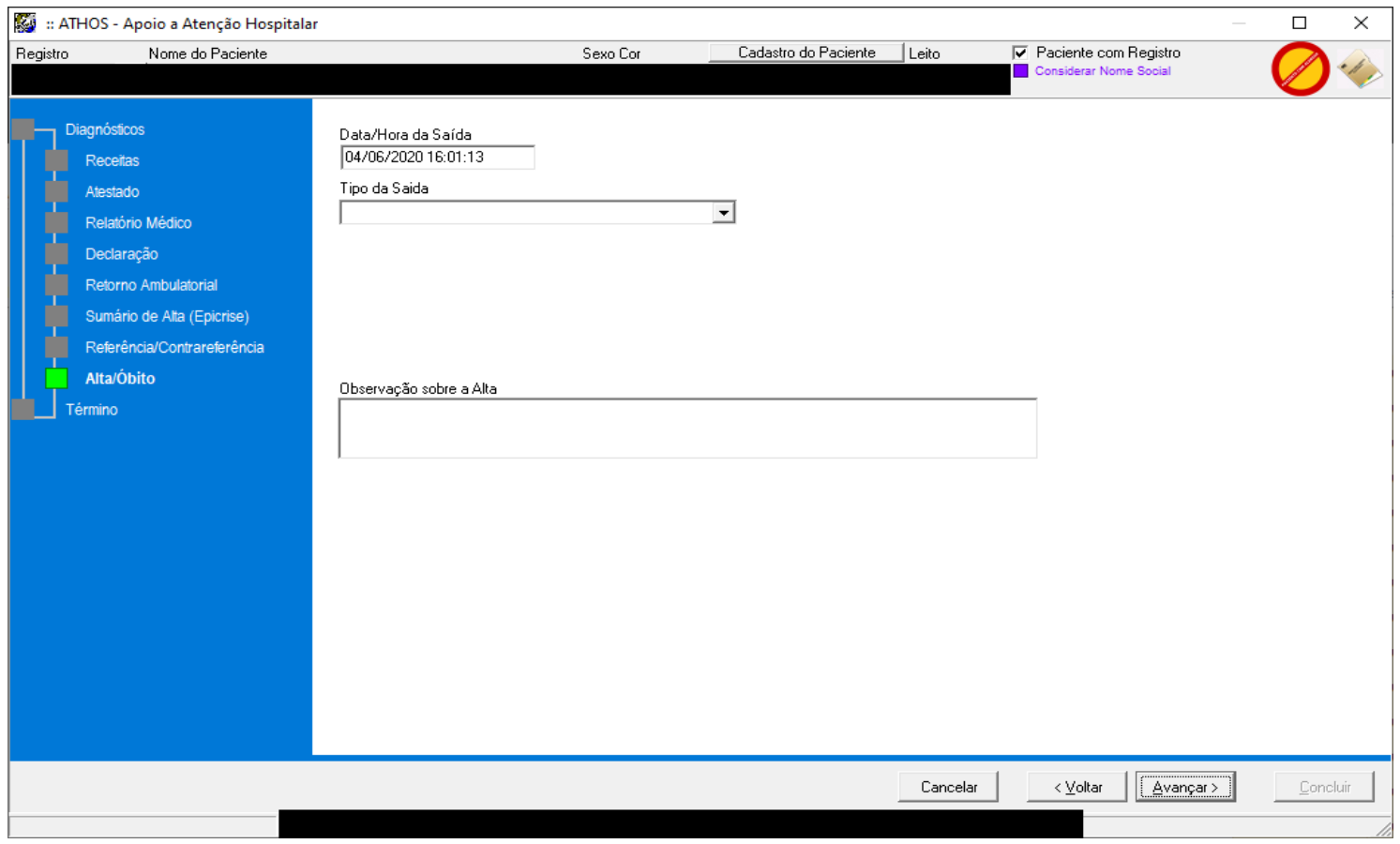

Fonte: Sistemas HCFMRP-USP.

Figura 13 - Assistente de Alta - Término

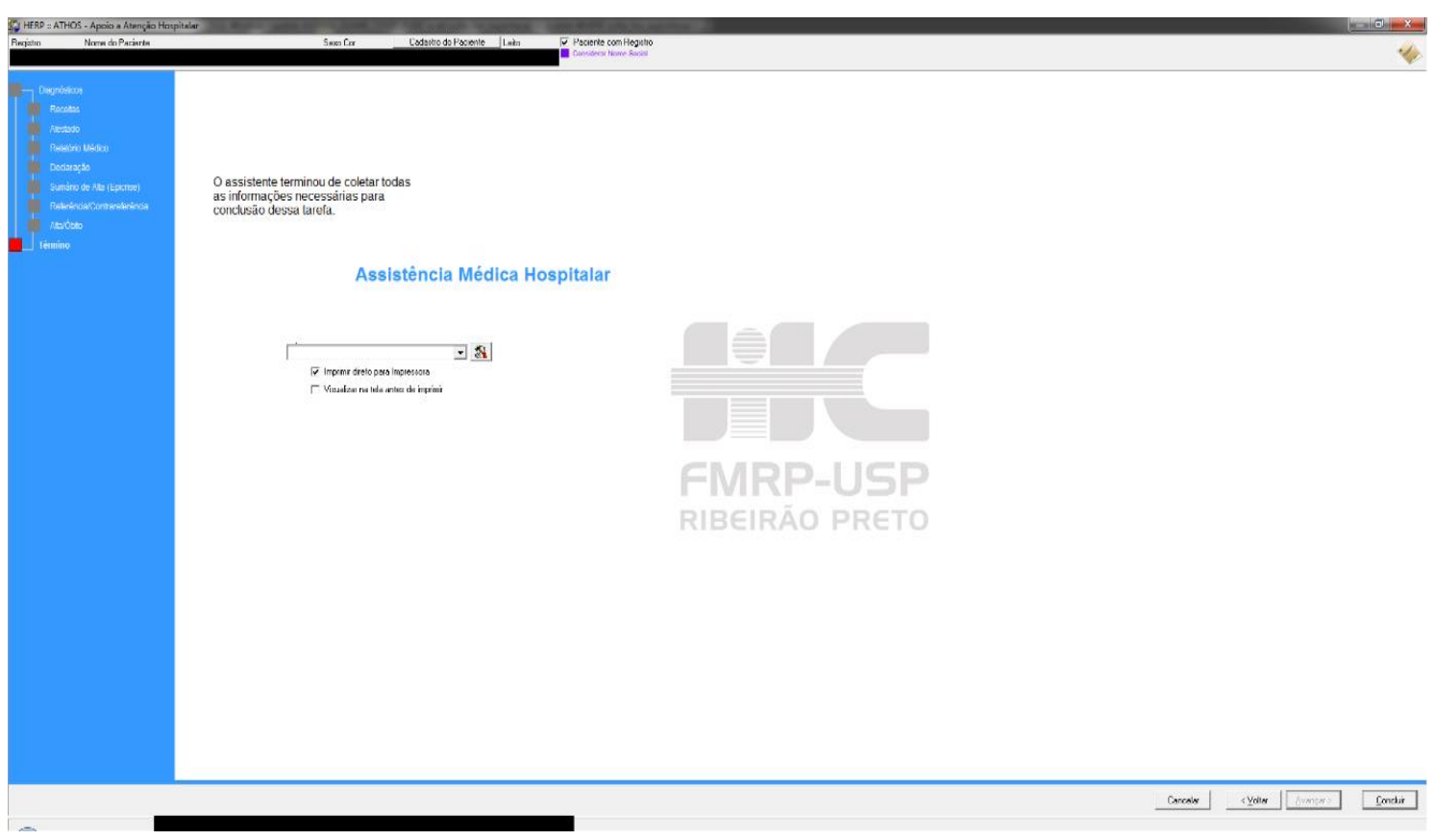

Fonte: Sistemas HCFMRP-USP.

Com a revisão do processo (parte inferior da Figura 2 - ATUAL), o registro do atendimento passou a ser encerrado com a sinalização da equipe de enfermagem indicando que o paciente já se encontra em condições de sair do hospital e demais medidas tomadas. Desta forma a liberação do leito não fica mais condicionada a entrega de documentação ao controle de leitos. 
A Figura 14 demonstra as etapas da emissão do Aviso de Alta pela Enfermagem, que recebe sinalização da alta (registro destacado em verde) após o preenchimento dos dados de alta pelo médico terem sido efetivadas.

Figura 14 - Pacientes internados por Unidade. Destaque em verde para o paciente que recebeu alta pela Equipe Médica

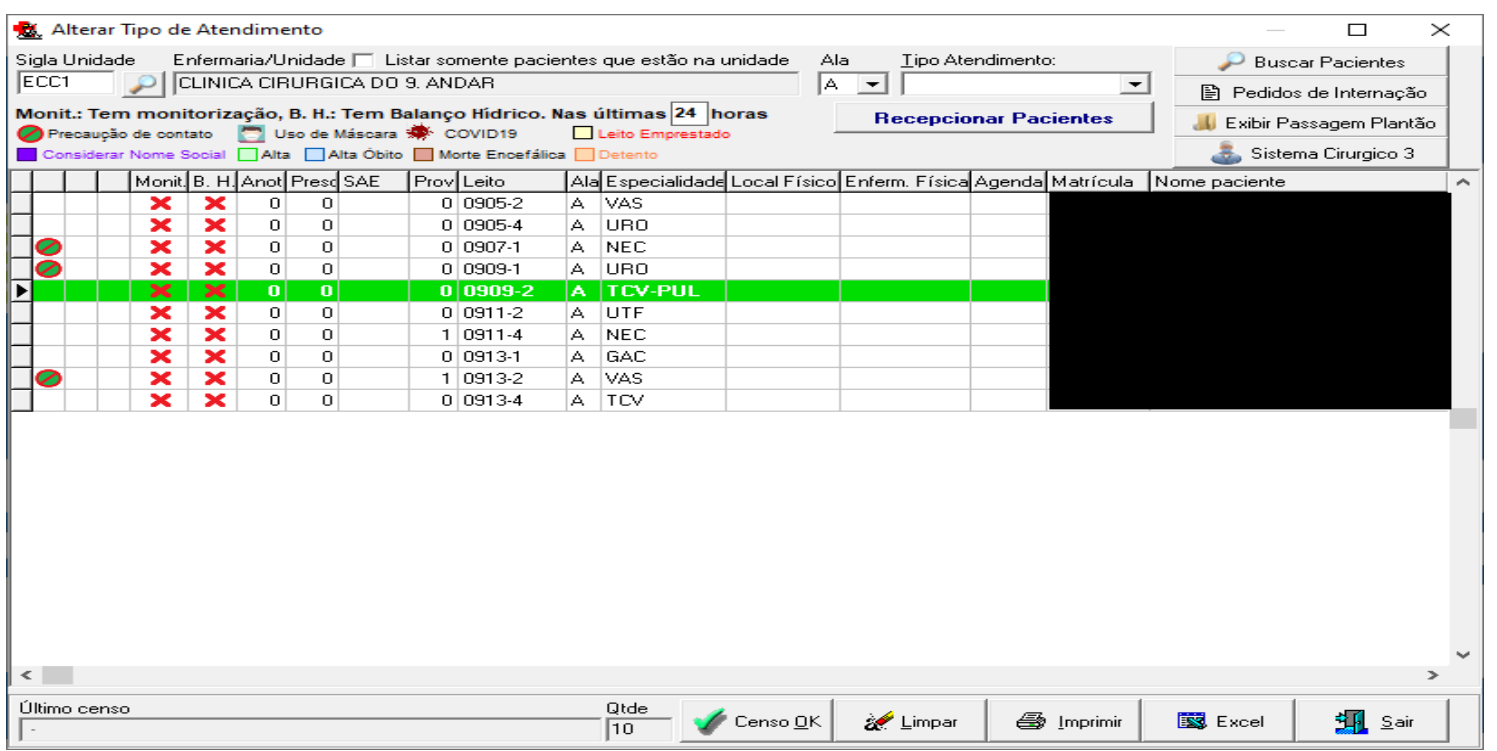

Fonte: Sistemas HCFMRP-USP.

Esta sinalização atua como gatilho para providências como o cancelamento de prescrições que se encontram ativas, bem como eventuais prescrições que possam ter sido feitas após a alta médica.

\subsection{VARIÁVEIS EXTRAÍDAS DO SISTEMA}

Como critério de inclusão foram considerados as altas hospitalares sinalizadas como Alta Médica ocorridas no HCFMRP-USP em sua unidade Campus durante os anos de 2011 e 2019, excluídas altas com dados incompletos de alta e fechamento. Os dados foram obtidos a partir das bases de dados de sistema informatizado da instituição em estudo. Os dados foram extraídos a partir da linguagem Structured Query Language (SQL) e exportados em formato Comma Separated Values (CSV). Este formato foi escolhido por ser de padrão aberto e poder ser utilizado pela grande maioria dos softwares de análise estatística. Uma vez exportados, os dados foram importados no software RStudio, que utiliza a linguagem R para a elaboração de análises, gráficos e relatórios.

Foram coletadas as seguintes variávies:

- Enfermaria de alta

- Data da internação 
- Data do fechamento do Atendimento

- Leito

- Especialidade Médica responsável pela alta

- Tipo de Convênio do paciente (Sistema Único de Saúde (SUS) ou não SUS)

Com relação variável Tipo de Convênio, os convênios foram enquadrados em duas categorias: Convênio SUS e todos os demais convênios em Não-SUS. As variáveis de data (Alta Médica e Fechamento do Atendimento) foram coletadas no formato dia/mês/ano hora,minuto e segundo. Registros de altas em que uma das variáveis mencionadas não constavam foram desconsideradas. Não foram coletadas variáveis pertinente ao paciente como registro ou dados demográficos. Com base nas datas de médica e no fechamento do atendimento foi calculado, em horas, a diferença de tempo entre essas duas datas e partir desta variável derivada foi calculado mediana mensal. Foi escolhido a mediana em vez da média pelo fato desta primeira ser menos suscetível a valores extremos distoantes (outliers).

\subsection{ANÁLISE ESTATÍSTICA}

Foi utilizada a análise de séries temporais interrompidas para avaliar o impacto da intervenção na alta hospitalar. Utilizou-se a metodologia descrita mais detalhadamente por Bernal JL et al e sumarizados na Equação 1 e na Equação $2^{(29)}$ :

Equação 1 - Série de Tempo Interrompida para um grupo

$$
Y_{t}=\beta_{0}+\beta_{1} T+\beta_{2} X_{t}+\beta_{3} T X_{t}+{ }_{-} \mathrm{t}
$$

$\mathrm{Y}_{\mathrm{t}}=$ tempo até a saída do paciente após a alta hospitalar

$\beta_{0}=$ valor de $Y$ no tempo 0

$\beta_{1}=$ valor da variação de $Y_{t}$ em função do tempo (T)

$\beta_{2}=$ valor da variação de nível após a intervenção

$\mathrm{X}_{\mathrm{t}}=$ variável que assume o valor 0 antes da intervenção e 1 após a interevenção

$\beta_{3}=$ valor da inclinação da reta após a intervenção

$\mathrm{TX}_{\mathrm{t}}=$ termo de interação entre o tempo e a presença da intervenção

${ }_{-} \mathrm{t}=$ erro residual

Equação 2 - Série de Tempo Interrompida - Comparação entre grupos

$$
\begin{aligned}
Y_{t}= & \beta_{0}+\beta_{1} T+\beta_{2} X_{t}+\beta_{3} T X_{t}+\beta_{4} Z+\beta_{5} Z T_{t}+\beta_{6} Z X_{t}+\beta_{7} Z X_{t} T_{t}+{ }_{-} t \\
& Y_{\mathrm{t}}=\text { tempo até a saída do paciente após a alta hospitalar } \\
& \beta_{0}=\text { valor de Y no tempo } 0
\end{aligned}
$$




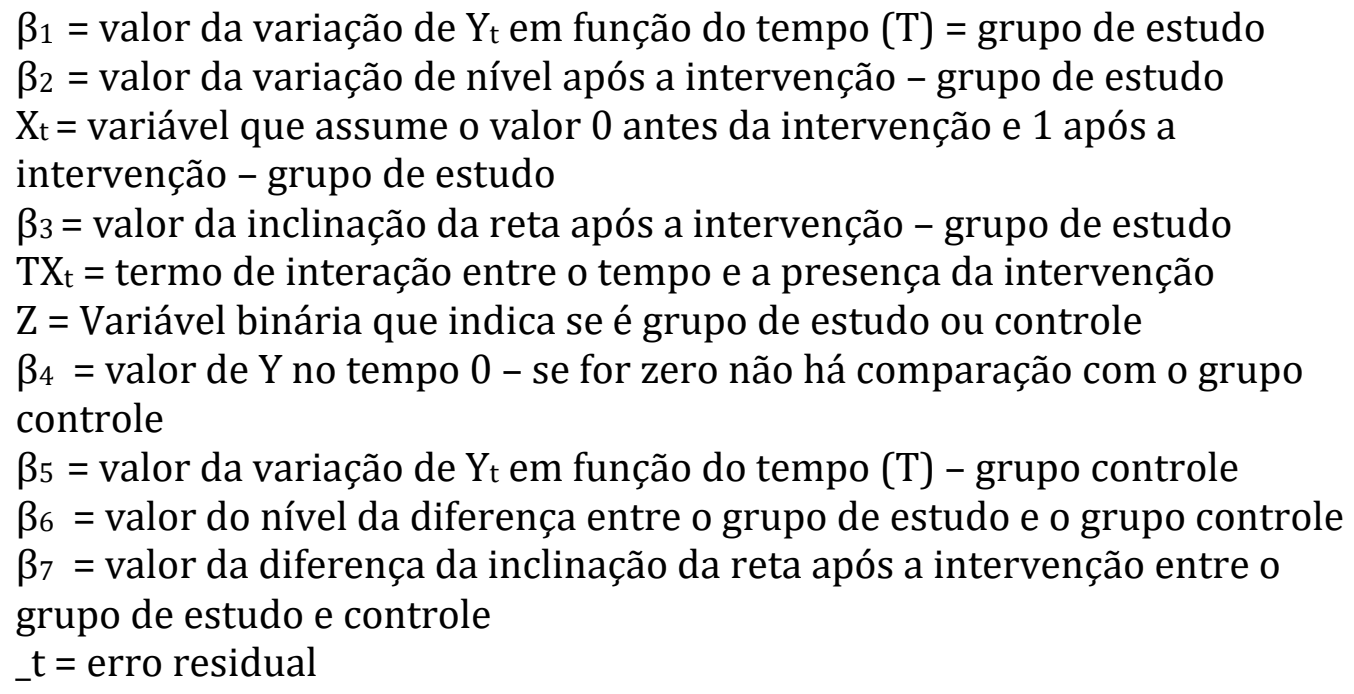

Os valores de tempo para alta hospitalar foram expressos em mediana ao longo de meses, para se respeitar o pré-requisito de que os intervalos temporais tenham que ser similares.

Assumiu-se para a construção dos modelos que o efeito da intervenção seria imediato após análise gráfica do comportamento. Com relação a possíveis fatores de confusão, incluiu-se um número de pontos suficiente para excluir a sazonalidade, além da análise do comportamento da variável tempo para deixar o hospital após a alta frente a possíveis fatores de sazonalidade, como o tempo de internação. Para analisar o impacto da sazonalidade, foi comparado o tempo para saída do hospital após a alta hospitalar entre os grupos que estiveram internados com mais ou menos de 7 dias.

Não foram realizadas outras intervenções para alterar o comportamento do tempo para deixar o hospital após a alta. Não se observou dispersão excessiva (“Overdispersion”) do tempo pósalta que pudesse ferir os preceitos da análise. Finalmente, estudou-se a auto-correlação e da auto-correlação parcial graficamente. Observando-se o comportamento da auto-correlação, realizou-se uma análise de sensibilidade nos modelos construídos, variando-se o "lag" de 0 a 8. Foi realizada a análise com os dados totais e separando-se de acordo com os grupos com internação maior ou menor de 7 dias.

A análise foi realizada utilizando-se o comando itsa do Programa STATA Versão 15®. 


\section{4 - CONSIDERAÇÕES ÉTICAS}

O projeto foi aprovado pelo Comitê de Ética em Pesquisa do HCFMRP-USP (CAE 2.846.460). O presente estudo considera apenas dados administrativos obtidos em sistema informatizado do HCFMRP-USP. Considerando que o tamanho da amostra é significativo, a consulta individualizada dos pacientes poderia ser onerosa e comprometer o desenvolvimento do estudo, foi obtida a dispensa do termo de consentimento livre e esclarecido de acordo com a resolução do Conselho Nacional de Saúde no 466 de 12 de dezembro de 2012 ( APÊNDICE 1 - APROVAÇÃO NO COMITÊ DE ÉTICA MÉDICA - HCFMRP-USP 


\section{RESULTADOS}

A Tabela 4 mostra o tempo mediano de alta ao longo do tempo. Após aplicação dos critérios de inclusão e exclusão, foram analisadas 210.645 altas no período de janeiro de 2011 a dezembro de 2019.

Tabela 4 - Tempo mediano entre a alta médica e o fechamento do atendimento de acordo com o ano e mês

\begin{tabular}{cccccccccc}
\hline Ano & $\mathbf{2 0 1 1}$ & $\mathbf{2 0 1 2}$ & $\mathbf{2 0 1 3}$ & $\mathbf{2 0 1 4}$ & $\mathbf{2 0 1 5}$ & $\mathbf{2 0 1 6}$ & $\mathbf{2 0 1 7}$ & $\mathbf{2 0 1 8}$ & $\mathbf{2 0 1 9}$ \\
\hline Jan & 6,1 & 6,3 & 6,3 & 6,6 & 7,1 & 6,2 & 2,5 & 2,3 & 2,4 \\
\hline Fev & 6,2 & 6,7 & 6 & 6,3 & 6,5 & 6 & 2,5 & 2,3 & 2,5 \\
\hline Mar & 6,5 & 6,1 & 6 & 5,7 & 6,3 & 5,8 & 2,4 & 2,3 & 2,4 \\
\hline Abr & 5,3 & 6,1 & 5,7 & 6,3 & 6,5 & 5,8 & 2,2 & 2,2 & 2,2 \\
\hline Mai & 5,5 & 6,2 & 5,7 & 6,1 & 6,4 & 5,6 & 2,2 & 2,4 & 2,2 \\
\hline Jun & 6,4 & 6,3 & 5,4 & 6 & 6,2 & 5,7 & 2,3 & 2,5 & 2,4 \\
\hline Jul & 6 & 6,3 & 5,8 & 6,2 & 6,2 & 5,4 & 2,2 & 2,4 & 2,1 \\
\hline Ago & 5,7 & 6 & 5,9 & 6,1 & 5,9 & 5,6 & 2,3 & 2,3 & 2,3 \\
\hline Set & 6 & 6,4 & 6 & 6,2 & 5,8 & 5,6 & 2,3 & 2,3 & 2,2 \\
\hline Out & 6,2 & 6,4 & 6,2 & 6,6 & 6,1 & 5,7 & 2,2 & 2,3 & 2,5 \\
\hline Nov & 6,2 & 6,4 & 6,6 & 6,5 & 6,2 & 5,5 & 2,2 & 2,3 & 2,4 \\
\hline Dez & 6,1 & 6,5 & 6,7 & 6,6 & 6 & 5,6 & 2,4 & 2,4 & 2,4 \\
\hline
\end{tabular}

Na Tabela 4 pode-se observar a mudança nos tempos medianos a partir de janeiro de 2017, mês em que foi implementada a mudança no processo de alta. Até o mês de dezembro de 2016 os tempos medianos variaram de 5,32 a 7,12 horas (variação de 1,8 horas), enquanto que de janeiro de 2017 a dezembro de 2019, os tempos medianos variaram de 2,2 a 2,5 (variação de 0,3 horas).

Com base nos dados da Tabela 5, verifica-se que a redução geral do tempo mediano com periodicidade anual ocorreu em todas as enfermarias da instituição. Ao comparar os anos de 2011 e 2018 observa-se as maiores reduções da ordem de 83,71\% na enfermaria de Psiquiatria, 79,4\% na Enfermaria Particular e 78,35\% na Enfermaria de Transplante de Medula Óssea. As enfermarias de Clínica Médica (divididos pelo quarto, quinto e sexto andar) tiveram reduções de $60,66 \%, 65,00 \%$ e $61,41 \%$. As menores variações ocorreram nas enfermarias de Unidade Metabólica, Ginecologia e Neurologia com 36,73\%, 42,62\% e 44,26\% de reduções respectivamente. 
Tabela 5 - Tempo mediano de saída do paciente da instituição após a alta médica segundo Enfermaria de Alta e Ano

\begin{tabular}{|c|c|c|c|c|c|c|c|c|c|}
\hline Enfermaria & 2011 & 2012 & 2013 & 2014 & 2015 & 2016 & 2017 & 2018 & 2019 \\
\hline Berçário & 5,6 & 6,0 & 5,7 & 5,9 & 6,4 & 5,6 & 2,7 & 2,1 & 2,2 \\
\hline Clínica Cirúrgica 10. Andar & 5,4 & 5,8 & 5,5 & 6,0 & 5,8 & 5,5 & 2,4 & 2,1 & 1,9 \\
\hline Clínica Cirúrgica 9. Andar & 6,8 & 7,4 & 7,5 & 7,4 & 7,0 & 6,3 & 3,0 & 3,2 & 3,0 \\
\hline Clínica Médica - 4. Andar & 7,5 & 7,6 & 6,9 & 6,9 & 7,2 & 6,2 & 3,1 & 2,9 & 2,4 \\
\hline Clínica Médica - 5. Andar & 5,4 & 5,7 & 5,2 & 5,5 & 5,4 & 4,9 & 1,8 & 1,9 & 2,0 \\
\hline Clínica Médica - 6. Andar & 5,5 & 5,7 & 5,5 & 6,1 & 5,8 & 5,3 & 1,9 & 2,1 & 2,2 \\
\hline Epilepsia & 7,0 & 7,1 & 6,6 & 5,9 & 5,8 & 5,7 & 1,7 & 1,8 & 1,9 \\
\hline Ginecologia & 5,6 & 5,4 & 5,5 & 6,7 & 6,6 & 6,3 & 2,5 & 3,2 & 2,9 \\
\hline Moléstia Infecto Contagiosa & 5,4 & 6,3 & 5,9 & 6,4 & 6,1 & 5,2 & 2,0 & 2,6 & 2,0 \\
\hline Neurologia & 7,5 & 8,1 & 7,8 & 7,6 & 6,9 & 6,6 & 3,7 & 4,2 & 4,4 \\
\hline $\begin{array}{l}\text { Oftalmologia/Otorrinolaringologia/ } \\
\text { Cirurgia de Cabeça e Pescoço }\end{array}$ & 6,7 & 6,9 & 6,3 & 6,5 & 6,8 & 6,5 & 2,6 & 2,6 & 2,8 \\
\hline Obstetrícia & 5,2 & 5,3 & 5,8 & 5,7 & 6,0 & 5,4 & 2,2 & 2,3 & 2,1 \\
\hline Ortopedia & 6,8 & 6,6 & 6,0 & 6,1 & 5,9 & 5,5 & 2,4 & 2,3 & 2,3 \\
\hline Particular & 5,7 & 6,2 & 6,2 & 6,1 & 5,8 & 5,1 & 1,0 & 1,2 & 1,3 \\
\hline Pediatria & 5,8 & 6,3 & 5,3 & 6,0 & 6,2 & 5,6 & 1,8 & 1,9 & 1,8 \\
\hline Psiquiatria & 5,2 & 5,8 & 6,4 & 5,6 & 5,1 & 4,5 & 1,0 & 0,8 & 0,7 \\
\hline $\begin{array}{l}\text { Terapia de Doenças } \\
\text { Infecciosas }\end{array}$ & 6,5 & 7,2 & 5,6 & 5,5 & 4,3 & 4,4 & 2,1 & 1,9 & 2,1 \\
\hline $\begin{array}{l}\text { Transplante de Medula } \\
\text { Óssea }\end{array}$ & 6,3 & 6,0 & 6,5 & 6,7 & 5,7 & 5,3 & 2,0 & 1,3 & 1,7 \\
\hline $\begin{array}{l}\text { Unidade de Cuidados } \\
\text { Intermediários Neonatal }\end{array}$ & 7,3 & 6,6 & 6,2 & 5,7 & 5,7 & 5,0 & 1,5 & 1,6 & 1,8 \\
\hline Unidade de Pesquisa Clínica & 7,6 & 7,2 & 8,5 & 6,9 & 6,1 & 6,0 & 2,0 & 3,0 & 5,3 \\
\hline $\begin{array}{l}\text { Unidade de Terapia Intensiva } \\
\text { Neonatal }\end{array}$ & 3,8 & 4,6 & 4,9 & 13,4 & 3,4 & 4,7 & 1,1 & 0,3 & 0,7 \\
\hline $\begin{array}{l}\text { Unidade de Transplante } \\
\text { Renal }\end{array}$ & 6,1 & 6,3 & 5,8 & 6,7 & 6,5 & 6,0 & 1,5 & 1,4 & 1,7 \\
\hline Unidade Metabólica & 7,3 & 6,6 & 7,4 & 8,9 & 7,7 & 7,2 & 6,0 & 4,6 & 6,3 \\
\hline
\end{tabular}




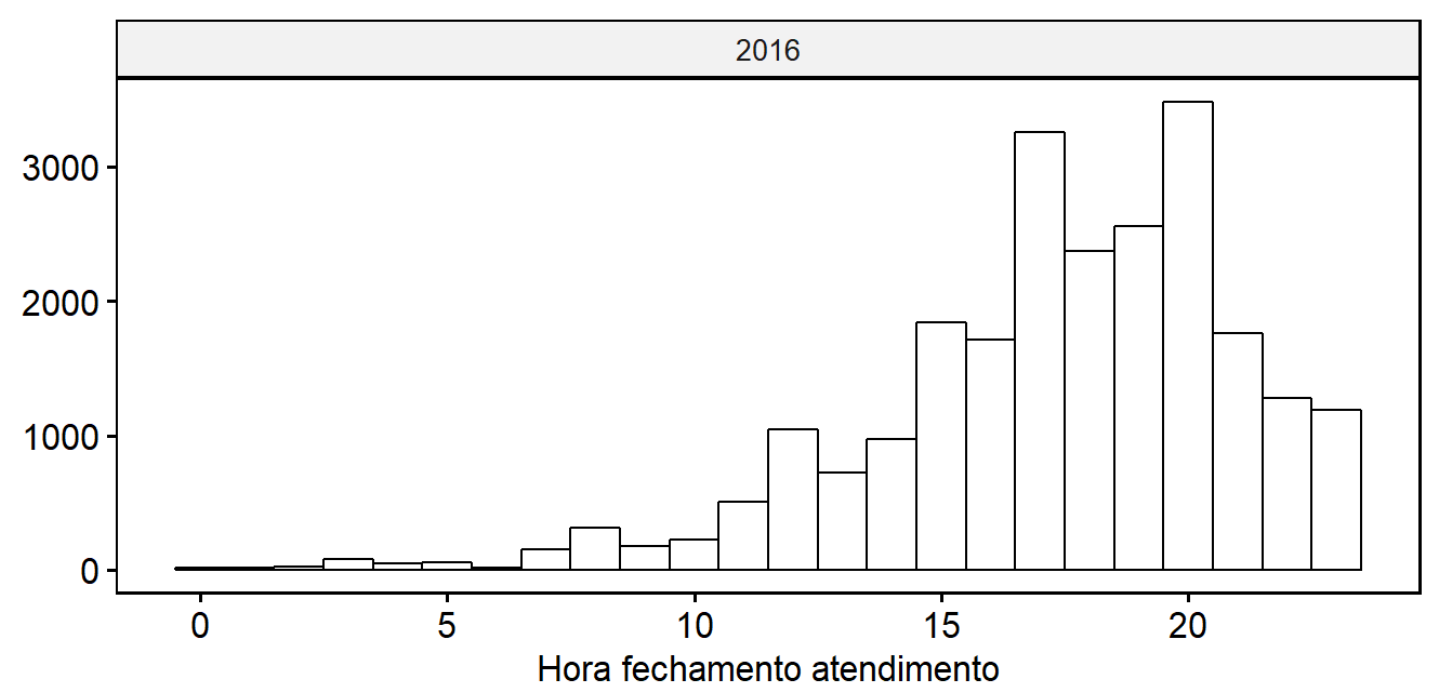

Fonte: Elaboração própria.

Figura 16 - Volume de Saída de Pacientes segundo Hora do Fechamento do Atendimento - ano de 2017

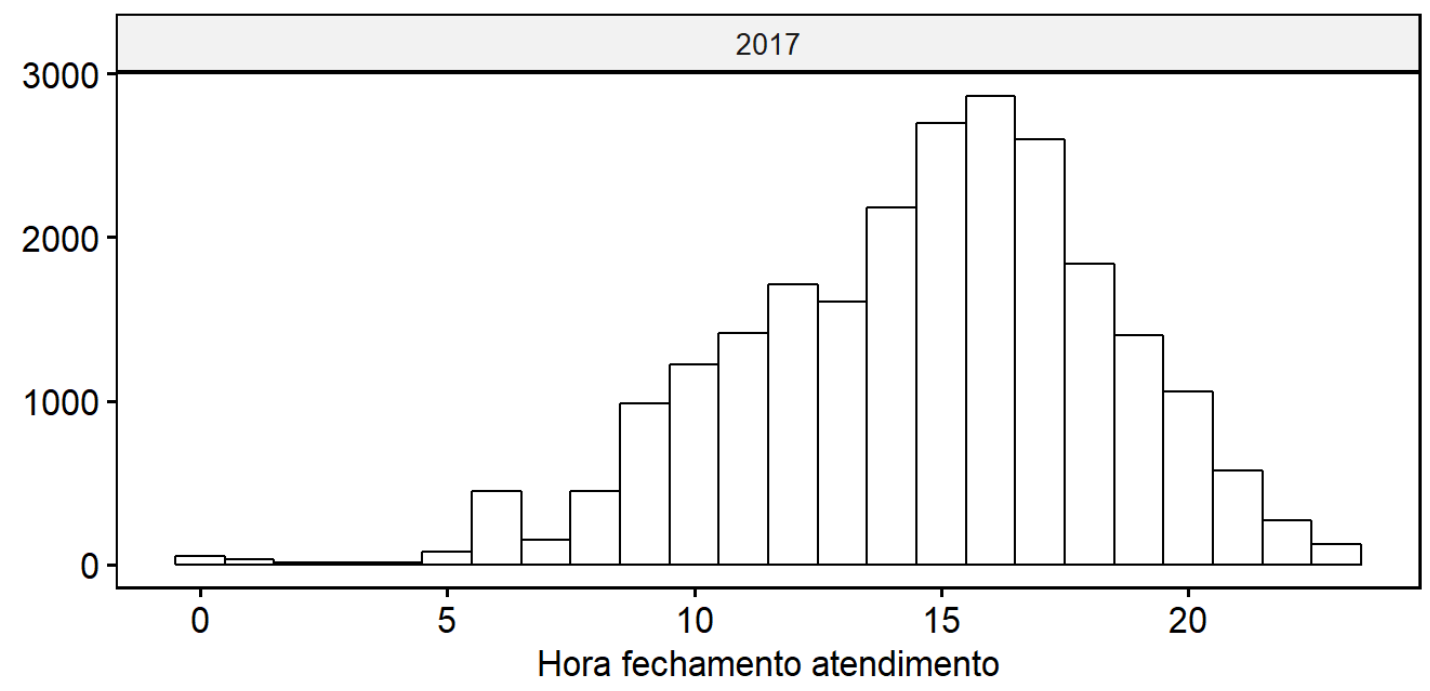

Fonte: Elaboração própria.

As Figuras 15 e 16 demonstram o volume de saída de pacientes segundo hora do término do atendimento estratificadas pelo ano da alta nos anos de 2016 e 2017. Observa-se que, no ano de 2016, a distribuição das saídas segundo o horário de fechamento do atendimento caracteriza-se por ser uma distribuição para a direita, devido ao fato de termos um volume pouco expressivo de altas encerrando o atendimento entre as 0 e as 5 horas da manhã. Observa-se também que os maiores volumes de alta estão concentrados após as 17 horas com picos as 17 e 20 horas, com mais de 3000 altas. Além destes picos observa-se que após as 21 horas concentram-se volumes 
superiores a 1000 altas por faixa de horário. No ano de 2017, após o início da intervenção, houve mudança no comportamento desta distribuição, na qual os maiores volumes de alta estão concentrados na faixa de horário das 14 as 18 horas. Tal mudança de comportamento pode ser considerada positiva pois indica que a maioria dos atendimentos passaram a ser encerrados ainda durante o período diurno, embora ainda observa-se um volume significante de atendimentos sendo encerrados até as 20 horas. Após as 21 horas, o volume de altas torna-se menos expressivo, bem como na faixa de horário das 0 as 5 horas da manhã.

Quando se estratifica os histogramas de distribuição das saídas de paciente após a alta médica de acordo com o ano (Figura 17), observa-se que há uma evolução de uma distribuição bimodal para uma distribuição normal. O nadir da distribuição bimodal é ao redor das 19h, horário de troca de turno da enfermagem. Após a intervenção, além da distribuição se tornar normal, há deslocamento para a esquerda, com maiores liberações de pacientes no período da tarde e redução no período noturno. 
Figura 17 - Histograma de distribuição do número de pacientes dispensados de acordo com o horário dia. A reta vermelha representa o horário das 19 horas - troca de plantão da enfermagem

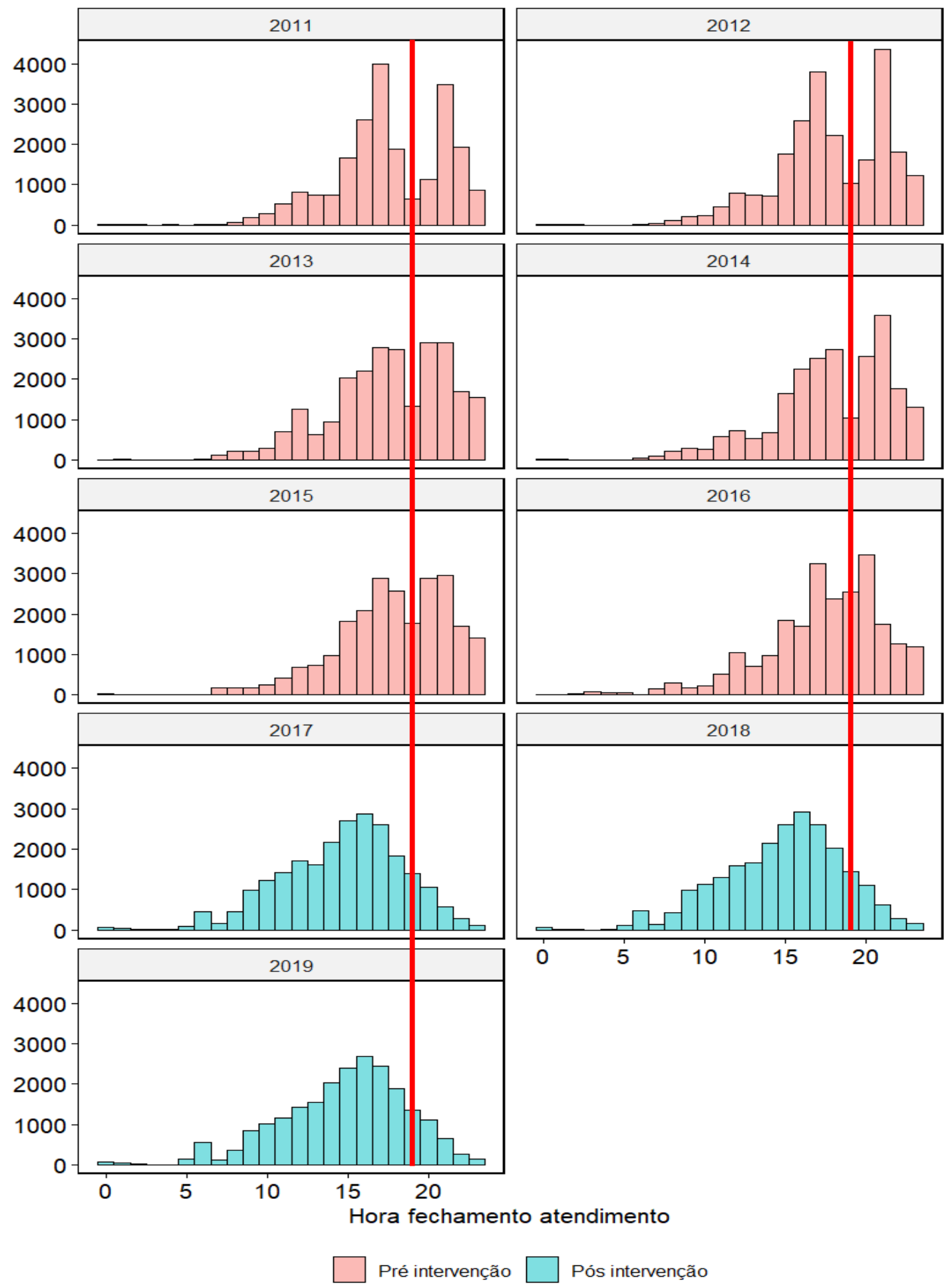

Fonte: Elaboração própria.

A comparação do comportamento do tempo para saída do hospital após a alta hospitalar demonstrou diferença estatística apenas quando estratificado antes e após a intervenção, mas não quando realizada a análise total (Tabela 6). Estes achados implicaram na realização da 
análise da série temporal interrompida geral e estratificada de acordo com a duração da internação hospitalar.

Tabela 6 - Comparação entre os valores medianos de tempo para saída após alta hospitalar de acordo com o grupo (<ou > de 7 dias) e o período de intervenção

\begin{tabular}{cccc}
\hline & $<7$ dias & $>7$ dias & $p$ \\
\hline Antes & $6,0(5,8 ; 6,1)$ & $6,4(6,2 ; 6,5)$ & $<0,01$ \\
\hline Depois & $2,3(2,2 ; 2,3)$ & $2,5(2,4 ; 2,6)$ & $<0,01$ \\
\hline Total & $4,8(4,4 ; 5,1)$ & $5,1(4,7 ; 5,5)$ & 0,15 \\
\hline
\end{tabular}

Foi realizada a análise de auto-correlação e auto-correlação parcial para os dados que estão dispostas nas Figuras 18 e 19, respectivamente. Frente aos achados da Figura 18, observou-se que um "Lag" de até 8 intervalos seriam necessários para evitar a auto-correlação e realizou-se a análise de sensibilidade dos modelos geral e estratificado variando-se o "Lag" de 1 a 8. Só estão demonstrados os achados de 1 e de 8 por não serem distintos.

Figura 18 - Análise de auto-correlação do tempo de alta médica ao fechamento do Atendimento

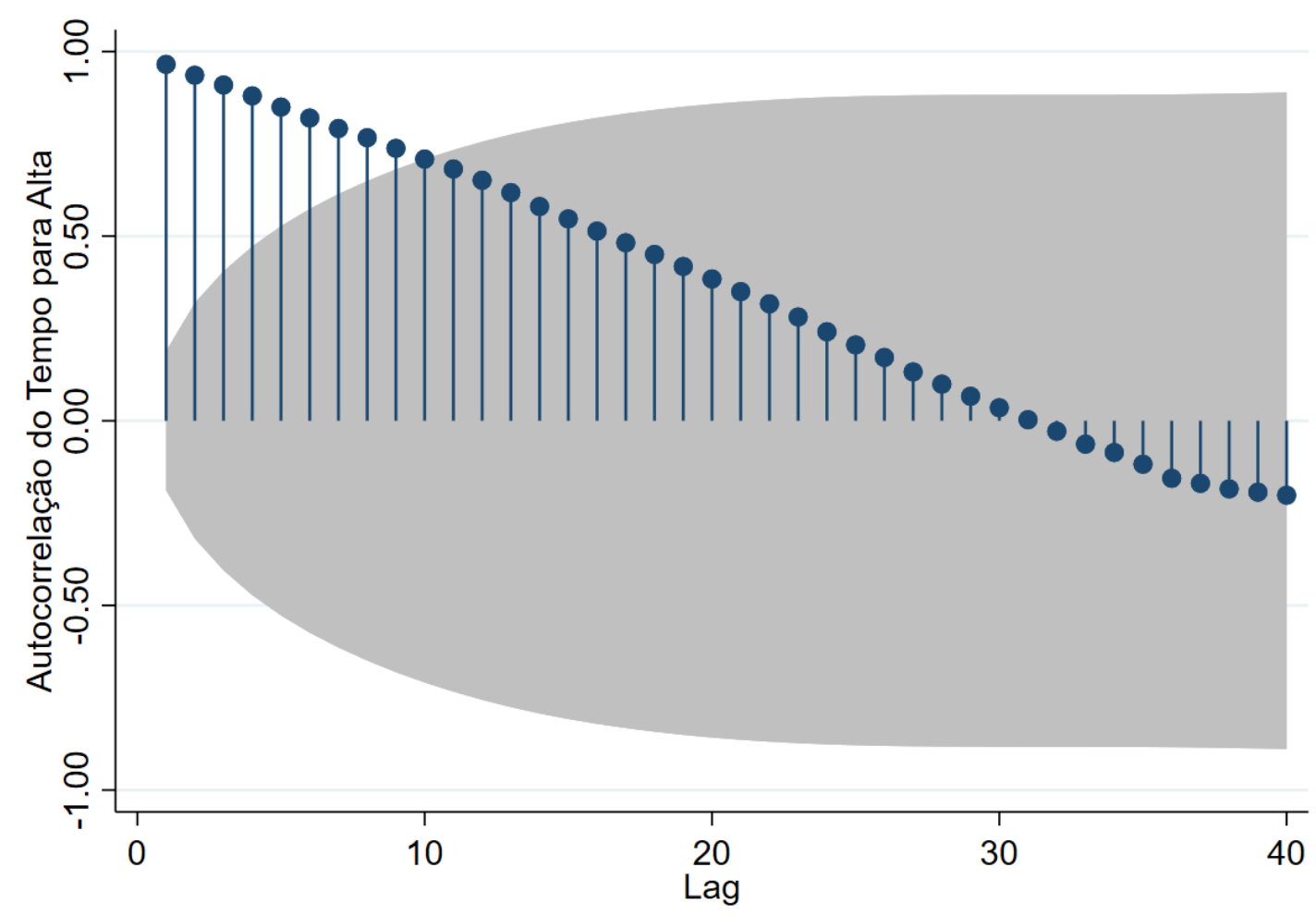

Bartlett's formula for MA(q) $95 \%$ confidence bands

Fonte: Elaboração própria. 
Figura 19 - Análise de auto-correlação parcial do tempo de alta médica ao fechamento do Atendimento

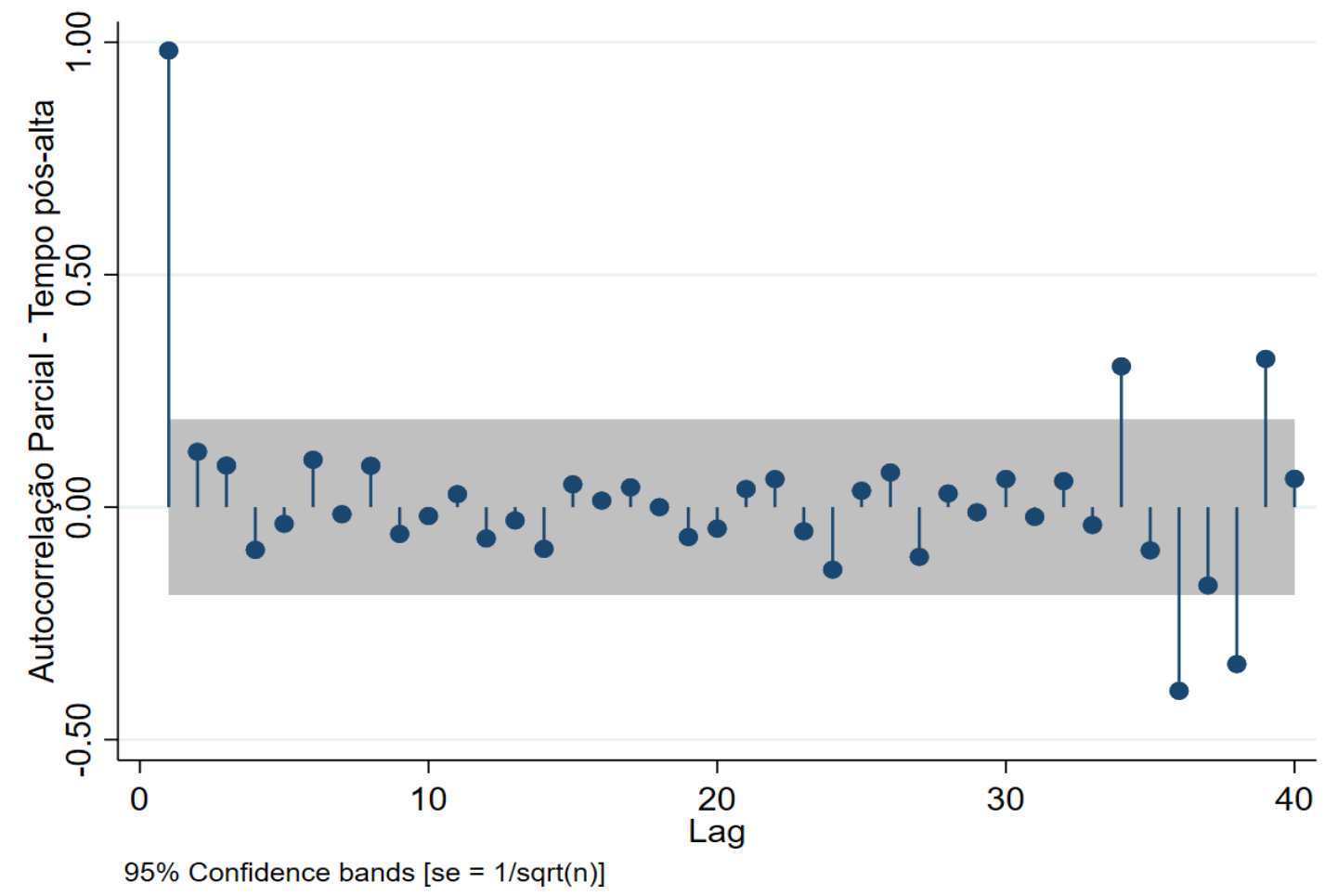

Fonte: Elaboração própria.

Figura 20 - Análise de Série Temporal Interrompida Geral para o tempo mediano de Alta Médica ao Fechamento do Atendimento

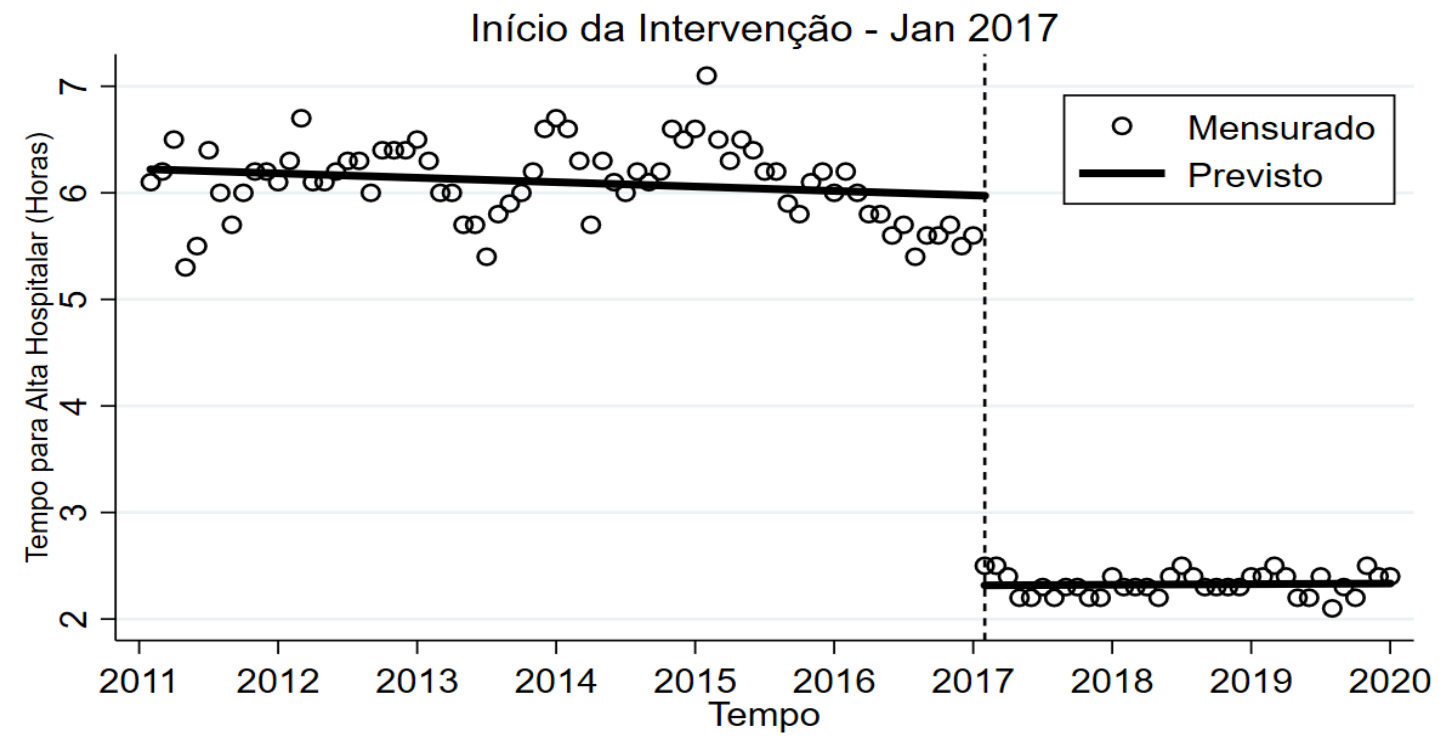

Regression with Newey-West standard errors - lag(1)

Fonte: Elaboração própria.

A análise de série temporal interrompida demonstrou um comportamento de mudança de nível imediato (Coeficiente $\beta 2$-3,6 - Intervalo de Confiança 95\% -3,9; -3,4 - Lag1), mas não uma modificação da inclinação do comportamento da curva pós-intervenção (Coeficiente $\beta 3$ 0,0005 
- Intervalo de Confiança 95\% -0,0040; 0,0050 - Lag1) - Figura 20 e Tabela 7. A análise de sensibilidade variando o "Lag" de 0 a 8 não interferiu com os resultados encontrados (Tabela $8)$.

Tabela 7 - Análise de Série Temporal Interrompida com Lag 1

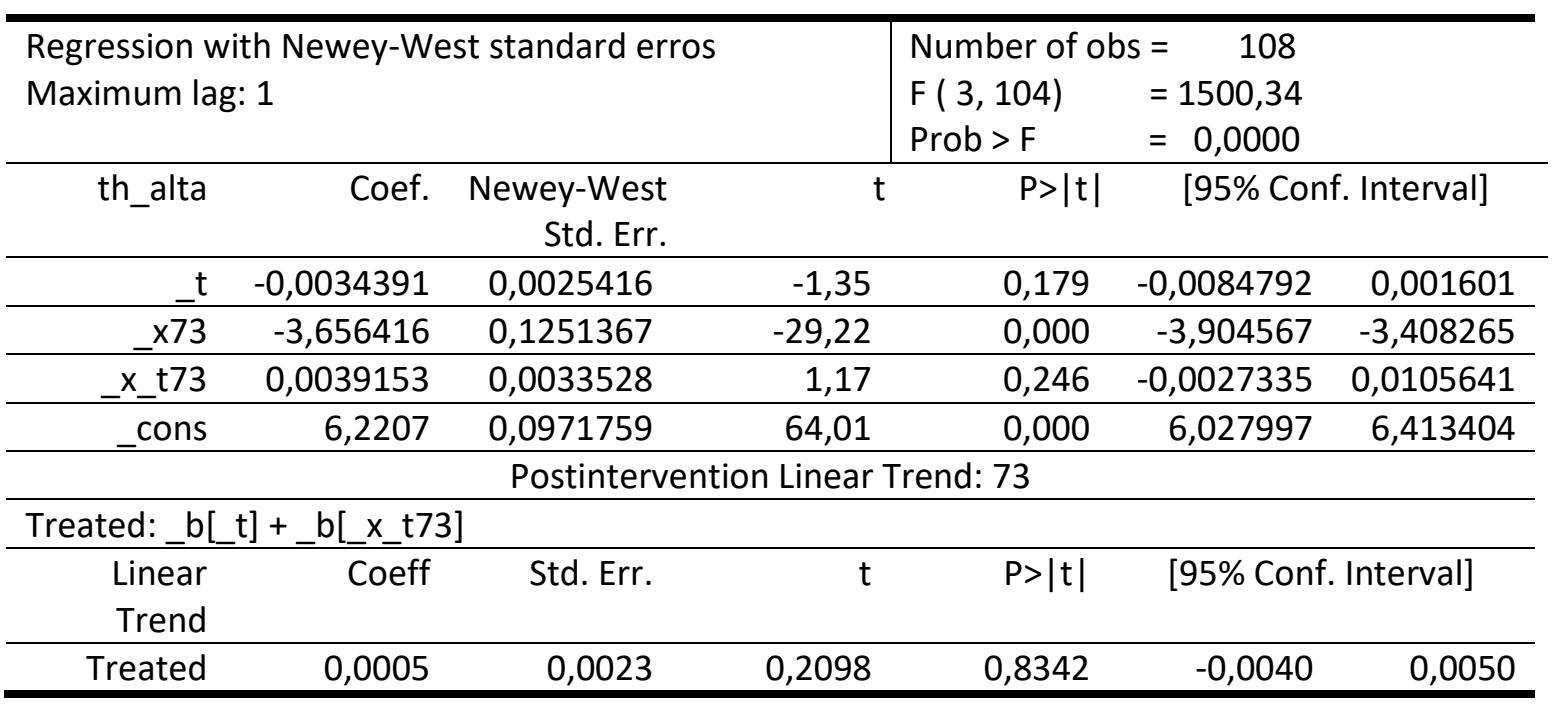

Tabela 8 - Análise de Série Temporal Interrompida Geral com Lag 8

\begin{tabular}{|c|c|c|c|c|c|c|}
\hline \multicolumn{4}{|c|}{$\begin{array}{l}\text { Regression with Newey-West standard erros } \\
\text { Maximum lag: } 8\end{array}$} & \multicolumn{3}{|c|}{$\begin{array}{lr}\text { Number of obs } & =108 \\
F(3,104) & =939,81 \\
\text { Prob }>F & =0,0000\end{array}$} \\
\hline th_alta & Coef. & $\begin{array}{l}\text { Newey-West } \\
\text { Std. Err. }\end{array}$ & $\mathrm{t}$ & $P>|t|$ & \multicolumn{2}{|c|}{ [95\% Conf. Interval] } \\
\hline t & $-0,0034391$ & 0,0039154 & $-0,88$ & 0,382 & $-0,0112034$ & 0,0043252 \\
\hline X73 & $-3,656416$ & 0,2088442 & $-17,51$ & 0,000 & $-4,070562$ & $-3,24227$ \\
\hline x_t73 & 0,0039153 & 0,0037746 & 1,04 & 0,302 & $-0,0035698$ & 0,0114004 \\
\hline cons & 6,2207 & 0,1253457 & 49,63 & 0,000 & 5,972135 & 6,469265 \\
\hline \multicolumn{7}{|c|}{ Postintervention Linear Trend: 73} \\
\hline \multicolumn{7}{|c|}{ Treated:_b[_t] +_b[_x_t73] } \\
\hline $\begin{array}{r}\text { Linear } \\
\text { Trend } \\
\end{array}$ & Coeff & Std. Err. & $\mathrm{t}$ & $P>|t|$ & {$[95 \%$ Conf } & Interval] \\
\hline Treated & 0,0005 & 0,0019 & 0,2566 & 0,7980 & $-0,0032$ & 0,0042 \\
\hline
\end{tabular}

Ao realizar-se a análise estratificada de acordo com a duração da internação hospitalar, vários achados merecem destaque. Em primeiro lugar, ao se considerar o período pré-intervenção, o grupo com internação superior a 7 dias apresenta maior variabilidade sazonal - Coeficiente $\mathrm{Z}$ 0,87 (Intervalo de Confiança 95\% 0,60;1,15) e Coeficiente ZT -0,012 (Intervalo de Confiança 95\% (-0,020; -0,005) - Figura 21 e Tabela 9. Já o grupo com internação menor que 7 dias não mostrou valores significativos. 
Ao se considerar o impacto da intervenção, observa-se que o mesmo modelo de impacto imediato - Coeficiente X -3,6 (Intervalo de Confiança -3,97;-3.43) - para um "Lag” de 1 (Tabela 9). A variação de "Lag” não afetou significativamente o resultado (Tabela 10).

Quanto ao comportamento posterior à intervenção, embora significativo do ponto de vista estatístico, os valores não o são do ponto de vista prático - Tabelas 9 e 10.

Figura 21 - Análise de Série Temporal Interrompida Estratificada comparando-se o impacto da intervenção de acordo com a duração da internação hospitalar

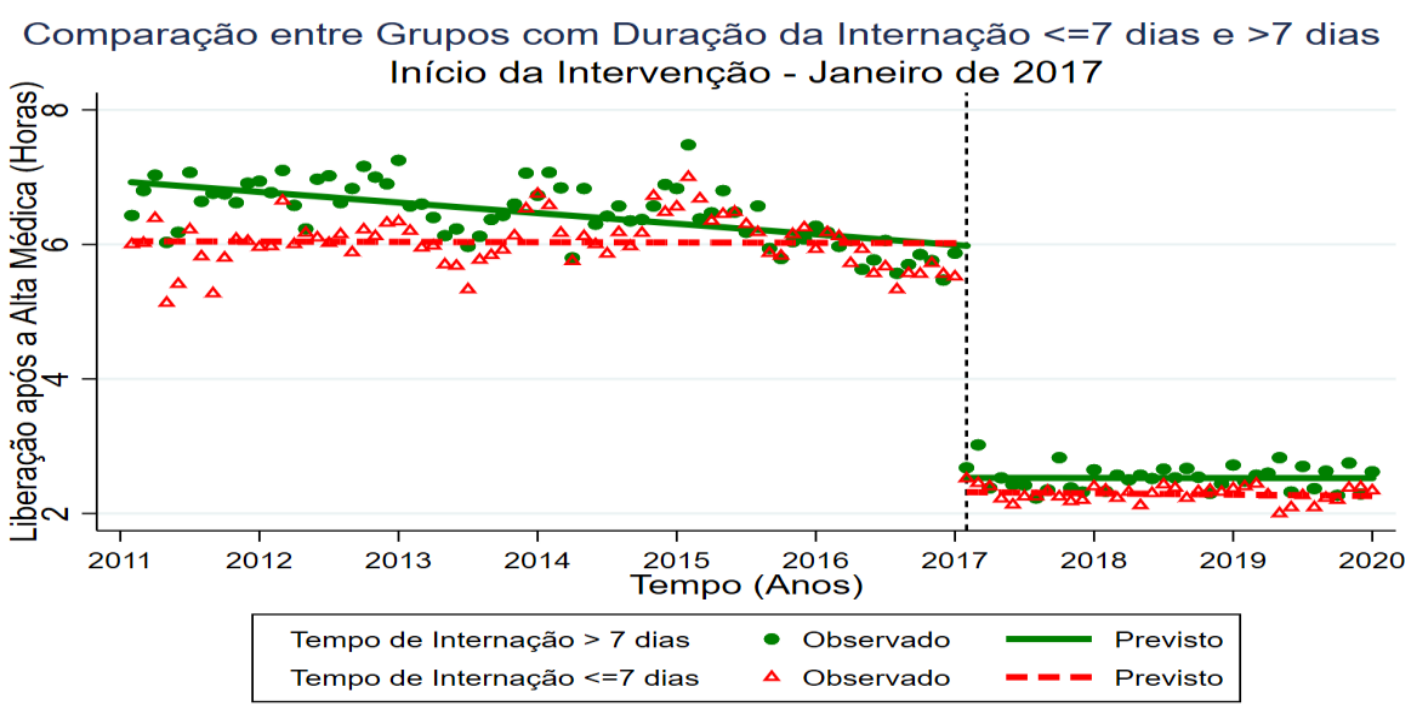

Regression with Newey-West standard errors - lag(1)

Tabela 9 - Série Temporal Interrompida estratificada para 2 grupos (internação até 7 dias e maior que 7 dias) - Lag 1

\begin{tabular}{|c|c|c|c|c|c|c|}
\hline \multicolumn{4}{|c|}{$\begin{array}{l}\text { Regression with Newey-West standard erros } \\
\text { Maximum lag: } 1\end{array}$} & \multicolumn{3}{|c|}{$\begin{array}{l}\text { Number of obs }=216 \\
F(7,208)=1304,40 \text { Prob }>F=0,0\end{array}$} \\
\hline th_alta & Coef. & $\begin{array}{l}\text { Newey-West } \\
\text { Std. Err. }\end{array}$ & $\mathrm{t}$ & $P>|t|$ & [95\% Conf & Interval] \\
\hline$-\mathrm{t}$ & $-0,0003876$ & 0,0027552 & $-0,14$ & 0,888 & $-0,0058193$ & 0,05044 \\
\hline z & 0,8779909 & 0,1401287 & 6,27 & 0,000 & 0,6017362 & 1,154245 \\
\hline z_t & $-0,0127368$ & 0,0036294 & $-3,51$ & 0,001 & $-0,019892$ & $-0,0055817$ \\
\hline X73 & $-3,700262$ & 0,1367949 & $-27,05$ & 0,000 & $-3,969944$ & $-3,430579$ \\
\hline x_t73 & $-0,0012571$ & 0,0036163 & $-0,35$ & 0,728 & $-0,0083864$ & 0,0058721 \\
\hline _z_x73 & 0,2503223 & 0,1853675 & 1,35 & 0,178 & $-0,1151177$ & 0,6157623 \\
\hline z_x_t73 & 0,0142838 & 0,0052598 & 2,72 & 0,007 & 0,0039145 & 0,0246531 \\
\hline cons & 6,0464 & 0,1010536 & 59,83 & 0,000 & 5,84718 & 6,245621 \\
\hline \multicolumn{7}{|c|}{ Comparison of Linear Postintervention Trends: 73} \\
\hline \multicolumn{7}{|c|}{ Treated:_b[_t] +_b[_z_t] +_b[_x_t73]+_b[_z_x_t73] } \\
\hline Linear Trend & Coeff & Std. Err. & $\mathrm{t}$ & $\mathrm{P}>|\mathrm{t}|$ & [95\% Conf & Interval] \\
\hline Treated & $-0,0001$ & 0,0030 & $-0,0324$ & 0,9742 & $-0,0060$ & 0,0059 \\
\hline Controls & $-0,0016$ & 0,0025 & $-0,6702$ & 0,5035 & $-0,0065$ & 0,0032 \\
\hline Difference & 0,0015 & 0,0039 & 0,3977 & 0,6912 & $-0,0061$ & 0,0092 \\
\hline
\end{tabular}

Obs: O número 73 corresponde ao mês de Janeiro de 2017, quando foi iniciada a intervenção. 
Tabela 10 - Série Temporal Interrompida estratificada para 2 grupos (internação até 7 dias e maior que 7 dias) - Lag 8

\begin{tabular}{|c|c|c|c|c|c|c|}
\hline \multicolumn{4}{|c|}{$\begin{array}{l}\text { Regression with Newey-West standard erros } \\
\text { Maximum lag: } 8\end{array}$} & \multicolumn{3}{|c|}{$\begin{array}{llr}\text { Number of obs } & = & 216 \\
\mathrm{~F}(7,208) & = & 825,39 \\
\text { Prob }>\mathrm{F} & = & 0.0000\end{array}$} \\
\hline th_alta & Coef. & $\begin{array}{r}\text { Newey- } \\
\text { West Std. } \\
\text { Err. }\end{array}$ & $\mathrm{t}$ & $P>|t|$ & {$[95 \%$ Cont } & Interval] \\
\hline $\mathrm{t}$ & $-0,0003876$ & 0,0042999 & $-0,09$ & 0,928 & $-0,0088646$ & 0,0080893 \\
\hline$z$ & 0,8779909 & 0,1829251 & 4,80 & 0,000 & 0,5173659 & 1,238616 \\
\hline z_t & $-0,0127368$ & 0,0055418 & $-2,30$ & 0,023 & $-0,0236622$ & $-0,0018115$ \\
\hline X73 & $-3,700262$ & 0,2279488 & $-16,23$ & 0,000 & $-4,149648$ & $-3,250875$ \\
\hline x_t73 & $-0,0012571$ & 0,0042194 & $-0,30$ & 0,766 & $-0,0095755$ & 0,0070612 \\
\hline z_x73 & 0,2503223 & 0,2939934 & 0,85 & 0,395 & $-0,3292664$ & 0,829911 \\
\hline z_x_t73 & 0,0142838 & 0,0056165 & 2,54 & 0,012 & 0,0032112 & 0,253565 \\
\hline cons & 6,0464 & 0,131789 & 45,88 & 0,000 & 5,786587 & 6,306214 \\
\hline \multicolumn{7}{|c|}{ Comparison of Linear Postintervention Trends: 73} \\
\hline \multicolumn{7}{|c|}{ 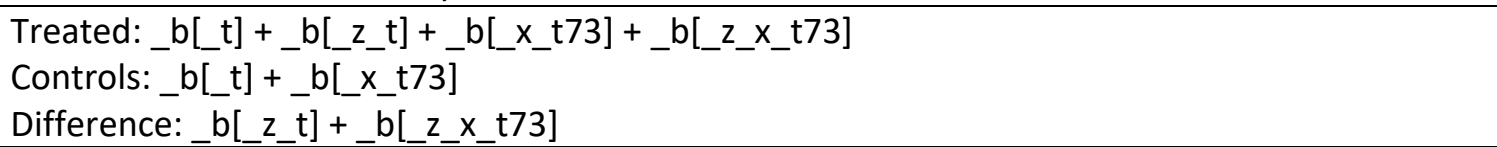 } \\
\hline Linear Trend & Coeff & Std. Err. & $\mathrm{t}$ & $\mathrm{P}>|\mathrm{t}|$ & [95\% Cont & Interval] \\
\hline Treated & $-0,0001$ & 0,0024 & $-0,0402$ & 0,9680 & $-0,0049$ & 0,0047 \\
\hline Controls & $-0,0016$ & 0,0020 & $-0,8166$ & 0,4151 & $-0,0056$ & 0,0023 \\
\hline Difference & 0,0015 & 0,0032 & 0,4895 & 0,6250 & $-0,0047$ & 0,0078 \\
\hline
\end{tabular}

Obs: O número 73 corresponde ao mês de Janeiro de 2017, quando foi iniciada a intervenção. 


\section{DISCUSSÃO}

O presente estudo demonstrou que ferramentas de informática (assinatura eletrônica) permitiram a revisão do processo de alta do paciente após a dispensa médica com redução significativa do tempo de espera decorrente de procedimentos burocráticos. Esta redução implica em maior giro-leito em períodos diurnos, reduzindo a necessidade de admissão noturna de internações não-programadas oriundas dos ambulatórios.

A permanência hospitalar além do necessário se constitui em preocupação permanente das instituições de saúde ${ }^{(29)}$, pois hospitalizações prolongadas estão associadas a maiores índices de complicação e custos de internação. Estudos demostram que atrasos na alta podem ter motivações externas à instituição de saúde, como problemas relacionados ao transporte de pacientes e problemas de natureza organizacional como o número de vezes em que o paciente pode ser remanejado dentro do hospital. Estes fatores estão mais associados com o atraso na alta do que propriamente com fatores relacionados ao paciente (fatores cognitivos e limitações funcionais). Estudo exploratório, descritivo e transversal, ocorrido no Hospital Auxiliar de Suzano (HAS) do Hospital das Clínicas da Faculdade de Medicina da Universidade de São Paulo (HCFM-USP) demonstrou que entre 2011 a 2014, 54,5\% dos atrasos na saída do paciente após a alta médica eram devidos a motivos relacionados ao transporte do paciente (aguardo de ambulância e transporte familiar) e 12,7\% foi devido a fatores relacionados ao suporte da rede (aguardo de vaga, transferência para outras instituições) ${ }^{(30)}$.

Atrasos na alta do paciente podem incorrer em maiores custos operacionais à instituição de Saúde como refeições, medicamentos prescritos e custos de hotelaria. Estes custos podem ser depreendidos na Figura 1 - ANTERIOR em que apenas apos a saída do paciente do hospital é que se cancelava efetivamente o envio de medicamentos e refeições que já estvam prescritas para os pacientes que se foram. Isto fazia com que estas refeições fossem desperdiçadas e os medicamentos tivessem que ser reencaminhados à Farmácia com um custoso processo de reintrodução no estoque.

A avaliação da custo-efetividade que esta simples reestruturação de processo com auxílio da informática trouxe à instituição não foi objetivo deste estudo. Isto seria desejável, mas se constitui numa limitação do presente estudo e foi abandonada por dificuldades da estruturação logística da instituição.

No tocante às refeições, a metodologia utilizada pelo Serviço de Nutrição e Dietética não permitiam a rastreabilidade no sistema informático para que pudesse ser recuperada num estudo 
de natureza observacional que inclui um braço retrospectivo (previamente à intervenção). Isto se dava porque as refeições que eram desprezadas porque o paciente havia tido alta não eram documentadas no sistema. Muito embora haja sido feita a tentativa de recuperar estes dados, eles não se mostraram confiáveis para o estudo.

Com relação às medicações, algo similar ocorreu. Um primeiro aspecto a ser mencionado é que as medicações que eram devolvidas estavam incluídas em grande parte no conjunto "SE NECESSÁRIO”, ou seja, aquelas prescritas pelo médico para que o paciente utilize caso desenvolva febre ou para controle de episódios de dor. Estas medicações são devolvidas para a Farmácia mesmo para os pacientes que não tiveram alta e não se pode recuperar a informação com confiabilidade. Um segundo aspecto é que as medicações são dispensadas por centro de custo e apenas recentemente a instituição se envolveu no processo de "Beira-Leito" em que se registra no sistema a medicação que é efetivamente aplicada no paciente. Como na parte retrospectiva do estudo esta informação não estava disponível, também foi uma limitação que não pode ser contornada.

Importante ressaltar que quanto maior precisão nas informações de retroalimentação das enfermarias aonde estão alocados os pacientes, menor a possibilidade de que haja a incidência de refeições devolvidas, bem como a de medicamentos devolvidos pois estas ações podem ser bloqueadas sistemicamente com o fechamento do atendimento ocorrendo de forma mais rápida. Tal fato indica que podemos ter uma redução de custos operacionais provenientes da entrega de refeições e medicamentos.

Além dos benefícios relacionados com os suprimentos enviados ao paciente, foi demonstrado no presente trabalho a melhora no tempo de disponibilização de leitos, pois o fechamento do atendimento ocorrendo de maneira mais rápida disponibiliza o leito em que o paciente estava mais rapidamente, permitindo um giro mais rápido nas enfermarias e admissão de novos pacientes. A Figura 17 demonstra claramente que anteriormente a intervenção, observa-se uma distribuição bimodal na frequência de admissões nas diversas enfermarias do hospital, com um descenso ao redor das 19 horas. Isto provavelmente se devia à mudanças de turno da enfermagem, que só retomava a burocracia da alta hospitalar de pacientes após esta troca de equipe. Com a simplificação do processo, a distribuição de admissões se aproximou da normalidade e, mais importante, se deslocou para a esquerda, ou seja, permitindo que as admissões ocorressem antes das 19 horas em sua maioria. Isto é muito importante, pois os pacientes que anteriormente eram admitidos após as 19 horas eram pacientes que estavam nos ambulatórios do HCFMRP-USP e necessitavam de internações não programadas. Ou seja, o 
retardo que se observava implicava que existia um represamento de pacientes no ambulatório que implicava na permanência de profissionais além da jornada de trabalho para o cuidado dos pacientes até a admissão. É importante detalhar que o fato do comportamento descrito ser observado mesmo quando se estratifica para as diversas enfermarias do hospital, ele deve ser mesmo uma função do padrão de trabalho da equipe de enfermagem (troca de turnos).

Muito embora o HCFMRP-USP venha tomando providências ao longo dos últimos anos para evitar que as admissões não-programadas ocorram tardiamente, ou seja, possam ser previstas por diversas variáveis na chegada ao ambulatório, como dependência no cuidado, alteração nos sinais vitais obtidos ou queixas transmitidas à enfermagem, e portanto, atendidas prioritariamente, este processo não era eficiente anteriormente pela ausência de leitos disponíveis para internações não-programadas. Com a instalação do processo de alta instalado no presente trabalho, estas duas iniciativas passam a se complementar e, provavelmente, outras iniciativas venham a permitir aprimoramento e maior interação nos processos futuros.

Outro dado importante da intervenção do presente estudo é que ela parte do processo de cadeia de produção ou de uma matriz de processos interconectados (Figura 2), pois uma ação desencadeada pela enfermagem tem impacto nos processos de trabalhos de outras equipes. As abordagens sobre fluxo de pacientes na literatura têm focado muito o efeito de aglomeração de pacientes decorrente de gargalos, como os frequentemente observados na sala de urgência, atribuindo este efeito à interconexão entre as diversas instâncias em que o paciente é albergado. De modo inovador, o presente trabalho apresenta a importância de se observar os impactos de aprimoramento de processo entre aquelas dependentes do trabalho de equipes de saúde, mas também de equipes de apoio. Provavelmente, o exemplo deste trabalho possa ser extrapolado para outras áreas que sofrem do fenômeno de aglomeração.

A guisa de exemplo, uma das soluções propostas para a aglomeração na sala de urgência realizada nos Estados Unidos, é a transferência de pacientes que já têm indicação de internação das salas de urgência para as salas de espera das enfermarias, partindo-se do pressuposto que a isto trará a percepção da agilidade que a enfermaria tem que ter para absorver o novo paciente $^{(31,32)}$. À luz dos dados do presente trabalho, observa-se que muito provavelmente o que se deve estudar é o processo de trabalho que está retardando a rotatividade do leito e não acrescentar um novo fator estressor ao trabalho das equipes. Mesmo porque, os pacientes que anteriormente esperavam mais de 7 horas para saírem do hospital por problemas processuais já exerciam pressão suficiente na equipe de enfermagem de nossa instituição. 
Destino L et al desenvolveu um trabalho quase-experimental similar ao presente trabalho, mas ao invés de uma intervenção no processo de trabalho da enfermagem, utilizou equipes para busca e agilização das altas hospitalares antes das 11 horas da manhã, demonstrando também por modelo de séries temporais interrompidas que houve um incremento de $8 \%$ para $16 \%$ no número de altas após a intervenção ${ }^{(33)}$. Outra iniciativa de Sampson MJ demonstrou resultados similares com equipes de cuidado para intervenção em população de pacientes diabéticos ${ }^{(34)}$. Como a natureza da intervenção é distinta entre estes trabalhos e o ora apresentado, a comparação é limitada, mas não é impossível supor que parte do trabalho das equipes envolvidas não tenha sido resolver o que foi automatizado em nossa intervenção.

Estes e outros trabalhos são exemplos da estratégia de Gerenciamento de Casos da Gestão da Clínica a qual pertence o presente trabalho. No entanto, a intervenção realizada neste trabalho é custo-efetiva, à medida que não depende de incorporação de novas equipes, não se restringe a populações específicas e a redução observada se manteve relativamente constante após a intervenção. No entanto, acreditamos que estas estratégias devam ser complementares se possível, pois parte do que é abordado pode ser de outra natureza que não problemas logísticos. Como anteriormente ressaltado, o auxílio na tomada de decisão de médicos em treinamento pode agilizar o fluxo de pacientes e não está na dimensão abordada pela intervenção estudada neste trabalho ${ }^{(35,36)}$. Como anteriormente destacado, esta iniciativa complementar é executada pelo NIR no contexto do HCFMRP-USP.

A permanência prolongada por motivos não clínicos também pode prejudicar o fluxo de pacientes afetando índices de rotatividade de leitos e duração média da internação.

Ferramentas de melhoria de qualidade como o Lean e o Seis Sigma podem ser usadas para o desenvolvimento de processos mais confiáveis. O Seis Sigma, por sua vez, é uma ferramenta de gerenciamento industrial com utilização crescente pela saúde ${ }^{(37)}$.

Surgido no final da década de 1960 com a Motorola, o processo Seis Sigma possui base no ciclo PDCA (Plan-Do-Check-Act; Planejar, Executar, Avaliar, Implantar), contemplando características como: ênfase em controle da qualidade, análise e solução de problemas com uso correto de recursos disponíveis, sistematização no uso de métodos estatísticos seguindo o ciclo DMAIC (define, measure, analyse, improve, control: definir, medir, analisar, melhorar, controlar) ${ }^{(38)}$.

Exemplo de caso de sucesso, a aplicação do método Lean Seis Sigma em processos hospitalares do Centro Médico Richard L. Roudebush em Indianapolis, Indiana, trouxe redução de cerca de 
$36 \%$ do tempo global de permanência do paciente passando de 5,3 a 3,4 dias em cirurgias de prótese de joelho e quadril ${ }^{(37)}$. A utilização destes métodos em problemas similares ao apresentado no presente trabalho é possível, porém não foram encontrados outras referências que permitissem a comparação.

O presente trabalho apresenta limitações. Algumas já foram apresentadas, como as limitações de obtenção de dados retrospectivos de informações não-estruturadas no sistema eletrônico do HCFMRP-USP no concernente à nutrição e devolução de medicamentos. Estes dados poderiam ter acrescentado dados mais objetivos da custo-efetividade do presente trabalho, mas embora não tenha sido possível mensurar a magnitude do efeito, não se pode negar que ele existiu e é significativo frente ao movimento de internações da instituição. Deve ser ressaltado que a instituição está empreendendo esforços de melhoria do sistema de logística que facilitarão estudos desta natureza num futuro próximo. Outra eventual limitação é a ocorrência de outras intervenções que pudessem justificar os achados e que não foram levadas em consideração. Apesar de possível, qualquer outra intervenção que afetasse sistemicamente a instituição como se observou no presente estudo seria difícil de passar despercebida. A perenidade do efeito após três anos do seu início também é um argumento contrário a esta possível intervenção. Finalmente, o trabalho apresenta limitações inerente ao seu desenho metodológico quasiexperimental.

O aprimoramento da intervenção pode ser pensado, mas é pouco provável que se consiga reduzir ainda mais o tempo de saída do paciente após a alta hospitalar. Este tempo deve ser influenciado pela disponibilidade de transporte que exigiriam a comunicação do sistema eletrônico da instituição com o de outras, sendo o benefício duvidoso. No entanto, o aprendizado do estudo matricial de processos e de como as ferramentas de informática podem auxiliar numa solução custo-efetiva pode ser transposto para outros processos institucionais, o que será muito importante. 


\section{CONCLUSÕES}

A modificação do processo de alta hospitalar, sinalizando o final do processo com a assinatura eletrônica da enfermeira responsável no HCFMRP-USP reduziu a diferença de tempo entre o momento que o médico indica a alta do paciente até o momento em que o paciente é efetivamente liberado.

Esta redução implica em maior giro-leito em períodos diurnos, reduzindo a necessidade de admissão noturna de internações não-programadas oriundas dos ambulatórios. 


\section{REFERÊNCIAS BIBLIOGRÁFICAS}

1. Kohn LT, Corrigan JM, Molla S. To Err Is Human [Internet]. T. KL, Corrigan JM, Donaldson MS, America C on Q of HC in, Medicine I of, editors. Regulatory Toxicology and Pharmacology. Washington, D.C.: National Academies Press; 2000. 312 p. Disponível em: https://doi.org/10.17226/9728 [acesso em 19/06/2020]

2. Bates DW, Singh H. Two decades since to err is human: An assessment of progress and emerging priorities in patient safety. Health Aff. 2018;37(11):1736-43.

3. Pazin-Filho A, Frezza G, Matsuno AK, De Alcântara ST, Cassiolato S, Bitar JPS, et al. Princípios de prescrição médica hospitalar para estudantes de medicina. Med. 2013;46(2):183-94.

4. Soriano L de A, Castro TT, Vilalva K, Borges M de C, Pazin-Filho A, Miranda CH. Validation of the pulmonary embolism severity index for risk stratification after acute pulmonary embolism in a cohort of patients in Brazil. J Bras Pneumol. 2019;45(1):1-7.

5. Pires HHG, Neves FF, Pazin-Filho A. Triage and flow management in sepsis. Int $\mathbf{J}$ Emerg Med. 2019;12(1).

6. Allder S, Silvester K, Walley P. Managing capacity and demand across the patient journey. Clin Med J R Coll Physicians London. 2010;10(1):13-5.

7. Gonçalves-Bradley DC, Lannin NA, Clemson LM, Cameron ID, Shepperd S. Discharge planning from hospital ( Review ) SUMMARY OF FINDINGS FOR THE MAIN COMPARISON. Cochrane Database Syst Rev. 2016;(1):74.

8. Bekker R, Koeleman PM. Scheduling admissions and reducing variability in bed demand. Health Care Manag Sci. 2011;14(3):237-49.

9. Allder S, Silvester K, Walley P. Understanding the current state of patient flow in a hospital. Clin Med J R Coll Physicians London. 2010;10(5):441-4.

10. Kroneman M, Siegers JJ. The effect of hospital bed reduction on the use of beds: A comparative study of 10 European countries. Soc Sci Med. 2004;59(8):1731-40.

11. Krall SP, Cornelius AP, Addison JB. Hospital factors impact variation in emergency department length of stay more than physician factors. West J Emerg Med. 2014;15(2):158-64. 
12. Mayer T, Jensen K. Hardwiring flow: systems and process for seamless patient care. Fire Starter Publishing; 2009. 295 p.

13. Anschau F, Webster J, Roessler N, Fernandes E de O, Klafke V, da Silva CP, et al. Avaliação de intervenções de Gestão da Clínica na qualificação do cuidado e na oferta de leitos em um hospital público de grande porte. Sci Med (Porto Alegre). 2017;27(2).

14. Adolfi Júnior MS, Pallini FM, Pessotti H, Wolf CM, Patelli HT, Capeli RD, et al. Emergency medical coordination using a web platform: A pilot study. Rev Saude Publica. 2010;44(6):1063-71.

15. Pazin-Filho A, de Almeida E, Cirilo LP, Lourençato FM, Baptista LM, Pintyá JP, et al. Impact of long-stay beds on the performance of a tertiary hospital in emergencies. Rev Saude Publica. 2015;49(B3).

16. Neves FF, Pazin-Filho A. Gestão de recursos em terapia intensiva: aplicação de um sistema de informação para organização da fila. Rev Eletronica Gestão Saúde. 2016;7(2):730-41.

17. Ministério da Saúde. Manual de Implantação e Implementação: Núcleo Interno de Regulação para Hospitais Gerais e Especializados [Internet]. 1st ed. Brasília - DF: Ministério da Saúde; 2017. p. 57. Disponível em: http://bvsms.saude.gov.br/bvs/publicacoes/manual_implementacao_hospitais_gerais_es pecializados.pdf [acesso em 21/06/2020].

18. Ferreira AJ, Laurindo MC, Moraes A de A, Cerantola R, Barbosa LB, Pereira JG da C, et al. A implantação do Núcleo Interno de Regulação em Hospital Público Terciário. Med (Ribeirao Preto Online). 2019;52(1):16-23.

19. Messler J, Whitcomb WF. A History of the Hospitalist Movement. Obstet Gynecol Clin North Am [Internet]. 2015;42(3):419-32. Disponível em: http://dx.doi.org/10.1016/j.ogc.2015.05.002 [acesso em 21/06/2020].

20. White HL, Glazier RH. Do hospitalist physicians improve the quality of inpatient care delivery? A systematic review of process, efficiency and outcome measures. BMC Med [Internet]. 2011;9(1):58. Disponível em: http://www.biomedcentral.com/17417015/9/58 [acesso em 21/06/2020].

21. Silva SA da, Valácio RA, Botelho FC, Amaral CFS. Fatores de atraso na alta hospitalar em hospitais de ensino. Rev Saude Publica. 2014;48(2):314-21. 
22. Yamamoto Tanaka NY, Merlo EM, Ferreira Nicoletti C, Góes WM, Novaes R, Fávero F, et al. Impacto da informatização intra-hospitalar sobre a gestão de custos. Integração da prescrição eletrônica das fórmulas pediátricas e das dietas enterais com suas respectivas áreas de produção. Rev Chil Nutr. 2015;42(1):30-4.

23. Ofir Ben-Assuli1, Itamar Shabtai ML. The impact of EHR and HIE on reducing avoidable admissions: Controlling main differential diagnoses. BMC Med Informatics Decis Mak 13. 2013;13(49).

24. Abul-Husn NS, Kenny EE. Personalized Medicine and the Power of Electronic Health Records. Cell [Internet]. 2019;177(1):58-69. Disponível em: https://doi.org/10.1016/j.cell.2019.02.039 [acesso em 20/06/2020]

25. Resolução Cfm No 1.821/2007 [Internet]. Vol. 2007, Diário Oficial da União. Brasília DF: Conselho Federal de Medicina; 2007. p. 252. Disponível em: https://sistemas.cfm.org.br/normas/visualizar/resolucoes/BR/2007/1821 [acesso em 21/06/2020]

26. Medida Provisória No 2.200-2, de 24 de agosto de 2001. [Internet]. 2001. Disponível em: http://www.planalto.gov.br/ccivil_03/MPV/Antigas_2001/2200-2.htm [acesso em $21 / 06 / 2020]$

27. Relatórios de Atividades [Internet]. 2018. Disponível em: https://site.hcrp.usp.br/wpcontent/uploads/2019/07/relatorio2018.pdf [acesso em 21/06/2020].

28. HCFMRP-USP em Números. 2020. Disponível em: https://site.hcrp.usp.br/hcfmrp-emnumeros/ [acesso em 21/06/2020].

29. Bernal JL, Cummins S, Gasparrini A. Interrupted time series regression for the evaluation of public health interventions: A tutorial. Int J Epidemiol. 2017;46(1):34855.

30. Ajimura FY, Malik AM. Por que eles permanecem: causas de atraso na saída em pacientes de alta médica. Espaço para a Saúde - Rev Saúde Pública do Paraná. 2016;17(2):134.

31. Khanna S, Sier D, Boyle J, Zeitz K. Discharge timeliness and its impact on hospital crowding and emergency department flow performance. EMA - Emerg Med Australas. 2016;28(2):164-70.

32. Stephens AS, Broome RA. Impact of emergency department occupancy on waiting 
times, rates of admission and representation, and length of stay when hospitalised: A data linkage study. EMA - Emerg Med Australas. 2018;31(4):555-61.

33. Destino LA, Bennett D, Wood M, Acuna C, Goodman S, Asch SM, et al. Improving patient flow: Analysis of an initiative to improve early discharge. J Hosp Med. 2019;14(1):22-7.

34. Sampson MJ, Crowle T, Dhatariya K, Dozio N, Greenwood RH, Heyburn PJ, et al. Trends in bed occupancy for inpatients with diabetes before and after the introduction of a diabetes inpatient specialist nurse service. Diabet Med. 2006;23(9):1008-15.

35. Pfeffer PE, Nazareth D, Main N, Hardoon S, Choudhury AB. Are weekend handovers of adequate quality for the on-call general medical team? Clin Med J R Coll Physicians London. 2011;11(6):536-40.

36. Ahmad A, Purewal TS, Sharma D, Weston PJ. The impact of twice-daily consultant ward rounds on the length of stay in two general medical wards. Clin Med J R Coll Physicians London. 2011;11(6):524-8.

37. Gayed B, Black S, Daggy J, Munshi IA. Redesigning a Joint Replacement Program using Lean Six Sigma in a Veterans Affairs Hospital. JAMA Surg. 2013;148(11):1050-6.

38. Pinto SHB, De Carvalho MM, Ho LL. Implementação de programas de qualidade: Um survey em empresas de grande porte no Brasil. Gest e Prod. 2006;13(2):191-203. 


\title{
8. ANEXO
}

\section{ANEXO 1 - PUBLICAÇÃO NA REVISTA QUALIDADE HC}

\author{
Revista Qualidade HC
}

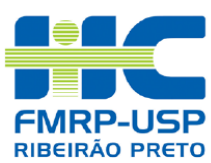

\section{INTRODUÇÃO}

A qualidade na Assistência ao paciente caracteriza-se como um tema de extrema relevância sendo de interesse mútuo entre paciente, instituições de saúde, órgãos de regulação e a sociedade como um todo. Sua gestão constitui-se como tema mais complexo do que em outro tipo de instituição, por envolver especialidades e procedimentos de grande diversidade ${ }^{7}$. Tendências recentes apontam que esforços tem sido direcionados para redução do tempo de permanência de pacientes nas instituições hospitalares e direcionando certos aspectos do cuidado para a comunidade. Neste contexto de revisão do processo de alta estabelece-se como item de grande importância.

Neste contexto, a Tecnologia da Informação desempenha papel estratégico como ferramenta de apoio à mudança. Estudos mostram que a tecnologia da informação pode contribuir em aspectos relacionados à segurança do paciente, bem como servir de suporte para otimização de atividades². Ferramentas de Registros Eletrônicos de Saúde (EHR) e Sistemas de Troca de Informações Hospitalares (HIE), se bem implementados, podem contribuir na redução do número de admissões desnecessárias, reduzindo custos relacionados à Internação ${ }^{3}$.

Visando a busca da melhoria contínua em seus processos, o Hospital das Clínicas de Ribeirão Preto, hospital terciário, localizado no município de Ribeirão Preto, interior de São Paulo, realizou revisão sistemática no processo de alta de enfermagem, o qual passou a vigorar em janeiro de 2017.

\section{OBJETIVO}

O objetivo deste trabalho é realizar um estudo retrospectivo e exploratório em dados secundários do tempo de fechamento de alta antes e após a revisão da rotina de alta para verificar se a intervenção no processo surtiu em mudanças com relação ao tempo de fechamento de alta.

\section{MÉTODO}

A figura a seguir detalha o fluxo do processo de Alta Hospitalar do Hospital das Clínicas de Ribeirão Preto antes e após a sua revisão.

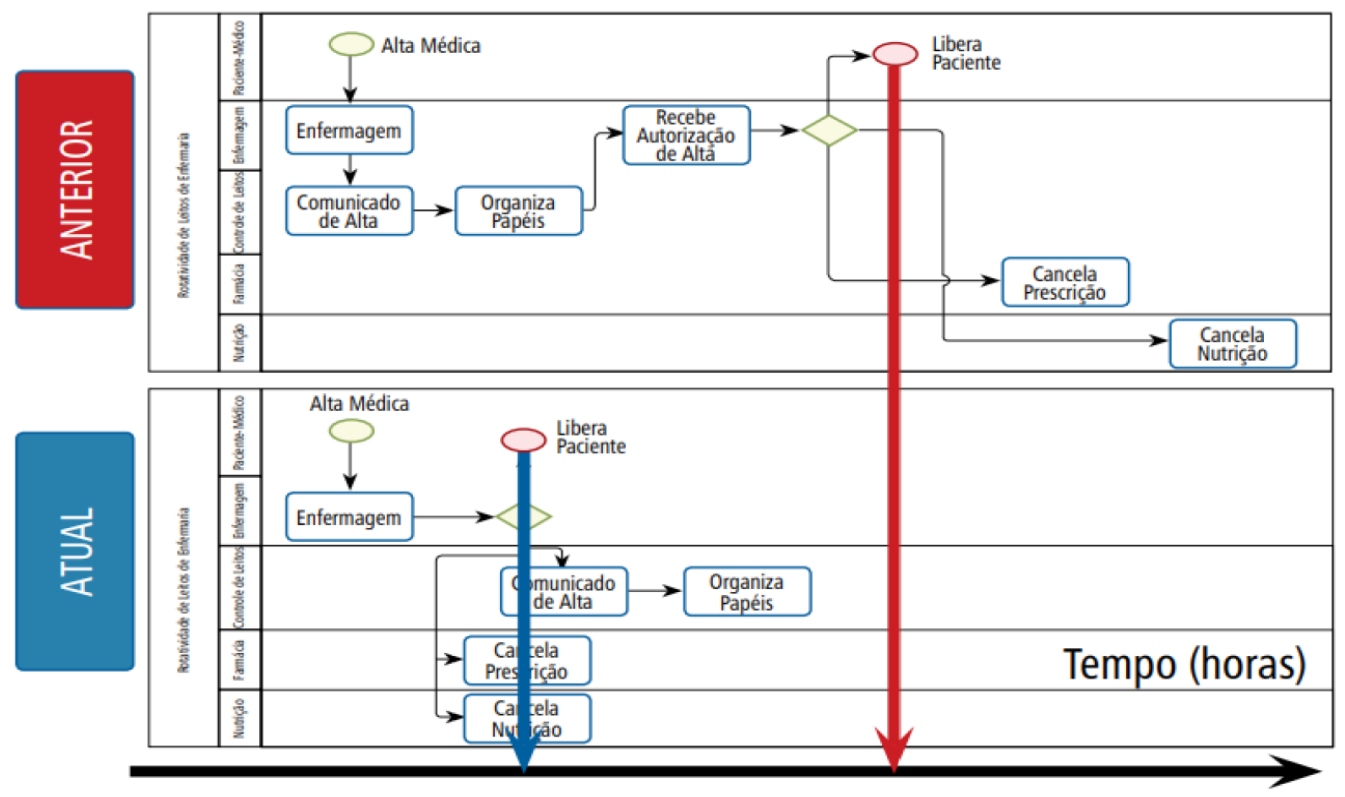

Figura 1: Diagrama do Processo de Alta do HCFMRP-USP antes e após revisão do processo Fonte: Relatório de Gestão HCFMRP-USP 2015- 2018 
Conforme observa-se na parte superior da Figura (ANTERIOR), o médico registrava a alta médica em sistema informatizado e o registro de atendimento ao paciente permanecia em aberto até toda a documentação pertinente ao paciente fosse entregue ao setor de Controle de Leitos, o qual efetivava o fechamento do atendimento, e assim o leito era então disponibilizado para nova admissão. Com a revisão do processo (parte inferior da Figura - ATUAL), o registro do atendimento passou a ser encerrado com a sinalização da equipe de enfermagem indicando que o paciente já se encontra em condições de sair do hospital e demais medidas tomadas. Desta forma a liberação do leito não fica mais condicionada a entrega de documentação ao controle de leitos. Esta sinalização atua como gatilho para providências como o cancelamento de prescrições que se encontram ativas, bem como eventuais prescrições que possam ter sido feitas após a alta médica.

Como critério de inclusão foram considerados as altas hospitalares ocorridas no Hospital das Clínicas da Faculdade de Medicina de Ribeirão Preto da Universidade de São Paulo em sua unidade Campus durante os anos de 2011 e 2017.

Os dados foram obtidos a partir das bases de dados de sistema informatizado da instituição em estudo. Os dados foram extraídos a partir da linguagem SQL e exportados em formato CSV (valores separados por vírgula). Este formato foi escolhido por ser de padrão aberto e poder ser utilizado pela grande maioria dos softwares de análise estatística. Uma vez exportados, os dados foram importados no software RStudio, que utiliza a linguagem R para a elaboração de análises, gráficos e relatórios. Foram coletatas as seguintes variáveis: Enfermaria da Alta; Data da internação; Data da Alta Médica; Data do fechamento da internação; Leito em que o paciente estava no momento da alta; Especialidade médica responsável pela alta; Tipo de Convênio do paciente.

Com relação variável Tipo de Convênio, os convênios foram enquadrados em duas categorias: Convênio SUS e todos os demais convênios em Não-SUS. As variáveis de data (Alta Médica e Fechamento do Atendimento) foram coletadas no formato dia/mês/ano hora, minuto e segundo. Registros de altas em que uma das variáveis mencionadas não constavam foram desconsideradas. Com base nas datas de médica e no fechamento do atendimento foi calculado, em horas, a diferença de tempo entre essas duas datas e partir desta variável derivada foi calculado mediana mensal. Foi escolhido a mediana em vez da média pelo fato desta primeira ser menos suscetível a valores extremos distoantes (outliers).

O projeto foi aprovado pelo Comitê de Ética em Pesquisa do HCFMRP-USP (CAE 2.846.460). O presente estudo considera apenas dados administrativos obtidos em sistema informatizado do Hospital das Clínicas da Faculdade de Medicina de Ribeirão Preto. Considerando que o tamanho da amostra é significativo, a consulta individualizada dos pacientes poderia ser onerosa e comprometer o desenvolvimento do estudo, foi obtida a dispensa do termo de consentimento livre e esclarecido de acordo com a resolução do Conselho Nacional de Saúde no 466 de 12 de dezembro de 2012.

\section{RESULTADOS}

A Tabela 01 mostra o tempo mediano de alta ao longo do tempo. Após aplicação dos critérios de inclusão e exclusão, foram analisadas 188.363 altas no período de janeiro de 2017 a dezembro de 2018. A Figura 02 e a Tabela 01 apresentam os tempos medianos de alta do instituto Campus no período citado. 


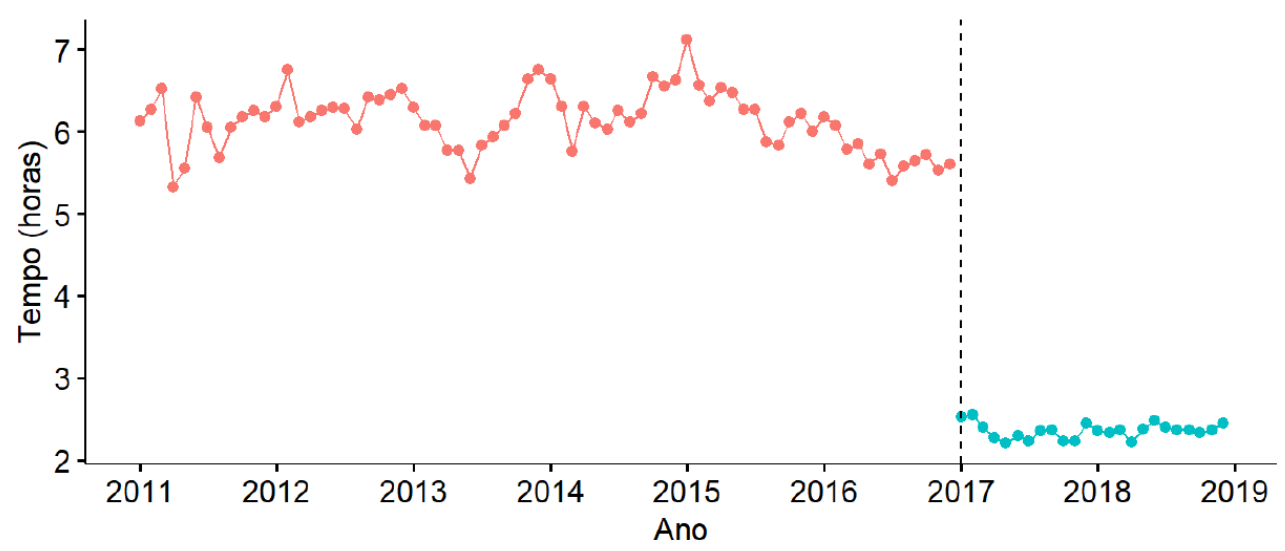

Figura 2: Evolução Mensal do tempo mediano de alta- HCRMP Unidade CampusTabela 1: Tempo mediano entre a alta médica e o fechamento do atendimento

\begin{tabular}{lllllllllllll} 
ANO & JAN & FEV & MAR & ABR & MAI & JUN & JUL & AGO & SET & OUT & NOV & DEZ \\
\hline 2011 & 6,13 & 6,27 & 6,52 & 5,32 & 5,55 & 6,42 & 6,05 & 5,68 & 6,05 & 6,18 & 6,25 & 6,17 \\
2012 & 6,30 & 6,75 & 6,12 & 6,17 & 6,25 & 6,29 & 6,28 & 6,03 & 6,42 & 6,38 & 6,45 & 6,52 \\
2013 & 6,29 & 6,07 & 6,07 & 5,77 & 5,77 & 5,43 & 5,83 & 5,93 & 6,07 & 6,22 & 6,63 & 6,75 \\
2014 & 6,63 & 6,30 & 5,76 & 6,30 & 6,10 & 6,03 & 6,25 & 6,12 & 6,22 & 6,67 & 6,55 & 6,62 \\
2015 & 7,12 & 6,57 & 6,37 & 6,53 & 6,47 & 6,27 & 6,27 & 5,88 & 5,83 & 6,12 & 6,22 & 6,00 \\
2016 & 6,18 & 6,07 & 5,78 & 5,85 & 5,60 & 5,73 & 5,40 & 5,58 & 5,65 & 5,72 & 5,53 & 5,60 \\
2017 & 2,53 & 2,55 & 2,40 & 2,27 & 2,20 & 2,30 & 2,23 & 2,35 & 2,37 & 2,23 & 2,23 & 2,45 \\
2018 & 2,35 & 2,33 & 2,36 & 2,22 & 2,38 & 2,48 & 2,40 & 2,37 & 2,37 & 2,33 & 2,37 & 2,45
\end{tabular}

Fonte: Sistemas HCRP

Na Tabela 1 pode-se observar a mudança nos tempos medianos a partir de janeiro de 2017, mês em que foi implementada a mudança no processo de alta. Até o mês de dezembro de 2016 os tempos medianos variaram de 5,32 a 7,12 horas (variação de 1,8 horas), enquanto que de janeiro de 2017 a dezembro de 2018, os tempos medianos variaram de 2,20 a 2,55 (variação de 0,35 horas).

Tabela 2: Tempo mediano de alta segundo Enfermaria de Alta e Ano

\begin{tabular}{lcccccccc} 
Enfermaria & $\mathbf{2 0 1 1}$ & $\mathbf{2 0 1 2}$ & $\mathbf{2 0 1 3}$ & $\mathbf{2 0 1 4}$ & $\mathbf{2 0 1 5}$ & $\mathbf{2 0 1 6}$ & $\mathbf{2 0 1 7}$ & $\mathbf{2 0 1 8}$ \\
\hline Berçário & 5,62 & 5,99 & 5,68 & 5,95 & 6,43 & 5,65 & 2,77 & 2,13 \\
Clínica Cirúrgica 10. Andar & 5,45 & 5,85 & 5,57 & 5,98 & 5,85 & 5,53 & 2,40 & 2,17 \\
Clínica Cirúrgica 9. Andar & 6,82 & 7,43 & 7,50 & 7,47 & 7,00 & 6,33 & 3,03 & 3,20 \\
Clínica Médica - 4. Andar & 7,50 & 7,62 & 6,90 & 6,95 & 7,23 & 6,23 & 3,11 & 2,95 \\
Clínica Médica - 5. Andar & 5,43 & 5,73 & 5,23 & 5,55 & 5,47 & 4,89 & 1,87 & 1,90 \\
Clínica Médica - 6. Andar & 5,52 & 5,70 & 5,52 & 6,08 & 5,82 & 5,32 & 1,92 & 2,13 \\
Epilepsia & 7,07 & 7,17 & 6,65 & 5,92 & 5,78 & 5,69 & 1,77 & 1,87 \\
Ginecologia & 5,63 & 5,38 & 5,48 & 6,70 & 6,63 & 6,35 & 2,48 & 3,23 \\
Moléstia Infecto Contagiosa & 5,47 & 6,30 & 5,88 & 6,42 & 6,16 & 5,27 & 2,02 & 2,62 \\
\hline
\end{tabular}


Revista Qualidade HC

\begin{tabular}{|c|c|c|c|c|c|c|c|c|}
\hline Enfermaria & 2011 & 2012 & 2013 & 2014 & 2015 & 2016 & 2017 & 2018 \\
\hline Neurologia & 7,50 & 8,13 & 7,78 & 7,63 & 6,97 & 6,67 & 3,77 & 4,18 \\
\hline $\begin{array}{l}\text { Oftalmologia/Otorrinolaringologia/ } \\
\text { Cirurgia de Cabeça e Pescoço }\end{array}$ & 6,77 & 6,89 & 6,32 & 6,57 & 6,80 & 6,52 & 2,58 & 2,65 \\
\hline Obstetrícia & 5,18 & 5,35 & 5,82 & 5,73 & 6,02 & 5,46 & 2,21 & 2,30 \\
\hline Ortopedia & 6,87 & 6,67 & 6,07 & 6,15 & 5,90 & 5,57 & 2,47 & 2,28 \\
\hline Particular & 5,73 & 6,38 & 6,25 & 6,13 & 5,80 & 5,13 & 0,98 & 1,18 \\
\hline Pediatria & 5,78 & 6,35 & 5,32 & 6,07 & 6,23 & 5,58 & 1,87 & 1,90 \\
\hline Psiquiatria & 5,22 & 5,83 & 6,38 & 5,64 & 5,10 & 4,50 & 1,05 & 0,85 \\
\hline Terapia de Doenças Infecciosas & 6,55 & 7,20 & 5,66 & 5,50 & 4,33 & 4,45 & 2,08 & 1,90 \\
\hline Transplante de Medula Óssea & 6,33 & 5,99 & 6,53 & 6,72 & 5,69 & 5,35 & 1,98 & 1,37 \\
\hline $\begin{array}{l}\text { Unidade de Cuidados Intermediários } \\
\text { Neonatal }\end{array}$ & 7,28 & 6,65 & 6,22 & 5,72 & 5,75 & 5,05 & 1,48 & 1,58 \\
\hline Unidade de Pesquisa Clínica & 7,67 & 7,25 & 8,56 & 6,95 & 6,15 & 6,03 & 2,03 & 3,02 \\
\hline Unidade de Terapia Intensiva Neonatal & 3,82 & 4,65 & 4,90 & 13,46 & 3,42 & 4,74 & 1,08 & 0,35 \\
\hline Unidade de Transplante Renal & 6,13 & 6,37 & 5,84 & 6,69 & 6,57 & 6,03 & 1,48 & 1,38 \\
\hline Unidade Metabólica & 7,35 & 6,65 & 7,38 & 8,88 & 7,77 & 7,18 & 6,07 & 4,65 \\
\hline
\end{tabular}

Fonte: Sistemas HCRP.

Com base nos dados da Tabela 2, verifica-se que a redução geral do tempo mediano com periodicidade anual ocorreu em todas as enfermarias da instituição. Ao comparar os anos de 2011 e 2018 observa-se as maiores reduções da ordem de 83,71\% na enfermaria de Psiquiatria, 79,4\% na Enfermaria Particular e 78,35\% na Enfermaria de Transplante de Medula Óssea. As enfermarias de Clínica Médica (divididos pelo quarto, quinto e sexto andar) tiveram reduções de 60,66\%, $65,00 \%$ e $61,41 \%$. As menores variações ocorreram nas enfermarias de Unidade Metabólica, Ginecologia e Neurologia com $36,73 \%, 42,62 \%$ e $44,26 \%$ de reduções respectivamente.

Os gráficos a seguir demonstram o volume de altas segundo hora do término do atendimento estratificadas pelo ano da alta nos anos de 2016 e 2017.

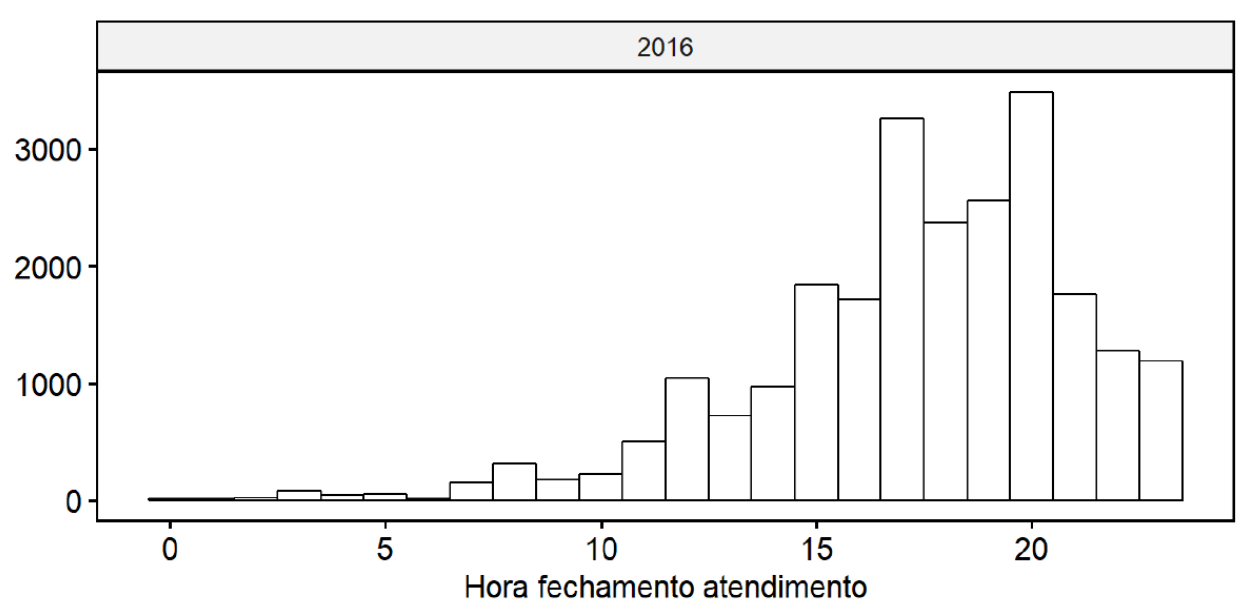

Figura 3: Volume de Altas segundo Hora do fechamento do atendimento - ano de 2016 Fonte: Sistemas HCRP 


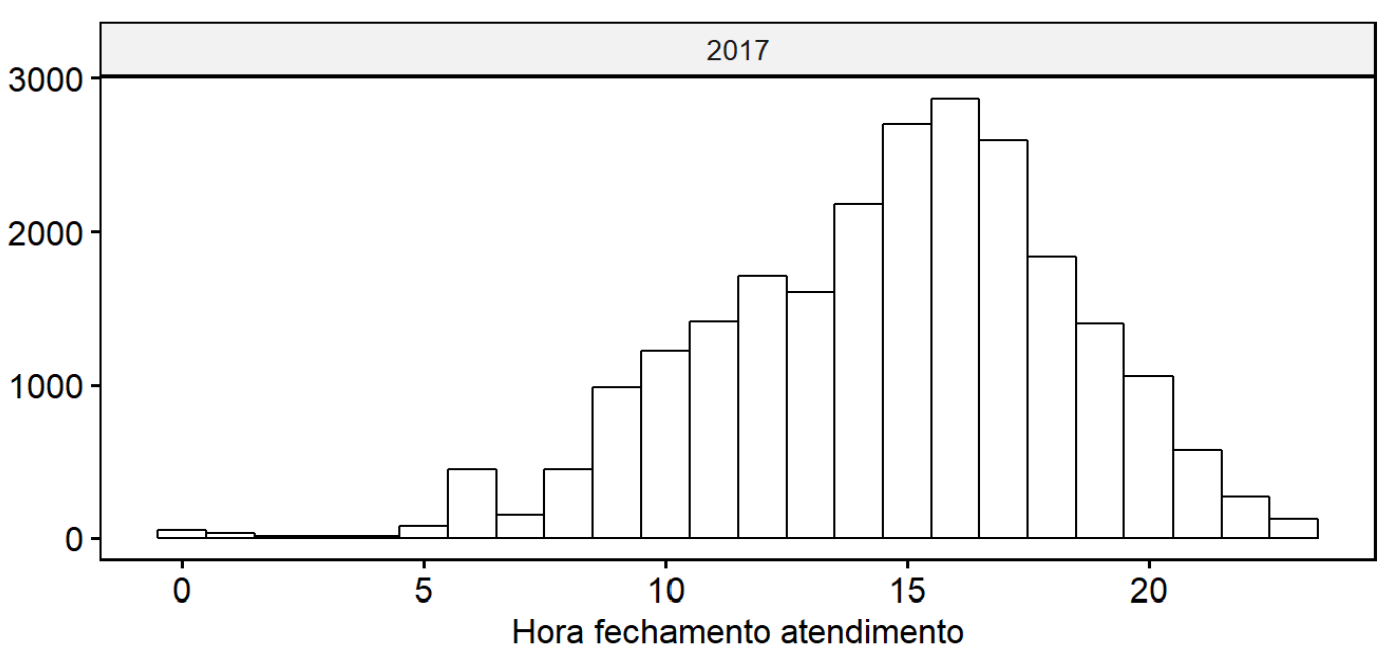

Figura 4: Volume de Altas segundo Hora do Fechamento do Atendimento- ano de 2017 Fonte: Sistemas HCRP

Observa-se nas Figuras 3 e 4 que, no ano de 2016, a distribuição das altas segundo o horário de fechamento do atendimento caracteriza-se por ser uma distribuição com cauda a esquerda, devido ao fato de termos um volume pouco expressivo de altas encerrando o atendimento entre as 0 e as 5 horas da manhã. Observa-se também que os maiores volumes de alta estão concentrados após as 17 horas com picos as 17 e 20 horas, com mais de 3000 altas. Além destes picos observa-se que após as 21 horas concentram-se volumes superiores a 1000 altas por faixa de horário. No ano de 2017, após o início da intervenção, houve mudança no comportamento desta distribuição, na qual os maiores volumes de alta estão concentrados na faixa de horário das 14 as 18 horas. Tal mudança de comportamento pode ser considerada positiva pois indica que a maioria dos atendimentos passaram a ser encerrados ainda durante o período diurno, embora ainda observa-se um volume significante de atendimentos sendo encerrados até as 20 horas. Após as 21 horas, o volume de altas torna-se menos expressivo, bem como na faixa de horário das 0 as 5 horas da manhã.

\section{DISCUSSÃO}

O presente estudo demonstrou que ferramentas de informática (assinatura eletrônica) permitiram a revisão do processo de alta do paciente após a dispensa médica com redução significativa do tempo de espera decorrente de procedimentos burocráticos.

A permanência hospitalar além do necessário se constitui em preocupação permanente das instituições de saúde ${ }^{8}$, pois hospitalizações prolongadas estão associadas a maiores índices de complicação e custos de internação. Estudos mostram que atrasos na alta podem ter motivações externas a instituição de saúde como problemas relacionados ao transporte de pacientes e problemas de natureza organizacional como o número de vezes em que o paciente pode ser remanejado dentro do hospital. Estes fatores estão mais associados com o atraso na alta do que propriamente com fatores relacionados ao paciente (fatores cognitivos e limitações funcionais). Estudo exploratório, descritivo e transversal, ocorrido no Hospital Auxiliar de Suzano (HAS) do Hospital das Clínicas da Faculdade de 
Medicina da Universidade de São Paulo (HCFM-USP) demonstrou que entre 2011 a 2014, $54,5 \%$ dos atrasos na saída do paciente após a alta médica eram devidos a motivos relacionados ao transporte do paciente (aguardo de ambulância e transporte familiar) e 12,7\% foi devido a fatores relacionados ao suporte da rede (aguardo de vaga, transferência para outras instituições) $)^{1}$.

Atrasos na alta do paciente podem incorrer em maiores custos operacionais à instituição de Saúde como refeições, medicamentos prescritos e custos de hotelaria. A permanência prolongada por motivos não clínicos também pode prejudicar o fluxo de pacientes afetando índices de rotatividade de leitos e duração média da internação.

Ferramentas de melhoria de qualidade como o Lean e o Seis Sigma podem ser usadas para o desenvolvimento de processos mais confiáveis. O Seis Sigma, por sua vez, é uma ferramenta de gerenciamento industrial com utilização crescente pela saúde. ${ }^{4}$

Surgido no final da década de 1960 com a Motorola, o processo Seis Sigma possui base no ciclo PDCA (Plan-Do-Check-Act; Planejar, Executar, Avaliar, Implantar), contemplando características como: ênfase em controle da qualidade, análise e solução de problemas com uso correto de recursos disponíveis, sistematização no uso de métodos estatísticos seguindo o ciclo DMAIC (define, measure, analyse,improve, control: definir, medir, analisar, melhorar, controlar). ${ }^{6}$

Exemplo de caso de sucesso, a aplicação do método Lean Seis Sigma em processos hospitalares do Centro Médico Richard L. Roudebush em Indianapolis, Indiana, trouxe redução de cerca de $36 \%$ do tempo global de permanência do paciente passando de 5,3 a 3,4 dias em cirurgias de prótese de joelho e quadril. ${ }^{5}$

Importante ressaltar que quanto menor esse tempo, menor a possibilidade de que haja a incidência de refeições devolvidas, bem como a de medicamentos devolvidos pois estas ações podem ser bloqueadas sistemicamente com o fechamento do atendimento ocorrendo de forma mais rápida. Tal fato indica que podemos ter uma redução de custos operacionais provenientes da entrega de refeições e medicamentos. Além dos benefícios relacionados com os suprimentos enviados ao paciente, também podemos ter uma melhora no tempo de disponibilização de leitos pois o fechamento do atendimento ocorrendo de maneira mais rápida o leito em que o paciente estava, por sua vez, é disponibilizado mais rapidamente, permitindo um giro mais rápido nas enfermarias. A partir deste estudo nos é possível buscar a mensuração do impacto que essa melhoria no processo de alta pode ter resultado nas atividades de nutrição e farmácia, constituindo assim exemplo dos resultados que podemos alcançar na busca pela melhoria contínua e excelência.

\section{CONSIDERAÇÕES FINAIS}

A modificação do processo de alta hospitalar, sinalizando o final do processo com a assinatura eletrônica da enfermeira responsável no Hospital das Clínicas reduziu a diferença de tempo entre o momento que o médico indica a alta do paciente até o momento em que o paciente é efetivamente liberado.

\section{REFERÊNCIAS BIBLIOGRÁFICAS}

1. AJIMURA, F. Y, MALIK A. M.. Por quê eles permanecem: causas de atraso na saída em pacientes de alta médica. Espaço para a Saúde. Revista de Saúde Pública do Paraná. Volume 17 [ 2 ]: 134 - 142, Dezembro 2016 
2. TANAKA N. Y Y.,MERLO E. M.,NICOLETTI C. F.,GÓES W. M., NOVAES R., FÁVERO F., NONINO B. C., MARCHINI J. S. Impacto da informatização intra-hospitalar sobre a gestão de custos Integração da prescrição eletrônica das fórmulas pediátricas e das dietas enterais com suas respectivas áreas de produção. Revista chilena de nutrición. Volume 42 No. 1 , Santiago Mar. 2015. [Acesso em: 25 out 2017]. Disponível em http://www.scielo.cl/scielo. php?script=sci_arttext\&pid=S0717-75182015000100003.

3. BEN-ASSULI O., Shabtai I., Leshno M. The Impact of EHR and HIE on reducing avoidable admissions controlling main differential diagnoses. [Acesso em 25 out 2017]. Disponível em https://www.ncbi.nlm.nih.gov/pubmed/23594488.

4. GHADA R. EL-EID, ROLAND KADDOUM, HANI TAMIM, EVELINE A. HITTI. Improving Hospital Discharge Time: a successfull implementation of Six Sigma methodology. [Acesso em 10 out 2018]. Disponível em https://www.ncbi.nlm.nih.gov/pmc/articles/PMC4554014/.

5. GAYED BENJAMIN, BLACK STEPHEN, DAGGY JOANNE. Redesigning a Joint Replacement Program Using Lean Six Sigma in a Veterans Affairs Hospital. [Acesso em 10 abr 2018] Disponivel em https://www.ncbi.nlm.nih.gov/pubmed/24026166.

6. PINTO, SILVIA H. B., HO MARLY M. C. L., Implementação de Programas de Qualidade: Um Survey em Empresas de Grande Porte no Brasil. [Acesso em 10 abr 2018]. Disponível em http://www.scielo.br/pdf/gp/v13n2/31167.pdf.

7. Teixeira, José M. C. (2003), Fernandes, Alfredo M. S., Bonato Vera, L., Fernandes, José A. Planejamento estratégico e operacional em saúde, pp 42.

8. $\quad$ LIM SC, DOSHI V, CASTASUS B, LIM JK, MAMUN K. Factors causing delay in discharge of elderly patients in an acute care hospital. Ann Acad Med Singapore. 2006 Jan; 35(1): 27-32. [Acesso em 28 abr 2019]. Disponível em http://www.annals.edu.sg/pdf/35VolNo1200601/ V35N1p27.pdf. 


\section{APÊNDICE}

\section{APÊNDICE 1 - APROVAÇÃO NO COMITÊ DE ÉTICA MÉDICA - HCFMRP-USP}

USP - HOSPITAL DAS
CLÍNICAS DA FACULDADE DE PSP-RIBEIRÃO
MEDICINA DE RIBEIRÃO

\section{PARECER CONSUBSTANCIADO DO CEP}

\section{DADOS DO PROJETO DE PESQUISA}

Título da Pesquisa: IMPACTO DA REESTRUTURAÇÃO MATRICIAL DO PROCESSO DA ALTA HOSPITALAR NA CADEIA DE SUPRIMENTOS E NO TEMPO DE ALTA DE UM HOSPITAL TERCIÁRIO

Pesquisador: Diego Moroço

Área Temática:

Versão: 1

CAAE: 96424318.2 .0000 .5440

Instituição Proponente: Faculdade de Medicina de Ribeirão Preto da Universidade de São Paulo

Patrocinador Principal: Financiamento Próprio

\section{DADOS DO PARECER}

Número do Parecer: 2.846 .460

Apresentação do Projeto:

O incremento da demanda sobre qualidade na Assistência aos pacientes e as restrições econômicas atuais têm impulsionado as instituições hospitalares a reverem seus diversos processos. Um destes processos é a alta hospitalar, que dentre seus vários aspectos a serem considerados, existe a necessidade de agilizar 0 tempo entre a alta e as saída do hospital. As novas técnicas incorporadas nas instituições hospitalares, como a assinatura digital oferecem oportunidades de melhoria deste processo. O HCFMRP-USP implantou um novo passo no processo de alta com base na assinatura digital que pode trazer implicações significativas e deve ser caracterizada.

Objetivo da Pesquisa:

Avaliar o impacto da reestruturação do processo na alta hospitalar e nos processos da cadeia de suprimentos

\section{Avaliação dos Riscos e Benefícios:}

Riscos: Informações constantes na alta estarem não preenchidas completamente. Poderão ocorrer limitações na análise em itens que não forem dispensados diretamente ao paciente.

Beneficios: Confirmar se a intervenção na alta hospitalar pode trazer benefícios em termos de otimização de recursos.

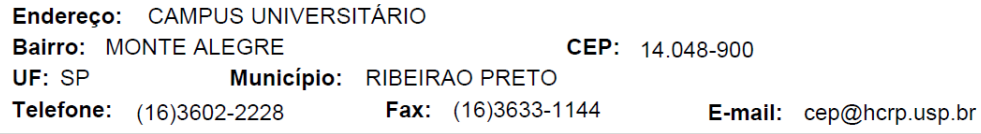




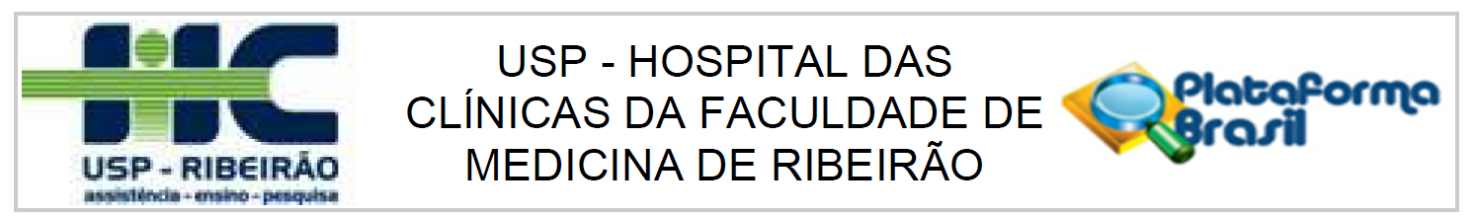

Continuação do Parecer: 2.846 .460

Comentários e Considerações sobre a Pesquisa:

Será realizado estudo retrospectivo em altas de pacientes no Hospital das Clínicas de Ribeirão Preto da Universidade de São Paulo, Unidade Campus, nos anos de 2016 e 2017. Serão coletados dados dos tempos de alta médica e encerramento do atendimento, enfermaria e convênio. Além dos dados mencionados também serão obtidos dados de indicadores de enfermaria a seguir: número de internações, altas, Censo Médio, Índice de Rotatividade e Duração Média da Internação.Com relação ao processo de suprimento de medicamentos serão obtidas as seguintes informações:

Medicamento dispensado, data/hora da dispensação, quantidade dispensada ou devolvida. Todos estes dados são de natureza administrativa e disponíveis na base eletrônica do Hospital das Clínicas da Faculdade de Medicina de Ribeirão Preto.

Considerações sobre os Termos de apresentação obrigatória:

Documentos devidamente apresentados. Solicita a dispensa de aplicação do Termo de Consentimento Livre e Esclarecido.

O presente estudo considerará apenas dados administrativos obtidos em sistema informatizado do Hospital das Clínicas. Considerando que o tamanho da amostra é significativo, a consulta individualizada dos pacientes poderia ser onerosa e comprometer o desenvolvimento do estudo.

Considerando também os benefícios que serão gerados pelo estudo e principalmente, o fato de não implicar em dano significativo para os pacientes, está sendo solicitado a dispensa do termo de consentimento livre e esclarecido. No entanto deve se destacar que todos os princípios éticos de sigilo, confidencialidade e segurança da informação serão seguidos rigorosamente.

Recomendações:

não se aplica

Conclusões ou Pendências e Lista de Inadequações:

Diante do exposto e à luz da Resolução CNS 466/2012, o projeto de pesquisa, assim como a solicitação de dispensa de aplicação do Termo de Consentimento Livre e Esclarecido, podem ser enquadrados na categoria APROVADO.

\section{Considerações Finais a critério do CEP:}

Projeto Aprovado: Tendo em vista a legislação vigente, devem ser encaminhados ao CEP, relatórios parciais anuais referentes ao andamento da pesquisa e relatório final ao término do trabalho. Qualquer modificação do projeto original deve ser apresentada a este CEP em nova versão, de forma objetiva e com justificativas, para nova apreciação.

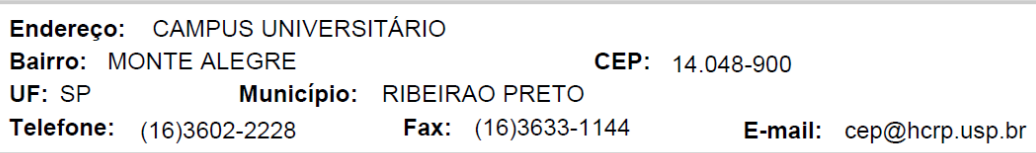




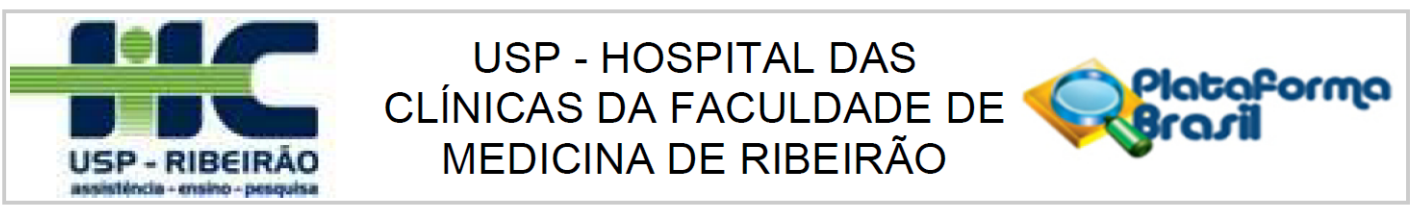

Continuação do Parecer: 2.846 .460

Este parecer foi elaborado baseado nos documentos abaixo relacionados:

\begin{tabular}{|l|l|c|l|c|}
\hline \multicolumn{1}{|c|}{ Tipo Documento } & \multicolumn{1}{|c|}{ Arquivo } & Postagem & Autor & Situação \\
\hline Informações Básicas & PB_INFORMAÇŌES_BASICAS_DO_P & $21 / 08 / 2018$ & & \\
do Projeto & ROJETO 1201307.pdf & $22: 00: 19$ & & \\
\hline TCLE / Termos de & Solicitacao_exclusao_TCLE.pdf & $21: 58: 24$ & & Aceito \\
Assentimento / & & & & \\
Justificativa de & & $21 / 08 / 2018$ & Diego Moroço & Aceito \\
Ausência & & $21: 54: 14$ & & \\
\hline $\begin{array}{l}\text { Projeto Detalhado / } \\
\text { Brochura } \\
\text { Investigador }\end{array}$ & Projeto_Mestrado_v_0_4.pdf & $20 / 08 / 2018$ & Diego Moroço & Aceito \\
\hline Outros & & $22: 07: 17$ & & Aceito \\
\hline Outros & Orcamento_v_0_1.pdf & $20 / 08 / 2018$ & Diego Moroço & \\
\hline Folha de Rosto & Aprovacao_Orcamento_UPC_com_Assi & $22: 06: 52$ & & Aceito \\
\hline
\end{tabular}

Situação do Parecer:

Aprovado

Necessita Apreciação da CONEP:

Não

RIBEIRAO PRETO, 27 de Agosto de 2018

Assinado por:

MARCIA GUIMARÃES VILLANOVA

(Coordenador)

Endereço: CAMPUS UNIVERSITÁRIO

Bairro: MONTE ALEGRE CEP: $14.048-900$

UF: SP Município: RIBEIRAO PRETO

Telefone: (16)3602-2228 Fax: (16)3633-1144_ E-mail: cep@hcrp.usp.br 


\section{APÊNDICE 2 - DECLARAÇÃO DA SUPERINTENDÊNCIA DO HCFMRP- USP}

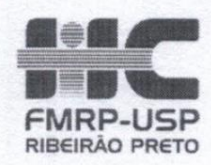

\section{DECLARAÇÃo}

Declaro para os devidos fins que o código desenvolvido por Diego MARQUeS MORoço como parte da sua Dissertação de Mestrado "Impacto da Informatização do Processo de Alta Hospitalar em um Hospital Público Terciário", desenvolvido junto ao Programa de Mestrado Profissional de Gestão de Organizações de Saúde, foi incorporado aos Sistemas de Prontuário Eletrônico do Hospital das Clínicas da Faculdade de Medicina de Ribeirão Preto-USP.

Trata-se de um produto da Dissertação que implicou em ganhos significativos para o tempo de alta dos pacientes na Instituição e que constitui um importante legado do projeto desenvolvido. Foi, inclusive, publicado na Revista Qualidade HC de 2020.

Coloco-me à disposição para eventuais esclarecimentos.

Atenciosamente,

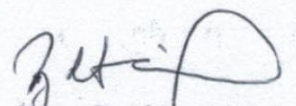

Prof. Dr. Benedito Carlos Maciel Superintendente 